\title{
Heart vascular endothelial cells in immune reactivity : an experimental model in the rat
}

Citation for published version (APA):

Derhaag, J. (1998). Heart vascular endothelial cells in immune reactivity : an experimental model in the rat. [Doctoral Thesis, Maastricht University]. Universiteit Maastricht. https://doi.org/10.26481/dis.19980703jd

Document status and date:

Published: 01/01/1998

DOI:

10.26481/dis.19980703jd

Document Version:

Publisher's PDF, also known as Version of record

\section{Please check the document version of this publication:}

- A submitted manuscript is the version of the article upon submission and before peer-review. There can be important differences between the submitted version and the official published version of record.

People interested in the research are advised to contact the author for the final version of the publication, or visit the DOI to the publisher's website.

- The final author version and the galley proof are versions of the publication after peer review.

- The final published version features the final layout of the paper including the volume, issue and page numbers.

Link to publication

\footnotetext{
General rights rights.

- You may freely distribute the URL identifying the publication in the public portal. please follow below link for the End User Agreement:

www.umlib.nl/taverne-license

Take down policy

If you believe that this document breaches copyright please contact us at:

repository@maastrichtuniversity.nl

providing details and we will investigate your claim.
}

Copyright and moral rights for the publications made accessible in the public portal are retained by the authors and/or other copyright owners and it is a condition of accessing publications that users recognise and abide by the legal requirements associated with these

- Users may download and print one copy of any publication from the public portal for the purpose of private study or research.

- You may not further distribute the material or use it for any profit-making activity or commercial gain

If the publication is distributed under the terms of Article $25 \mathrm{fa}$ of the Dutch Copyright Act, indicated by the "Taverne" license above, 


\section{Heart vascular endothelial cells in immune reactivity}

An experimental model in the rat 
ISBN $90-5681-037-5$

Publication of this thesis was financially supported by:

Parke Davis B.V. the Netherlands.

Printed by:

Unigraphic, Maastricht, The Netherlands.

Cover illustration:

Part of the primary clone of endothelial cells subsequently expanded to RHEC 3. 


\section{Heart vascular endothelial cells in immune reactivity}

An experimental model in the rat

\section{PROEFSCHRIFT}

ter verkrijging van de graad van doctor aan de Universiteit Maastricht,

op gezag van de Rector Magnificus, Prof. Dr. A. C. Nieuwenhuijzen Kruseman volgens het besluit van het College van Decanen,

in het openbaar te verdedigen

op vrijdag 3 juli 1998 orn 14.00 uur

door

Josien Gerarda Derhaag

geboren te Sittard op 25 maart 1967 


\section{Promotor:}

Prof. Dr. P. J. C. van Breda Vriesman

\section{Compromotor:}

Dr. A. M. Duijyestin

\section{Beoordelingscommussie:}

Prof. Dr. R. F. A. Zwaal (voorzitter)

Prof. Dr. J. W. Arends

Prof. Dr. M. R. Daha (Rijksuniversiteit Leiden)

Prof. Dr. Gr. J. wan der Vusse 
A man will turn over half a library to make one book S. Johnson 



\section{Contents}

Abbreviations $\quad 9$

Introduction to the Chapters 11

Chapter 1: General introduction $\quad 13$

Chapter 2: Production and characterization of spontaneous rat heart 35 endothelial cell lines

Chapter 3: Heart EC respond heterogeneous on cytokine stimulation in ICAM-1 and VCAM-1, but not in MHC expression. A study with 3 rat heart endothelial cell (RHEC) lines

Chapter 4: A dual role for endothelial cells in cytomegalovirus infection?

A study of cytomegalovirus infection in a series of rat endotheliai cell lines

Chapter 5: Effects of antibody reactivity to MHC and non-MHC alloantigens on graft endothelial cells in heart allograft rejection

Summary \& Discussion

Samenvatting \& Discussie

Publications

Dankwoord

Curriculum Vitae 


\section{Abbreviations}

$\mathrm{Ab}$

$\mathrm{AA}$

$\mathrm{ACE}$

APC

$\mathrm{BN}$

CCP

CD

CMV

EDRF

EC

ET

FACS

GlyCAM-1

GP

HUVEC

ICAM-1

IFN $\gamma$

II.

LEW

LEW.1N

LFA-1

LNC

MAdCAM-1

$\mathrm{MHC}$

$\mathrm{mAb}$

MAC

MCP-1

$\mathrm{MHC}$

m.o.i.

NO

PAI-1

PAF

PBS

PFU

$\mathrm{PG}$

$\mathrm{PGI}_{2}$
Antibody

Arachidonic acid

Angiotensin-converting-enzyme

Antigen presenting cell

Brown norway

Complement control proteins

Cluster of differentiation

Cytomegalovirus

Endothelium-derived relaxing factor

Endothelial cells

Endothelin

Fluorescence activated cell sorter

Glycosilation-dependent cell adhesion molecule-1

Guinea pig

Human umbilical vein endothelial cell

Intercellular adhesion molecule-11

Interferon $\gamma$

Interleukin

Lewis

Congeneic rats containing the $\mathrm{BN}$ MHC on a

Lewis background

Lymphocyte-function associated antigen-1

Lymph node cells

Mucosal addressin cell adhesion molecule-1

Major histocompatibility complex

Monoclonal antibody

Membrane attack complex

Monocyte chemotactic protein-1

Major histocompatibility complex

Multiplicity of infection

Nitric oxide

Plasminogen activator inhibitor -1

Platelet-activating-factor

Phosphate buffered saline

Plaque forming unit

Prostaglandin

Prostacyclin 
PMA

RCMV

RECA-1

REF

RHEC

TF

TFPI

TM

TNFo.

t-PA

TX

$\mathrm{Tx}$

VCAM-1

VLA-4

VWF

UPA
Phorbol-meristate-acetate

Rat cytomegalovirus

Rat endothelial cell antigen-1

Rat embryonal fybroblast

Rat heart endothelial cells

Tissue factor

Tissue factor pathway inhibitor

Thrombomodulin

Tumor necrosis factor $\alpha$

Tissue type plasminogen activator

Tromboxane

Transplantation

Vascular cell adhesion molecule

Very late antigen-4

von Willebrand Factor

Urokinase type plasminogen activator 


\section{Introduction to the Chapters}

Endothelial cells (EC) are relevant for almost all physiological and pathological processes, due to their location between the circulating blood and the tissues surounding the blood vessels. The advances in endothelial research over the past decade have given us insight in the role of EC in processes such as the control of blood flow, blood pressure and clotting as well as in pathological processes such as vasculitis, several autoimmune diseases and transplant rejection. The endothelium can be classified morphologically as one tissue, but because of it's heterogeneity between and within organs and within the vascular tree, it is mandatoryto use, for in vitro studies, the relevant $\mathrm{EC}$ type. In the present thesis an in vitro EC model was developed and used in studies addressing various aspects of endothelial physjology. Next to this, studies were executed to unravel the role of EC in immunological processes, we therefore choose a model for heart transplant rejection. The use of rat EC of the proper tissue, in this case from the heart of the used rat strain, was necessary. Since the isolation of EC from rat cardiac tissue is laborious and results in low yield, we developed a method to obtain endothelial cell lines out of rat hearts.

In Chapter 1, the general introduction, the concepts of the structure and physiological functions of the EC, and the current knowledge of the role of EC during immune reactivity are reviewed.

In Chapter 2 the technique to develop endothelial cell lines and the phenotypical

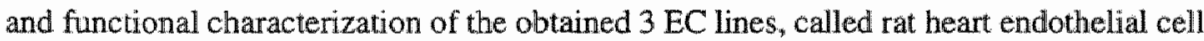
line (RHEC) 3, RHEC 10 and RHEC 11, are presented. In addition possible tumorigenicity of the spontaneously immortalized RHEC lines is studied.

During transplant rejection, a process in which inflammation and immune reactivity occur, interaction between $\mathrm{EC}$ and blood leukocytes is important for pathophysiological processes. In Chapter 3 the RHEC lines are studied for cytokine- 
induced expression of adhesion molecules and MHC antigens, both structures that are important for cell-cell interactions.

As cytokines the pro-inflammatory cytokine TNFo and the immune regulatory cytokine IFN $\gamma$ are used, individually or in combination, for periods from 4 to 64 hour. Observed heterogeneity in the induction of these molecules is further studied to gain more insight in the possible intrinsic regulation mechanisms in the EC monolayers.

To define whether the observed heterogeneity of the RHEC lines is of relevance for infection of the EC by CMV, the RHEC lines and other EC lines are studied for susceptibility for infection with rat CMV in Chapter 4 . In addition the effects of CMV infection on the EC monolayer and the production of infectious virus are examined.

During transplant rejection the graft vasculature is considered to be a major targett for immune reactants of the recipient. In Chapter 5 the role of alloantibodies to endothelial MHC and non-MHC alloantigens in graft vasculopathy is investigated. The effects of the allosera reactive with MHC or non-MHC alloantigens on graft EC are studied with respect to complement activation, complement-mediated cytotoxicity and adhesion molecule induction. Furthermore the isotype distribution of alloantibodies reactive with $\mathrm{MHC}$ and non-MHC alloantigens is studied.

Finally the data obtained in the various studies described in these chapters are summarized and discussed in the Summary \& Discussion. 


\title{
General introduction
}

\author{
Josien G. Derhaag
}

Department of Immunology, Maastricht University, Maastricht, The Netherlands

The word endothelium is used in a general sense for the cells lining the luminal side of the vessel wall. The endothelium, which was considered for a long time to be just an inert barrier, had been barely explored until three decades ago. Since then, there has been an upsurge of interest in the fine structure and function of endothelial cells (EC). In vivo and in vitro investigations have revealed that the endothelium is a key element in a wide variety of normal activities and diseases and is far from being metabolically inert. The EC crucially contributes to the regulation of the entire vascular system and to the systemic homeostasis as well. It is now widely recognized that EC are morphologically and physiologically highly differentiated along the vascular bed as a biological adaptation to local needs.

\subsection{Endothelial cell structure}

EC are of mesenchymal origin. Electron microscopy has provided information about various micro-organelles and structures in the EC. In situ EC are elongated with the long axis aligned with the blood stream. The monolayer of EC has a cobble stone pattern in which the nucleus of the cell bulges into the vascular lumen. In addition mitochondria (M), a well developed rough endoplasmatic reticulum (rER) and a golgi complex (G) are present (1), see figure 1. Like other eukaryotic cells, EC contain several subclasses of intermediate sized filaments, predominantly of the vimentin subclass. Microfilaments $(\mathrm{mf})$, decorated with the actin binding unit, and myosin-like filaments have also been 
identified. Microtubules (mt) are only sporadically mentioned, although their occurrence in EC is an established fact (2). Furthermore EC contain specific transcytotic vesicles (V). which organize barrier and transport functions of the EC monolayer, as described below (Chapter 1.3.1). Quite specific for EC is the presence of structures known as Weibel Palade bodies. These rod-shaped granules which represent the intracellular storage sites of the EC borne von Willebrand Factor (VWF) and P-selectin have a typical tube-like internal structure. The Weibel Palade bodies are less numerous in venules and normally absent in capillary EC.

\section{Ultrastructure of $\mathrm{EC}$}

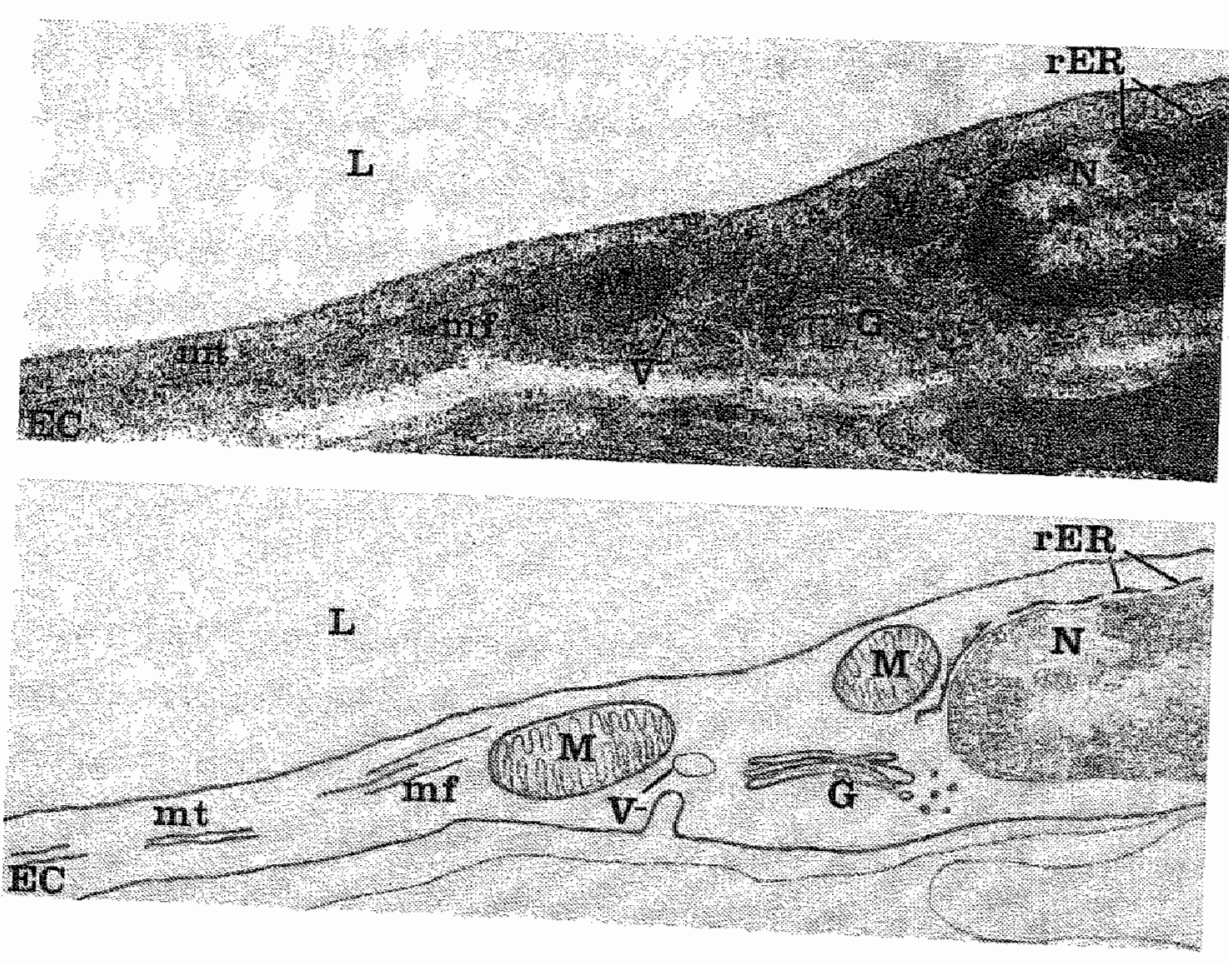
Figure 1: Electron microscopy and scheme of rat heart $\mathrm{EC}$, magnification $44000 \mathrm{X}$. L: lumen, V:
transcytotic vescicles. N: nucleus, $\mathrm{M}$ : mitochondria, G: golgi complex, rER: rough endoplasmatic
reticulum, mf: microfilaments, mt: microtubules. 


\subsection{Models for studying EC}

Already between 1884 and 1950 papers were published dealing with various cultivation techniques for EC. Again in 1973-1975, a new era started with refined culture methods and subcultivation as well as identification of $\mathrm{EC}$ and smooth muscle cells by Jaffe et al. (1) and Gimbrone et al. $(3,4)$. Since then a variety of systems have been used to study EC and their interactions. The first widely used successful method of isolating EC for culture involved infusion of a solution containing proteolytic enzymes to detach the endothelium from the intima. Of course it is possible that with this method structures like receptors will be destroyed, and the cells can not be used for studies involving these molecules. Methods for culturing EC from other organs and from different vasculature are all based on this enzymatic procedure. Specific markers used for identification of EC are the presence of angiotensin converting enzyme (ACE), and $\mathrm{WWF}$, the binding of the lectin GS-I-B4, and the internalization of Dil-ac-LDL. In human systems, umbilical vein EC (HUVEC), which are relatively easy to obtain, are usually used. EC, obtained as described above, are from macrovascular origin. When this method is used for isolation of EC of microvascular origin, the procedure is hampered by low yield of EC. This disadvantage made the development of EC lines required. The successful production of $\mathrm{EC}$ lines has been described for human and murine species, mostly using SV -40 and adenovirus infections $(5,6,7,8)$, or transfection with $S V-40$ and polyoma virus oncogene constructs coding for wiral $T$ antigens $(9,10,11)$. Unfortunately, the viral inserts may lead to interference with specific $\mathbb{E C}$ functions. In addition after long term culturing the EC can lose EC specific characteristics which makes it necessary to examine the transfected. EC line herefor during the experiments. Next to cultured cell monolayers, small pieces of the vessell wall, mostly rat aorta, with the intact EC still present as a monolayer are used for in vitro studies. In this method the interaction of the EC with its matrix and the possible effects of substances produced by EC on the underlying cells can also be studied. Because of the heterogeneity of the EC between species, and within a species among organs and even within the vascular bed of a single organ, it is important to use the most proper $\mathbb{E C}$ for every examination. 


\subsection{EC functions}

\subsubsection{Transport and regulation of permeability}

The endothelium consists of a single layer of cells and appears to play an important role for vessel wall structure and function. In this monolayer the endothelial plasma membrane exhibits luminal-abluminal polarity. Transport pathways are different in distinct vascular beds. Cooperative transport through the microvascular endothelial monolayer is accomplished by different pathways (Figure 2): (1) diffusion through the cell membrane; (2) via vesicular pathways; (3a) a cell surface layer pathway through the junctions; (3b) pore pathways localized at the intercellular junctions (small and large); (4) a non junctional channel variant formed by fusion of two or more vesicles; (5) open fenestrea in the endothelial monolayer of some organs (e.g. intestine); (6) fenestrae closed by a diaphragm $(12,13)$. Exchange of water and solutes across microvascular endothelium takes place through several intra- and intercellular pathways. In steady state, water and small lipid-soluble compounds diffuse through the entire endothelial surface, while the bulk flow of water and diffusion and convection of small lipid insoluble molecules can take place through intercellular channnels. Transport of plasma proteins and other large mollecules occurs via convection and diffusion through large pores or via vesicular exchange. Fenestrae, not present in all EC have a high permeability for water and ions as well as for small molecules (14). Although the EC is capable herein vascular permeability by receptor regulation of transcytosis the intercellular junctions seem to play the most important role for regulation of permeability. For instance, receptor activation (e.g. by bradikinin or thrombin) induces endothelial contraction by disconnecting the interaction between junction and actin filaments, which results in increased permeability between the EC (15). It should be noticed that the mechanisms involving transport and permeability are reflected in the distinct structural features that characterize EC in their various locations. These differences between local EC are associated with the specific functions of the tissues, e.g. the EC of the brain capillaries are connected by tight junctions to form a tight blood brain barriere protecting the connective brain tissue, and 
the EC of the intestinal mucosal and the renal glomerular capilaries form a fenestrated layer allowing transport of macromolecules.

\section{Transport pathways in EC}

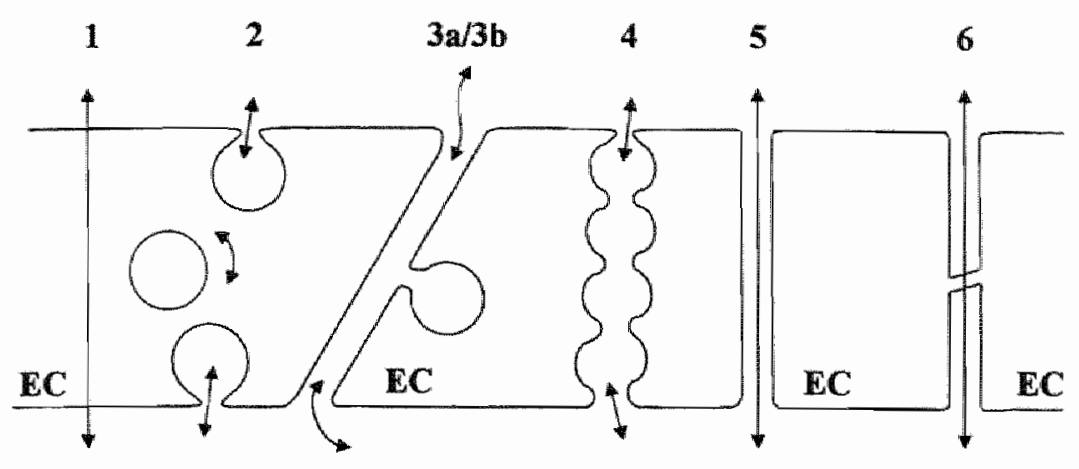

Figure 2: Scheme of transport pathways in microvascular endothelium. Transcytosis can occur via different pathways: 1) the cell membrane pathway consists of three barriers; apical plasma membrane, cytoplasm and basolateral plasma membrane. 2) the vesicular pathway, which tend to equilibrate luminal and abluminal fluids. 3a) The cell surface layer pathway through the junctions. $3 b$ and 4) the small and large pore pathway which allow convective flow of water and permeating solutes as well as diffusion exchange of water and solutes. 5) open fenestrae, allowing transport of macromolecules and 6) closed fenestrae (not present in all endothelium), characterized by the high permeability for water, ions and small molecules. (Based on Rerikin, E M. 1977, Circulation Research 41:735-743).

\subsubsection{EC in hemostasis}

EC form the luminal vascular surface and are well situated to play an important role in the regulation of the hemostasis. Normally multiple anticoagulant mechanisms are operative on the EC (Fig. 3), whereas the balance between anticoagulant and procoagulant activity is compromised during trauma by induction of procoagulant and suppression of anticoagulant mechanisms.

Under normal circumstances the EC form an anticoagulant layer that counteracts blood coagulation and prevents platelet activation, while stimulating fibrinolysis.

Activation of the coagulation cascade results in the formation of thrombin which converts fibrinogen into a fibrin gel. EC can interrupt the coagulation cascade by inactivation of activated coagulation factors. Heparan sulphates on the EC surface interact with 
antithrombin III, and this complex inhibits the activated coagulation factors $X a$ and thrombin (16). EC express thrombomodulin (TM), which promotes the activation of protein $C$ by thrombin resulting in inactivation of the coagulation factors $\mathrm{Va}$ and VIIIa (17, 18). In addition, EC prevent coagulation by production of tissue factor pathway inhibitor (TFPI) which inhibits the activation of the extrinsic coagulation pathway induced by tissue factor (TF)(19). EC can prevent thrombus formation by exhibiting antiplatelet activity. Platelet adhesion to the EC is prevented by surface-bound proteoglycans. Platelet activation is counter acted by $\mathrm{PGI}_{2}$ and $\mathrm{PGE}_{2}$, released by $\mathrm{EC}$ after stimulation with vasoactive substances like thrombin (20). The effect of $\mathrm{PGI}_{2}$ is enhanced by the production of nitric oxide (NO) by the EC. EC continuously produce tissue type plasminogen activator ( $\mathrm{PA}$ ), which together with the constant presence of plasminogen activator inhibitor-1 (PAI-1) results in a physiological balance of pro- and anti-coagulant processes (21). If coagulation occurs, EC provide regulatory components for fibrinolysis, like IPA via both constitutive secretion and release from a storage pool. This storage pool, especially effective in preventing local thrombus formation, can be released by vasoactive substances like platelet activating factor $(\mathrm{PAF})$, bradikinin and thrombin (22).

The anticoagulant phenotype of the vessel wall can be modulated to procoagulant in response to environmental stimuli of immune reactivity like in transplant rejection. Under challenging conditions, e.g. in the presence of endotoxin, tumor neccrosis factor (TNF)- $\alpha$ and interleukin (IL)- 1 , a shift occurs in the balance of anti- and procoagulant properties favoring activation of coagulation. The EC start to express TF, promote thrombin generation, reduce their TM activity and enhance their production of PAI-1 (21, 23). After damage of the endothelial wall, EC also release wWF which promotes platelet adhesion to the EC leading to hemostatic plug formation (24). Furthermore, activated EC induce the expression of PAF on their membrane. Besides platelet activation, PAF also activates EC, and cooperates with adhesion molecules in leukocyte transmigration (25). Activation of the coagulation response appears to be non-specific, but local production of the mediators provides the system with specificity and flexibility in response to 
environmental stimuli. Furthermore, differences exist in the production of tPA, NO, $\mathrm{PGI}_{2}$ and $\mathrm{PGE} 2$ between venous, arterial and microvascular $\mathrm{EC}$, resulting in different procoagulantanti-coagulant properties of the different vascular beds.

\section{Endothelial mediators in hemostasis}

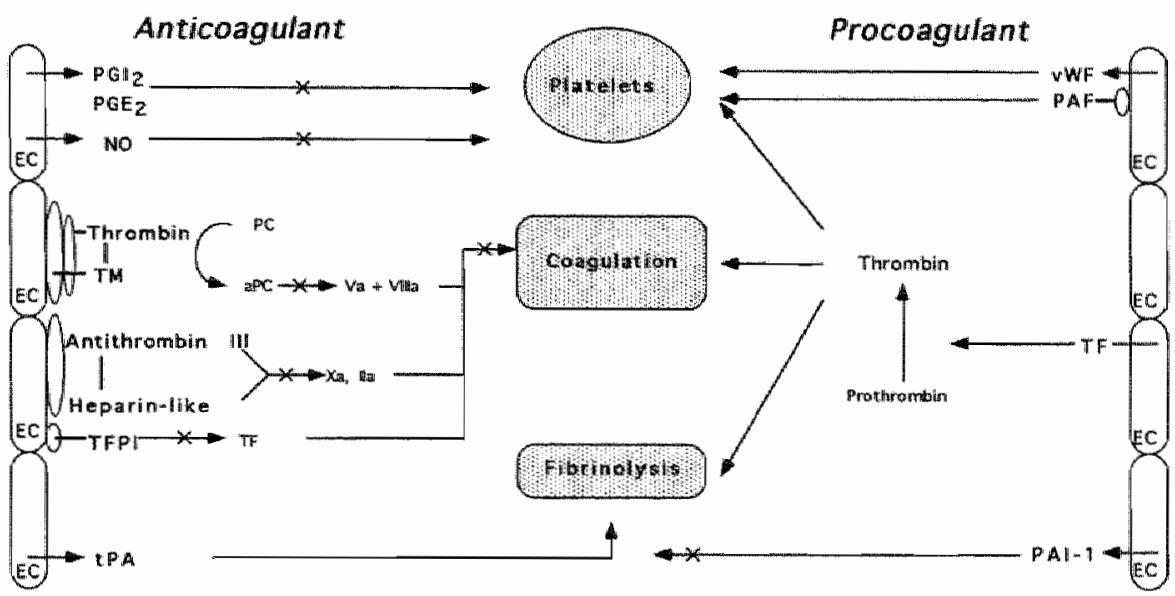

Figure 3: Anticoagulant and procoagulant properties of EC. On the left: inthibition of the platelet function by prostacyclin (PGI2), prostaglandin $\mathrm{E}_{2}\left(\mathrm{PGE}_{2}\right)$ and nitric oxide (NO), and inhibition of the coagulation. Thrombomodulin (TM) binds thrombin, promoting the activation of PC (Protein C) to aPC, which degrades factor Va and VIIla. The complex of heparin like molecules and anti thrombin III inhibits thrombin (IIa) and Xa. Tissue factor pathway inllibitor (TFPI) inhibits the tissue factor (TF)induced activation of the extrinsic coagulation pathway. On the right: won Willebrand factor ( $(W F$ ) released from stimulated EC promotes platelet adhesion. Expression of platelet activating factor (PAF) on the membrane of the stimulated EC activates platelets. TF on the stimulated EC serves as co-factor (factor VIIa) to actiwate several coagulation factors. Generated thrombir activates platelets, coagulation and fibrinolysis. In addition continuously produced tissue plasminogen activator (PA) actiwates fibrinolysis, a process which is inhibited by plasminogen activator inhibitor-1 (PAI-1), providing a balance of pro- and anti-coagulant processes. (Based on Wu, K. K. 1996 Annu. Rev. Med, 47:315-31). 


\subsubsection{Regulation of the vascular tone by $\mathrm{EC}$}

EC are an important cell type in the local regulation of the vascular tone. Hereto, the $\mathrm{EC}$ are able to rellease substances that result in vasodilatation or vasoconstriction (Table 1).

Endothelium-dependent relaxation in vascular tissue is mainly mediated by endothelium-derived relaxing factor (EDRF) which in later studies turned out to be NO (26). NO increases the amount of cyclic guanosine monophosphate (CGMP) within the smooth muscle cell resulting in vasodilatation (27). In addition $\mathrm{NO}$ inhibits aggregation and adhesion of platelets (see above). Another vasodilatator produced by EC is prostacyclin (PGI2). EC can be stimulated to synthesize PGI2 which results in induction of the rellease of adenosine tri phosphate (ATP) which is a potent vasodilatator (28). For producing its vasorelaxant effects, arachidonic acid (AA) is dependent on an endothelium dependent component, cytochrome P450 dependent mono-oxygenase (29). Agonists like acetylcholine, bradykinin or histamin can evoke production of relaxation factors effecting the endothelial layer.

In addition to the production of substances resulting in vasodilatation, endothelium can rellease vasoconstricting substances. Angiotensin converting enzyme (ACE), produced by $E C$, is responsible for the generation of the vasoconstrictor angiotensin II. Furthermore, EC produce endothelin (ET-1) which is the most active vasoconstricting substance yet discovered, with a potency some 10 times higher than angiotensin II. The main effects of ET-1 release, enhanced by for instance thrombin, are generated on the smooth muscle cell. This results in enhanced phosphorylation of the regulatory light chain of myosin, resulting in constriction (30). The specific, high-affinity binding of ET-1 to the smooth muscle cell results in a characteristic long lasting response. Ex viwo experiments show that vasoconstricting factor ET-1 induces the release of $\mathrm{PGI}_{2}$, PGE2 and sometimes thromboxane $\mathrm{A}_{2}$, which are vasodilatation factors. This suggests that ET- 1 is a local factor, released in high concentrations, inducing the release of $\mathrm{NO}$ and prostacyclin, probably to overcome local intense vasoconstriction (31). 
Endothelial mediators in the regulation of the vascular tone

\begin{tabular}{|c|c|}
\hline vasodilatation & vasoconstriction \\
\hline $\mathrm{NO}$ & $\mathrm{ET}-1$ \\
$\mathrm{PGI} 2$ & $\mathrm{ACE}$ \\
\hline
\end{tabular}

Table 1: NO: nitric oxide, PGI2: prostacyclin, ET-1: endothelin, ACE: angiotensin converting enzyme.

\subsubsection{EC and leukocyte migration}

The endothelium plays a regulatory role in leukocyte traffic. Adhesion molecules on EC can interact with counterpart adhesion molecules on leukocytes, thus allowing extravasation. This process is also influenced by the migratory capacity of the leukocytes and by chemoattractants and chemokines. Which adhesion molecules are present on the endothelial membrane is related to the anatomical site of the EC and to activation of EC by cytokines.

Leukocyte extravasation occurs via a multi-step mechanism $(32,33)$. The first step is the tethering and rolling of the leukocyte along the endothelium. During this step cell-cell interactions are mediated by selectins, e.g. L-selectin on circulating leukocytes and $\mathrm{P}$ - and $\mathrm{E}$-selectin on vascular endothelium. All selectins appear to recognize a sialylated carbohydrate determinant on their counterpart receptors. Receptors for $\mathrm{L}$ selectin are CD34 (34), glycosylation-dependent cell adhesion molecule-1 (GlyCAM-1) (35) and also mucosal addressin cell adhesion molecule-1 (MAdCAM-1) expressed on EC. Differential expression of adhesion molecules may direct different subsets of $\mathrm{T}$ cells to specific sites. CD44 also contributes to the adhesive interactions of lymphocytes and seems to play a role in the differencial migration of activated lymphocyte subsets (32). For firm adhesion to the endothelium, adhesion moleculles of the integrin family play an important role. Lymphocyte-function-associated antigen-1 (LFA-1, CD1 1a/CD18) (36) and $\mathrm{MAC}-1$ (CR3, CD1 1b/CD18), present on leukocytes, mediate binding to EC by interaction with intercellular cell adhesion molecule-1 (ICAM-1, CDS4) Before the 
integrins LFA-1 and MAC-1 can increase adhesiveness they require activation by chemokines like for instance IL-8 (37). Integrin molecules bind to adhesion molecules of the Ig superfamily on the EC. Induction of ICAM-1 by cytokines may increase cell-cell interactions and leukocyte extravasation, whereas constitutive expression of ICAM-2 may be important in particular for adhesion of lymphocytes (32). Vascular cell adhesion molecule-1 (VCAM-1) inducible on EC by cytokines, interact with very late antigen 4 (VLA-4, CD49d) $(33,38)$. These interactions of leukocytes with EC results in firm adhesion and flattening of the leukocytes, and to transendothelial migration into the extracellular matrix along a concentration gradient of chemoattractants (Figure 4).

\section{Transendothelial leukocyte migration}

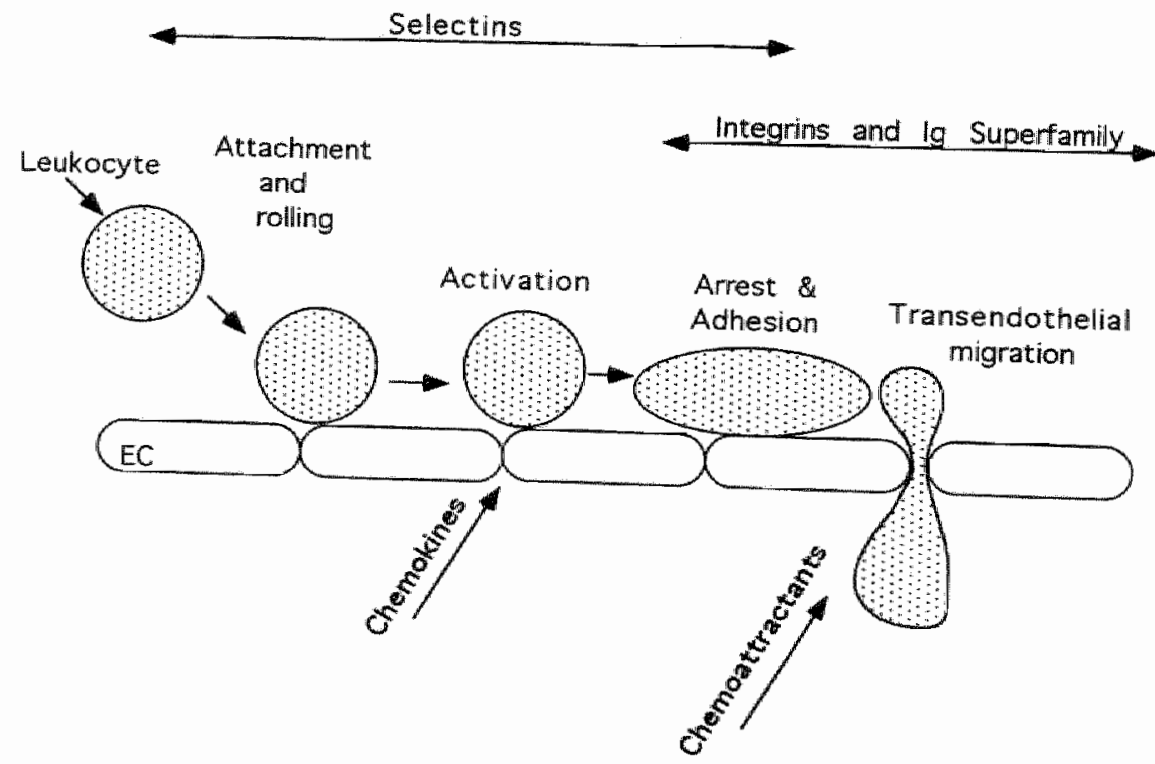

Figure 4: Transendothelial leukocyte migration a multistep model. The first step wnolwes attachment and rolling of the lewkocyte along the endothelium through interactions between selectins and their Tight binding between these molecules integrins on BC and activation of their ligands on the lenkocyte. migrates along a concentration gradient of chts rolling and results in adhesion. Finally the leukocyte Springer, T. A. 1994. Cell $76: 301-314$ ). 


\subsection{Cytokine regulation of $\mathrm{EC}$ function}

The vascular $\mathrm{EC}$ are both target and source of cytokines. Cytokines serve to communicate with leukocytes as well as with cells in other tissues and organs. The variety of EC responses elicited by cytokines during immunity inflammation and thrombosis is wide, sometimes with different cytokines activating the same EC function. Next to responding upon cytokines the EC produce cytokines and chemokines. The latter are relatively novel mediators which also have effects on $\mathrm{EC}$ and circulating cells (Table 2).

\subsubsection{Production of cytokines}

The production of cytokines and chemokines by EC is essential in the recruitment of leukocytes in inflammatory reactions, immunity and thrombosis. EC are an important source of and target for hematopoietic growth factors, such as stem cell factor (SCF) and several colony-stimulating factors (CSF). These factors affect migration and proliferation, and amplify EC responsiveness to other signals (39). During immune reactivity $\mathrm{EC}$ are induced to produce $\mathrm{IL}-1, \mathrm{IL}-6, \mathbb{I L}-8$ as well as $\mathrm{PAF}$, and produce EC chemokines of the CXC and CC family, $\mathbb{L}-8$ and monocyte chemotactic protein 1 (MCP1) are the best studied chemokines in relation to EC (39). IL-8, a chemoattractant in leukocyte extravasation, also seems to have angiogeneic properties, while MCP-1 induces EC activities similar to IL-8 and IFNy.

\subsubsection{Response upon cytokines}

During immune reactivity EC are activated by cytokines to alter their physiological properties and to acquire new pathophysiological functions $(40,41)$.

IL 1 and TNF induce production of PGI2, PAF and NO by EC. In the human system IL-1, TNF and IFN $\gamma$ stimulation of EC results in NO production, while for instance in the bovine systern, IFN $\gamma$ has inhibitory effects on the NO production by EC (42). IFNy amplifies responses to TNF and induces the chemokine MCP-1 and interferon inducible protein 10 (IP-10) which has angiostatic properties. TNFo, $\mathbb{L}-1$ and IFNy 
induce the expression of MHC class II and augment the expression of MHC class I, CD40 and ICAM-1 on EC $(43,44,45,46)$. Activation of EC by TNFa and IEN $\gamma$ occurs through different intracellular signaling pathways. Consequently, effects of EC stimulation with a combination of these cytokines may strongly differ from those of individual cytokine stimulation in expression levels of induced molecules and also the kinetics of induction. In vitro studies predominantly with HUVEC have showm overlapping as well as more specific effects of stimulation with individual cytokines. For induction of the adhesion molecules E-selectin and VCAM-1, TNF $\alpha$ appears a poterit cytokine (47-51), whereas for the induction of MHC class II molecules IFN $\gamma$ plays a dominant role. With respect to induction or enhancement of ICAM-1, both cytokines have more or less similar induction capacities $(52,53)$. IFN $\gamma$ prolongs the effect of TNFa on E-selectin expression (46) and $\Pi-4$ prolongs the effect of TNF $\alpha$ on VCAM-1 expression (54). $\mathrm{IL}-1$ and TNF also induce the production of cytokines by $\mathrm{EC}$, including chemokine $\mathbb{L}-6$ and $\mathbb{L}-1$ itself $(39,51)$. The procoagulant activity of $\mathrm{EC}$ is enhanced by down regulation of proteoglycans (55) and TM (56) on the EC surface, an effect induced by IFNy and also TNF.

Data about the effects of IL-6 on EC, mainly based on HUVEC studies, are not conclusive. Experiments suggest that IL-6 plays a role in amplifying leukocyte recruitment and, in combination with the soluble $\mathrm{LL}-6$ receptor, activates a unique functional program in EC (57). IL-10, also known as cytokine synthesis inhibitory factor, augments the action of $\mathrm{IL}-1$ and TNF on EC. Furthermore IL-10 inhibits the antigen presentation function by human microvascullar dermal EC (58). IL-4 induces urokinase-type plasminogen activator (UPA) in microvascular but mot in macrovascular endothelium. $\mathbb{L}-4$ selectively induces VCAM-1 and inhibits expression of ICAM-1 and E-selectin. IL-4 is a weak inducer of $\mathbb{L}-6$ and MCP- $\mathbb{1}$ production by EC but amplifies production of these mediators in concert with other stimuli (39) II-13 and IL-4, which in general show structural and functional similarities, also have similar activities on EC which may be the result of sharing receptor binding domains by these cytokines $(59)$. $\mathrm{L}$. 
12 has anti-angiogenic activity, but this is probably not a direct effect on the EC but is mediated through effects of $\mathrm{L}-12$-induced IFNY production (60).

It has been shown that not all EC respond similarly to cytokine stimulation and that differences such as species, strains, tissue and blood vessel type are important in this respect $(61,62,63,64)$. 


\section{Effects of cytokines on $\mathrm{EC}$}

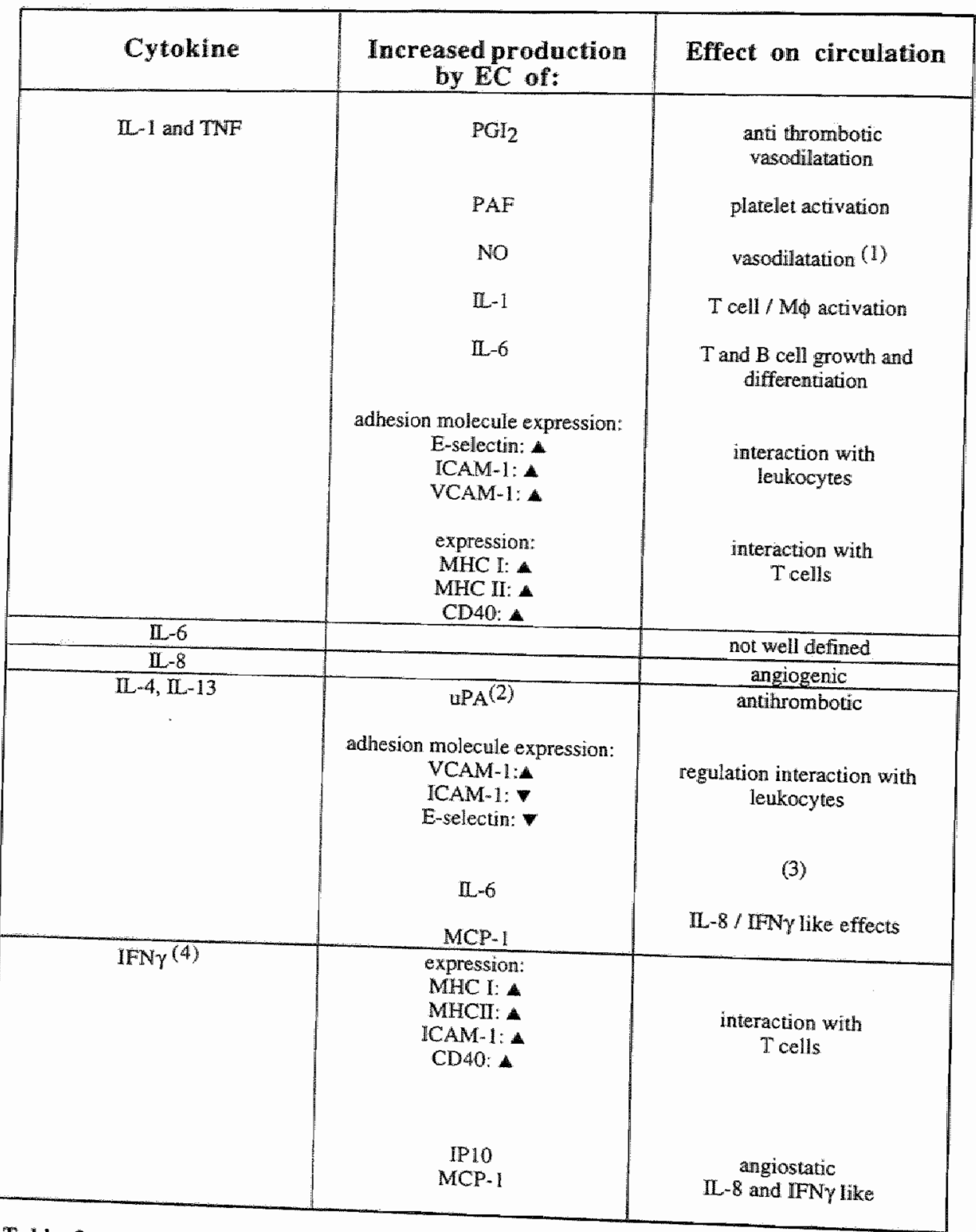

\section{Table 2:}
(1): in the human system IFN $\gamma$ is also required
(2): only macrovascular EC produce UPA after IL-4 stimulation
(4). synergistic with TNF
4: induced or upregulated
: down regulated 


\section{5 $\mathrm{EC}$ in immune reactivity}

\subsubsection{General aspects}

When vascular endothelium is involved in immune reactivity it undergoes a number of functional and morphological alterations. Upon activation the EC alter their anticoagulant surface phenotype into one that promotes thrombosis and coagulation. In inflarmmation, activated EC induce vasodilatation by production of $\mathrm{PGI} 2$ and $\mathrm{NO}(65)$.

Transendothelial leukocyte migration is increased during immune reactivity. The molecular mechanisms mediating physiological migration can be upregulated during immune reactivity. Neutrophil migration occurs mainly by cytokine-induced expression of E-selectin on the endothelium (66). Accumulation of lymphocytes and monocytes is a result of induction or upregulation of a series of adhesion molecules by cytokines in combination with production of chemoattractants by EC. In time, infiltrates change from cell types. These changes correlate with alterations in the adhesion molecules expressed by EC. These differences in adhesion molecules on the EC, and the production of chemoattractants and chemokines, allow fine tuning of leukocyte migration, allowing infiltration of different leukocyte populations in immune reactive lesions (65).

Besides induction of adhesion molecules by cytokines during immune reactivity the cytokines also enhance MHC class I and induce MHC class II expression in the EC. These MHC molecules are necessary for presenting antigenic peptides to T-lymphocytes, in the process of $\mathrm{T}$ cell activation. MHC binds peptides in the groove of the MHC molecule, allowing T lymphocytes to recognize the MHC/peptide complex with their $T$ cell receptor (TCR)(67). For $T$ cell activation the interaction between the $T$ cell and the antigen presenting cell (APC) requires costimulatory signals, i.e. receptor/ligand interactions such as CD2/LFA-3, LFA-1/ICAM-1 and CD28/B7-1 or B7-2 and CD40/CD40 ligand (68). Without these costimulatory signals, antigen presentation may result in T cell anergy and abrogation of the immune response (69). Since $\mathrm{EC}$ can express most of the molecules involved in costimulatory signaling, they may function as APC. 


\subsubsection{EC in organ allograft rejection}

The stimulus of rejection is based on the recognition by $T$ cells of cells bearing foreign histocompatibility antigens. The exact nature of $T$ cell allo-responses to (non-self) MHC is controversial to this day. T cells may recognize polymorphic MHC directly, or they may recognize non-self MHC peptides that are presented by self MHC proteins, or both. During rejection donor interstitial dendritic cells, which are the passenger leukocytes in the graft, or recipient dendritic cells can present the donor derived antigens. In the allograft, besides the prementioned cells, EC may contribute in antigen presentation processes (70, 71). Antigen presentation by EC may result in antigen-specific $\mathrm{T}$ cell activation, but more likely induces a state of allospecific unresponsiveness (72). Circumstantial evidence for such APC functions of EC is the finding that MHC class II expression is upregulated in EC in human renal, cardiac and liver allografts undergoing rejection $(73,74,75)$. In the rat, however, no induction of MHC class II in the vasculature was seen in rejected kidney allografts(76).

During allograft rejection EC become activated by cytokines. The most important lymphokines involved are probably IFNy, IL-1 and TNF. Activated CD4 and CD8 lymphocytes produce IFNy, and monocytes are the main producers of TNF. These cytokines induce adhesion molecule expression in EC resulting in increased transmigration of leukocytes through the endothelium of the graft, and by differential expression of the various adhesion molecules, infintration of relevant leukocyte subsets is controlled $(45,77)$. In human beart allograft rejection there is a relation between rejection and increased ICAM-1 expression. The role played by other cellular adhesion molecules such as VCAM-1 and especially E-selectin is less certain (78), although animal transplantation studies suggest that also the induction of VCAM-1 on the vasculature plays an important role in the rejection process (79). Applications of antibodies against VCAM-1, LFA-1 and ICAM-1 can inhibit the graft rejection phenomena in rat cardiac allografts $(80,81,82)$. Thus, adhesion molecules that are upregulated on $\mathrm{EC}$ in settings of inflammation to support recruitment of immunological cells play an important role in rejection of transplanted organs $(83,84)$. 
In addition, the cytokine-activated EC also promote inflammatory reactions during organ allograft rejection by secretion of a number of cytokines like $I L-1, I L-6$ and $I L-8$ as well as PAF and PAI-1. These mediators activate blood cells (65) and affect the balance of anticoagulation and procoagulation (56).

Transplantation in combination with cytomegalovirus (CMV) infection results in more often and earlier induction of the rejection process than without CMV infection. CMV infection induces an inflammatory type of response in the EC, because CMV is, in contrast to Herpes Simplex Virus, only able to infect but not to kill the endothelial cell (85). This inflammatory response results in an increase in leukocyte-EC interactions by adhesion mollecules and MHC class II molecules on the EC $(86,87)$.

\subsubsection{EC as target in the allograft rejection process}

In organ allograft rejection the endothelium of the graft is of donor origin and therefore can be considered a target structure for the immmunological rejection process generated by the recipient. As such the EC can be threatened by alloantibodies and cytotoxic T cells $(88,89)$, and additionally by Fic-receptor-expressing killer cells through antibodydependent cell cytotoxicity (ADCC) mechanisms $(90,91,92)$. The most dominant EC antigens involved in the rejection process are the constitutively expressed MHC class I antigens, but also the inducible MHC class II antigens. In addition to these MHC antigens EC may express other alloantigens, sometimes classified as "minor histocompatibility antigens" or as non-MHC alloantigens $(93,94,95,96)$. Cell mediated immune responses against EC may affect lysis and subsequently vascular insufficiency. With respect to anti EC alloantibodies it is not clear yet which effect they may have on EC. Although complement-mediated cytotoxicity by anti EC antibodies has been demonstrated, in general, EC are rather resistant to this process. However, it has been shown that antibody reactivity with $\mathrm{EC}$ effects various processes in the graft vasculature. Antibody-induced sublytic complement activation triggers processes that lead to alterations in endothelial integrity. In addition complement activation on EC by antobodies results in production of $\mathrm{UL}-1, \mathrm{TF}$ and PAF $(97,98,99)$ and induction of the 
adhesion molecules for leukocytes $(100,101)$. The production of C3a and C5a on the EC during complement activation influences recruitment and effector functions of platelets and leukocytes (102). The fact that in vascular rejection the progress of the rejection process is associated with the presence and the amount of alloantibodies reactive with endothelial MHC or non-MHC antigens suggests a role for these antibodies in the rejection process $(92,103)$.

\subsection{References}

1. Jaffe EA. Cell biology of endothelial cells. Human Pathology 1987; 18: 234.

2. Simionescu M. Simionescu N. Ultrastructure of the microvascular wall: functional correlations. In: Handbook of Physiology Sect 2, Vol IW, 42-101.

3. Gimbrone MA, Cotran RS. Human wascular smooth muscle in culture, Growth and ultrastructure. Laboratory Investigation $1975 ; 33: 16$.

4. Gimbrone MA, Cotran RS, Folkman J. Human vascular endothelial cells in culture. Growth and DNA synthesis. Journal of Cell Biology 1974; 60:673.

5. O'Connel KA, Edidin M. A mouse lymphoid endothelial cell line immortalized by simian virus 40 binds lymphocytes and retains functional characteristics of normal endothelial cells. Journal of Irmmunogy $1990 ; 144: 521$.

6. Harder $\mathrm{R}$, Uhlig $\mathrm{H}$, Kashan $\mathrm{A}$, et al. Dissection of murine lymphocyte-endothelial cell interaction mechanisms by SV-40-transformed mouse endothelial cell lines: novel mechanisms mediating basal binding, and 04-integrin-dependent cytokine-induced adhesion. Exp Cell Res 1991; 197: 259.

7. Tatsuta T, Naiot M, Oh-hara $T$, Sugawara I, Tsuruo T. Funetional involvement of ICAM- 1 in the adherence of resting versus activated lymphocytes to high endothelial cells. Int Immunol 1992; 2 :
165 .

8. Laulajainen T, Juikunen 1, Haltia A, Knutila S, Miettinen A, Holthofer H. Establishment and characterisation of a rat glomerular endothelial cell line. Lab Invest 1993; 69:183.

9. Ades EW, Hierholzer C, George V. Black J, Candal F. Viral susceptibility of an immortalized human microvascular endothelial cell line. Journal of Virological Methods 1992; 39: 83.

10. Fickling SA, Tooze JA, J WGS. Characterization of human umbilical veín endothelial cell lines produced by transfection with early region of SV4O. Exp Cell Res 1992; 201: 517.

11. Juillerat-Jeanneret L. Aguzzi A, Wiestler D, Darekar P, Janzer R-C. Dexamethasone selectively regullates the activity of enzymatic markers of cerebral endothelial cell lines. In Vitro Cell Dev
Biol 1992: 284.537

12. Renkin EM. Multiple pathways of capillary permeability. Circulation Research 1977; 41:735.

13. Renkin EM. Cellular aspects of transvascular exchange: $A$ 40 year perspective. Microcirculation
$1994 ; 1: 157$

14. Ghitescu L. Bendayan M. Transendothelial transport of senum albumin; a quantitative imurnunocytochemical study. Journal of Cell Biology 1992; 117: 745 .

15. Haselton FR, et al. Modulation of endothelial paracellular permeability. In: $\mathbb{N}$. Simionescu eds. Endothelial cell dysfunctions. New York: Plenum Press, 1992: 103

16. Wu KK, Thi
$47 ; 315$ Haemostasis $1993 ; 70: 29$.
Holecular events that control the protein C anticoagulant pathway. Thrombosis and R. W. H. Coleman J. Marder, E. W. Salmon, E W Philadelphia, PA: Lippincott, 1994: 837 . E. W. eds. Hemostasis and Thrombosis.

19. Rappaport SI Rao LYpincott 1994: 837 Arteriosclerosis and Thrombosis 1991; 12: 1111 . Intiation and regulation -dependent blood coagulation.

10. Moncada S Vane JR Thrombos thromboxane A2 and procology and endogenous roles of prostaglandin endoperoxides,

21. KJuft C. Constitutive synthesis of tissue type plogical Reviews 1979: 30: 293 . inhibitor type 1 (PAI-1): conditions and therapeutic tar acts Fyar (TPA) and plasminogen activator 
22. Hinsberg van VWM, Kooistra T, Emeis JJ, Koolwijk P. Regulation of plasminogen actiwator production by endothelial cells: role in fybrinolysis and local proteolysis. International Journal Radiation Biology 1991; 60: 246.

23. Hinsberg van VWM, Sprengers ED, Kooistra T. Effect of thrombin on the production of plasminogen activators and PA inhibitor-1 by human forskin microvascular endothelial cells. Thromb Haemostas 1987; 57: 148.

24. Moake IL, Turner NA, Stathopoulos NA. Involvement of large plasma WWF multimers in shearstress induced platelet aggregation. Journal of Clinical Investigation 1986; 78: 1.456 .

25. Bussolino F, Camussi G. Platelet-actiwating factor produced by EC. A molecule with autocrine and paracrine properties. European Journal of Biochemistry 1995; 229:327.

26. Palmer RMJ, Ferrige AG, Moncada S. Nitric oxide release accounts for the biological activity of endothelium-derived relaxing factor. Nature 1987; 327:524.

27. Griffith TM, Edwards DH, Lewis MJ, Newby AC, Henderson AH. The mature of endothelium derived vascular relazant factor. Nature 1984: 308: 645 .

28. Wu KK, Kulmacz RJ, Wang $\mathrm{L}-\mathrm{H}_{\text {, }}$ et al. Molecular biology of prostacyclin biosynthesis. In: $\mathrm{G}$. $\mathrm{M}$. Rubanyi and J. Vane eds. Prostacyclin: New Prospectives for Basic and Novel Therapeutic Indications. New York: Elsevier Sci., 1992: 11

29. Mullane KM, Pinto A. Endothelium, arachidonic acid and coronary vascular tone. FASEB 1987; 46: 54 .

30. Yanagisawa M, Kurihara $\mathrm{H}$, Kimsura $\mathrm{S}$, al e. A novel potent vasoconstrictor peptide produced by vascular endothelial cells. Nature 1988; 332: 411 .

31. De Nucci G. Thomas R, D'Orleans-Juste P. Pressor effects of circulating endothelin are limited by it's removal in the pulmonary circulation by the release of prostacyclin and endothelium derived growth factor. Proc Natl Acad Sci USA 1988; 85: 9797

32. Springer TA. Traffie signals for lymphocyte recirculation and leukocyte emigration: the multi step paradigm. Cell 1994; 76: 301.

33. Carlos TM, Harlan IM. Leukocyte endothelial adhesion molecules. Blood 1994; 84: 2068.

34. Baumbeuter $S$, Singer MS, Henzel W, et al. Binding of L-selectin to the vascular sialomucin, CD34. Science $1993 ; 262: 436$.

35. Rosen SD, Bertozzi CR. The selectins and their ligands. Current Opinion in Cell Biology 1994; 6: 663.

36. Butcher EC. Cellular and molecular mechanisms that direct leukocyte traffic. American Journal of Pathology 1990; 136: 1 .

37. Zimmerman GA, Prescatt SM, Mc Intyre TM. Leukocyte-endothelial cell interactions. Immunology Today $1992 ; 13$ :

38. Rothlein R, Marlin SD, Rothlein R, Lawrence MB, McIntyre LV, Anderson DC. Leukocyte adhesion molecules, structure, function and regulation. In: T. A. Springer Anderson, D. C. Rosentahl, A. S. and Rothlein, R. eds. New York: 1990: 170

39. Mantovani $\mathrm{A}$, Bussolino $\mathrm{F}$, Dejana $\mathrm{E}$. Cytokine regulation of endothelial cell function. FASEB Journal 1992; 6: 2591.

40. Cotran RS, Pober JS. Effects of cytokines on wascular endothelium: their role in immune injury. Kidney International 1989; 35: 969

4.1. Mantovani A. Bussolino F. Introna M. Cylokine regulation of endothelial cell function: from molecular levell to the bedside. Immunology Today 1997: 18: 231 .

42. Rozenkranz-Weiss, P, Sessa WC, Milstien S, Kaufman S, Watson CA, Pober $\mathbb{B}$. Regulation of nitric oxide synthes is by proinflammatory cytokines in human umbilical wein endothelial cells. Journal of Clinical Investigation 1994; $93: 2236$.

43. Hollenbaugh $D$, Mischel-Petty N, Edwards CP. Expression of functional CD40 by wascular endothelial cells. Journal of Experimental Medicin 1995; 182: 33.

44. Yellin MJ. Brett J, Baum D. Functional interactions of T cells with endothelial cells. The role of CD40L-CD40 mediated signals. Journal of Experimental Medicin 1995; 182: 1857.

45. Sluiter W, Pietersma A, Lamers JMJ. J.F. K. Leukocyte adhesion molecules on the vascullar endothelium: Their role in the pathogenesis of cardiovascular disease and the mechanism underlying their expression. Journal of Cardiovascular Pharmacology 1993; 22; 37.

46. Leeuwenberg JFM, Damme van J, Maeger $T$, Jeunhomme TMMA, Buurman WA. Effects of tumar mecrosis factor on the interferon $\gamma$ induced major histocompatibility complex class II antigen expression by human endothellial cells. European Journal of Immunology 1988; 18: 1469.

47. Bevilaqua MP, Nelson RM. Selectins. Journal of Clincal Investigation 1993; 91 : 379.

48. Smith CW, Anderson DC, Taylor, Rossen RD, Entman ML. Leucocyt adhesion molecules and myocardial ischemia. Trends in Cardiovascular Medicin 1991;1:167.

49. Palluy O, Morliere L, Gris J. Bonne C, Modat G. Hypoxia/reoxygenation stimulates endothelium to promote neutrophil adhesion. Free Radic Biol Med 1992; 13:21. 
50. Oxborn $\mathrm{L}$, Hession $\mathrm{C}$. Tizard $\mathrm{R}$, et al. Direct expression cloning of vascular cell adhesion molecule 1 , a cytokine-induced endothelial protein that binds to lymphocytes. Cell 1989; 59: 1203 .

51. Pober JS, Cotran RS. Cytokines and endothelial cell biology. Physiol Rev 1990; 70: 427.

52. Fougerolles de $\mathbb{A} R$, Stacker $S A$, Schwarting $R$, Springer A. Characterization of ICAM-2 and evidence for a third counter receptor for LFA-1. Journal of Experimental Medicine 1991; 174: 253.

53. Carlos TM, Harlan IM. Membrame proteins involved in phagocyte adherence to endothelium. Immunological Review 1990; 114:

54. Iademarco MF, Barks $\mathrm{JL}$, Dean DC. Regulation of vascular cell adhesion molecule-1 expression by IL 4 and TNF $\alpha$ in cultured endothelial cells. Journal of Clinical Investigation 1995; 95: 264.

55. Thrcke. NS, Wrenshall LE, Platt JL. Role of heparan sulphate in immune system-bloodvessel interactions. Immunology Today 1993; 14:500.

56. Esmon CT. Cell mediated events that control blood coagulation and vascular injury. Rev Cell Biol 1993: 9: 1 .

57. Romano M. Sironi $M$. Toniati $C_{\text {, }}$ et al. Role of IL -6 and its soluble receptor in induction of chemokines and leukocyte recruitment. Immunity 1997; 6:315.

58. Vora $M$, Yssel H, Vries de JE., Karasek MA. Antigen presentation by human dermal microvascular endothelial cells. Immune regulatory effect of IFN $\gamma$ and IL-10. Journal of Immunology 1994: 152: 5734 .

59. Palmer-Cracker RL, Hugles CCW, Pober IS. IL-4 and IL-13 activate the LAK-2 tyrosine kinase and stat-6 in cultured human vascular EC through a common pathway that does not inwolve the gamma c chain. Journal of Clinical Investigations 1996; $98: 604$.

60. Voest EE, Kenyon BM, O'Reilly MS. Truitt G, D'Amato RJ, Folkman J. Inhibition of angiogenisis in vivo by interleukin 12. Journal of the National Cancer Institute 1995: 87: 581.

61. Linke AT, Male DK. Strain specific variation in constitutive and inducible expression of MHC class $\mathrm{II}_{\text {" class I }}$ and ICAM-I on rat cerebral endothelium. Immunology 1994; 82: 88.

62. Gumkowski F, Kaminska G, Kaminki M, L.W. M, Auerbach R. Heterogeneity of mouse vascular endothelium. Blood Vessels 1987; 24: 11 .

63. Petzelbauer P, Bender JR, Wilson J, Pober IS. Heterogeneity of dermal microvascular endothelial cell antigen expression and cylokine responsiveness in situ and in cell culture. the Journal of Immunology 1993; 151: 5062.

64. Wang JM, Kumar S, Pye D, Vanagthoven AJ, Krupinski J, Hunter RD. A monoclonal antibody detects heterogeneity in vascular endothelium of tumours and normal tissues. Int I Cancer $1993 ; 54: 363$

65. Pober JS, Cotram RS. The role of endothelial cells in inflammation. Transplantation 1990; 50:537.

66. Geng GJ, Bevilacqua MP, Moore $\mathrm{KL}_{4}$ et al. Rapid neutrophil adhesion to activated endothelium mediated by GMP-140. Nature 1990; 343: 757.

67. Clevers $H$, Alarcon $B$, Wileman $T$, Terhorst $C$. The T cell receptori $C D 3$ complex: A dynamic protein ensemble. Ann Rev Immunol 1988; 6: 629 .

68. Feldmann M. Cell cooperation in the antibody response. In: 1. Roitt, J. Brostoff and D. Male eds. Immunology. Barcellonat: Times: Mirror International publishers limited, 1997:8

69. Steinman RM, Young JW. Signalis arising from antigen prestenting cells. Current Opinion in Immunology 1991; 3:361.

70. Hughes CCW, Savage COS, Pober IS. The endothelial cells as a regulator of T-cell function. Irmmunol Rev 1990; 117: 85 .

71. Savage CO, hughes CW, MCIntyre BW, Picard JK, Pober IS , human CD4+ T cells proliferate to HLA-DR* allogeneic vascular endothelium. Transplantation 1993; 56: 128.

72. Marelli-Berg FM, Hargreaves REG, Carmichael P, Dorling A, Lombardi G, Lechler RI. Major histocompatibility complex class II-expressing endothelial cells induce allospecific nonresponsiveness in naive T cells. Journal of Experimental Medjcin 1996; 183:1603.

73. Fuggle SV, McWhinnie DL, Chapman JR, Taylor HM, Morris PJ. Sequential analysis of HLA-class II antigen expression in human renal allografts. Transplantation $1986 ; 42$ : 144 .

74. Rose ML, Coles MI, Griffin RJ, Pomerance A, Yacoub MH. Expression of class $I$ and class II major histocompatibility antigens in normal and transplanted human heart. Transplantation 1986; 41:
776 .

75. Gouw ASH, Huitema S, Grond J, et al. Early induction of MHC antigens in human liver grafts. American Journal of Pathology 1988; 133: 82 .

76. Duijvestijn AM, Breda Vriesman van PJC. Chronic renal allograft rejection. Transplantation 1991 ;
$52: 2$.

77. Bevilaqua MP. Endothelial-Leulkocyte Adhesion Molecules. Ann Rew Immunol 1993; 11: 767.

78. Tanio JW, Basu CB. Albelda SM, Eisen HJ. Differential expresion of the cell adhesion molecules ICAM-1, VCAM-1 and E-selectin in nomal and post-transplantation myocardium. Circulation
$1994: 489 \cdot 4$. 
79. Pelletier RP, Morgan CI. Sedmak DD, et al. Analysis of inflammatory endothelial changes, including VCAM-1 expression, in murine cardiac grafts. Transplantation 1993; 55:315.

80. Pelletier R, Ohye R, Kincade P, Ferguson R, Orosz C. Monoclonal antibody to anti VCAM-1 interferes with murine cardiac allograft rejection. Transplantation Proceedings 1993; 25: 839

81. Paul LC, Davidoff A, Benediktsson H, Issekutz TB. The efficacy of LFA-I and VLA-4 antibody treatment in rat vascularized cardiac allograft rejection. Transplantation 1992; 55 : 1196.

82. Paul LC, Davidoff A, Paul DW, Benediktsson H, Issekutz TB. Monoclonal antibodies against LFA-1 and VLA-4 inhibit graft vasculitis in rat cardiac allografts. Transplantation Proceedings 1993; 25: 813.

83. Sedmak DD, Orosz CG. The role of vascular endothelial cells in transplantation. Arch Pathol Lab Med 1991; 115: 260.

84. Robson SC, Candinas D, Hancock WW, Wrighton C. Winkler $\mathbb{H}$, Bach FH. Role of endotheliai cells in transplantation. International archives allergy Immunology 1995; 106: 305.

85. Span AHM, Boven van CPA, Bruggeman CA. The effect of cytomegalovirus infection on the adherence of polymorphonuclear leukocytes to endothelial cells. European Journal of Clinical Investigation $1989 ; 19: 542$.

86. Roberts WH, Sneddon JM, Waldman J, Stephens RE. Cytomegalovirus inffection af gastrointestinal endothelium demonstrated by simultaneous nuclei acid hybridization and immunohistochemistry. Arch Pathol Lab Med 1989; 113: 461.

87. Waldman WJ, Knight DA, Adams PW, Orosz CG, Sedmak DD. In vitro induction of endothelial adhesion molecule and MHC antigen expression by cytomegalovirus-activated CD4+T cells. Transplantation Proceedings 1995; 27: 1269.

88. Bolton EM, Gracie JA, Briggs JD, Kampinga J, Bradley JA. Cellular requirements for renal allograft rejection in the athymic nude rat. Journal of Experimental Medicin 1989; 169: 1931.

89. Ouwehand A.J, Baan CC, Vaessen LM, et al. Characteristics of graft infiltrating lymphocytes after human heart transplantation. HLA mismatches and the cellular immune response within the transplanted heart. Hum Immunology 1994; 39: 233.

90. Yard BA, Hollander den D, Reterink $T$, et al. Involvement of minor histocompatibility antigens in the rejection of an HLA identical renal transplant from a living related donor. Transplantation 1993 ;

91. Bradley JA, Mowat AM, Bolton EM. Processed MHC class I alloantigen as the stimulus for $\mathrm{CD} 4+$ T-cell dependemt antibody-mediated graft rejection. Immunology Today 1992; 13: 434.

92. Dunn MJ, Crisp SJ, Rose ML, Taylor PM, Yacoub MH. Anti-endothelial antibodies and coronary artery disease after cardiac transplantation. The Lancet 1992; 339: 1566.

93. Adams H, Tilney NL, Collins JJ, Karnovsky MJ. Experimental graft arteriosclerosis. Transplantation 1992; 53: 1115 .

94. Crisp SJ, Dunn MJ, Rose ML, Barbir M. Yacoub MH. Anti-endothelial antibodies after heart transplantation: the accelerating factor in transplant-associated coronary artery disease. Journal of Heart and Lung Transplantation 1994; 13: 81.

95. Joyce S, Flye MW, Mohanakumar T. Characterization of kidney cell-specific, non-major hisiocompatibility complex alloantigen using antibodies from rejected human renal allografts. Transplantation 1988; 46: 362

96. Gilks WR Gore SM, Bradley BA. Renal transplant rejection. Transient immunodominance of HLA mismatches. Transplantation 1990; 50: 141 .

97. Bevilaqua MP, Pober IS, Majeau GR, Cotran RS, Gimbrone MAJ, Interleukin 1(IL-1) induces biosynthesis and cell surface expression of procoagulant activity in human vascuiar endothelial cells. Journal of Experimental Medicin 1984; 160:618.

98. Saadi S. Platt J. Transient pertubation of endothelial integrity induced by natural antibodies and complement. Journal of Experimental Medicine 1995, 181: 21

99. Camussi G, Bussolino F, Salvidio G, Baglioni C. Tumor necrosis factor/cachetin stimulates peritoneal macrophages, polymorphonuclear neutrophils, and vascular endothelial cells to synthesize and release platelet-activating factor. Journal of Experimental Medicine 1987; 166: 1390 .

100. Vaporciyan AA, Mulligan MS, Warren JS, Barton PA, Miyasaka M, Ward PA. Up-regulation of lung vascular ICAM-1 in rats is complement dependent. The Journal of Immunology 1995; 155: 1442 .

101. Kilgore $K_{K} S$, Shen JP, Miller BF, Ward PA. Warren IS. Enhancement by the complement nembrane attack complex of tumor necrosis factor-induced endothelial cell expression of E-selectin and ICAM-1. The Journal of Immunology $1995 ; 155: 1434$.

102. Braver RB. Baldwin III WM, Tbrahim S, Sanfilippo F. The contribution of the terminall complement components to acute and hyperacute allograft rejection in the rat. Transplantation 1995; $59: 288$. 
103. Baldwin WM, Soulillou JP, Claas FHJ, Peyrat MA, Es van LA, Rood van JJ. Antibodies to endothelial antigens in eluates of 88 human kidneys; correlation with graft survival and presence of T- and B-cell antibodies. Transplantation Proceedings 1981: 13: 1547. 


\section{Production and characterization of spontaneous rat-heart-endothelial-cell lines}

Josien G. Derhaag, Adrian M. Duijvestijn, Jef J. Emeis*, Wim Engels\#, Peter J. C. van Breda Vriesman.

Department of Immunology, and Institute of Cardiovascular Diseases\#, CARMM, University of Limburg, Maastricht, The Netherlands, and Gaubius Laboratory TNO-PG*, Leiden, The Netherlands.

Published in Laboratory Investigation. 1996, Vol.74, No2, p. 437-451. 


\section{Abstract}

Encothelial cells (EC) are important regulatory cells in physiology and pathology. In vitro studies with rat $\mathrm{EC}$ from heart tissue are hampered by laborious isolation and purification procedures, Iow yield and, limited life span of the cells. Therefore, it is essential to obtain long-term heart endothelial cell lines offering a more adequate in vitro system to study rat heart $\mathbb{E C}$. An ex-vivo perfusion model was used to isolate EC from rat heart. Isollation and culture conditions were modified to allow spontaneous development of immortalized rat-heart-endothelial-cell (RHEC) lines. Produced cell lines were tested for endothelial nature using a panel of markers. The selected RHEC lines were subsequently tested for a series of phenotypic and functional properties representative to $\mathrm{EC}$ in the context of physiological and inflammatory functions in vivo. A series of 3 spontaneous (RHEC) lines were produced out of 13 isolations from Lewis rat hearts: RHEC-3, RHEC-10 and RHEC-11. These lines were stable for more than 30 passages (RHEC-3 even for more than 100). The cell lines were tumorigenic and developed hemangiomas on in vivo injection. All 3 lines expressed majorhistocompatibility-complex (MHC) class I, but no MHC class II. Intercellular adhesion molecule I was only expressed by RHEC-3. Cytokine stimulation induced Vascular cell adhesion molecule 1 in RHEC-3 and RHEC-11, and MHC class $I$ in all 3 lines in different quantities. The phenotypic characteristics of the different RHEC lines resembled the myocardial microvascular endothelium in situ. The three lines expressed angiotensin-converting enzyme, and responded to histamine and ATP, but not to thrombin and bradykinin. They constitutively produced small amounts of endothelin, and high levels of tissue plasminogen activator they produced little (after stimulation with pherbol ester PMA) or no von Willebrand factor. The RHEC lines produced thromboxane A2, but no prostacyclin, on stimulation with arachidonic acid and A23187, they produced prostaglandin E2. Therefore we conclude the following: 1) The described isolation and culture technique is successful for production of spontaneous stable EC lines from rat heart. 2) RHEC-3,10, and 11 can be considered a series of different lines representative of the heterogeneity of beart microvascular endothelium in vivo. 3) The RHEC lines offer a series of valuable tools to study various heart EC functions and mechanisms in physiology and pathology. 


\subsection{Introduction}

Endothelial cells (EC) are important regulatory cells in warious physiological and pathological processes. For example, they are involved in the regulation of vascular permeability and vascular tone through reactivity with vasoactive amines such as histamine and serotonin, and production of endothelin (ET), angiotensin-converting enzyme (ACE), nitric oxide, and prostacyclin respectively $(1,2,3,4)$. They act in hemostatic processes by releasing mediators such as von Willebrand Factor (vWF), tissue-factor, tissue-plasminogen activator (t-PA), and arachidonic acid (AA) products $(5,6,7,8)$. EC also play a role in inflammation and settings of immune reactivity by cell-cell interactions such as recruitment of blood leukocytes through expression of EC adhesion molecules $(9,10,11,12)$ and antigen presentation to $T$ cells through expression of major histocompatibility complex (MHC) class II antigens $(13,14,15)$. In addition EC release inflammatory mediators and cytokines, such as plateletactivating-factor, $\mathbb{L}-1$, and $\mathrm{L}-\mathrm{-8}(16,17,18)$. As such vascular EC are multipotential cells forming a flexible and regulatory interphase between blood and tissues. Clinical and experimental animal studies in vivo have contributed significantly to information on the role of vascular endothelium in physiology and pathophysiology. To extend and precisely dissect the complex mechanisms and potential functions of $\mathrm{EC}$ in wivo, access to in vitro endothelial cell culture systems is required. This led us, in the context of studies in experimental heart inflammation, transplantation and autoimmune models in Lewis rats, to develop endothelial cell cultures from Lewis heart tissue. However, culturing isolated EC from rat tissues and organs including heart is hampered by laborious isolation and purification techniques, low yield, and limiting life span of cell cultures. Therefore, long-term rat endothelial cell lines are extremely desirable. The successful production of endothelial cell lines has been described in human and in murine species, mostly using SV-40 and adenovirus infections $(19,20,21,22)$ or transfections with $\mathrm{SV}-40$ and polyoma virus oncogene-constructs coding for viral $\mathrm{T}$ antigens $(23,24,25)$. However, viral inserts in EC may lead to interference with specific cell functions by alteration of intracellular processes. Previously we noticed 
(26) that endothelial cell lines occasionally ( 2 out of 60 isolates) developed spontaneously from senescent cultures of rat heart endothelial cells (RHEC). Herein we describe how a modification of this technique allowed the development of EC lines from Lewis rat heart in a much higher frequency. A series of three EC lines was produced that expressed rat endothelial cell-specific antigen RECA-1 (27), ACE, and VWF, bound lectin GS-I-B4, and internalized DiI-ac-LDL. The RHEC lines were further studied for tumorigenicity, and a set of phenotypic and functional properties relevant to physiological and pathological processes. Phenotypic studies included expression of MHC antigens, as well as intercellular adhesion molecule 1 (ICAM-1) and vascular cell adhesion molecule 1 (VCAM-1). Functional properties that were tested included the responsiveness to cytokines, and other endothelial cell-activating agents, the production of AA products (prostaglandins (PG), thromboxane (TX)), t-PA, vWF, and ET. The data show that the 3 RHEC lines are heterogeneous in their phenotypic and functional characterization profiles, and can be considered representative for a series of aspects of microvascular heart EC in vivo. As such, the RHEC lines can be considered unique tools for further in vitro studies regarding various functions and mechanisms of cardiac EC 


\subsection{Materials \& methods}

Animals

Lewis rats were obtained from the Central Animal Facility of the University of Limburg. Male rats (8-12 weeks old) were used. Animals were bred under specified pathogen free conditions and had free access to food and water.

\section{Culture media}

EC work medium: contained: 90 \% M199 (Gibco BRL, Life Technologies B.V. Breda, the Netherlands), $10 \%$ ( $/ v$ ) inactivated fetal calve serum (FCS; Integro, Belgium), $100 \mathrm{units} / \mathrm{ml}$ penicillin, $100 \mu \mathrm{g} / \mathrm{ml}$ streptomycin, $2 \mathrm{mM} \mathrm{L}-\mathrm{glutamin}$ and 25 mM Hepes.

EC culture medium: contained: $40 \%$ RPMI 1640 (Gibco), 40\% M199 (Gibco), $20 \%(\mathrm{w} / \mathrm{v}$ ) inactivated FCS (Integro), 2mM L-glutamin, $13 \mathrm{MM} \mathrm{NaHCO} 3,10 \mathrm{mM}$ Hepes, $20 \mathrm{U} / \mathrm{ml}$ heparin, and $0.1 \%(\mathrm{v} / \mathrm{v})$ bovine brain extract $(14.93 \mathrm{mg} / \mathrm{ml})$ prepared as described by Maciag (28), 50 units/ml penicillin and $50 \mu \mathrm{g} / \mathrm{ml}$ streptomycin and 2 $\mu \mathrm{g} / \mathrm{ml}$ Fungizone.

Modified-Krebs-Ringer Solution (MKR): contained $115 \mathrm{mM} \mathrm{NaCl}, 2.6 \mathrm{mM}$ $\mathrm{KCl}, 1.2 \mathrm{mM} \mathrm{KH} 2 \mathrm{PO} 4,1.2 \mathrm{mM} \mathrm{MgSO} 4 . \mathrm{H} 2 \mathrm{O}, 10 \mathrm{mM}$ NaHCO3, $10 \mathrm{mM}$ Hepes, 1.1mM Glucose, $\mathrm{pH} 7.3$.

\section{Endothelial cell isolation}

EC isolations occurred as previously described (26) with modifications. Briefly, hearts were extirpated under ether anesthesia and rinsed in cold MKR. Hearts were connected with the aorta to the nozzle of a sterile in vitro perfusion system after which the right atrium was opened by incision. Hearts were retrogradely perfused with carbogen (95\% $\mathrm{O}_{2}$ plus $5 \% \mathrm{CO}_{2}$ )-gassed MKR plus $50 \mathrm{U} / \mathrm{ml}$ penicillin, $50 \mu \mathrm{g} / \mathrm{ml}$ streptomycin and $100 \mathrm{mM} \mathrm{CaCl} 2$ (MKR-plus) wia the aorta at $37^{\circ} \mathrm{C}$ for 10 minutes, followed by recirculation perfusion with $50 \mathrm{ml} \mathrm{MKR-plus} \mathrm{solution} \mathrm{containing} 163 \mathrm{U} / \mathrm{ml}$ collagenase type-II (Wortington Biochemical Corp. New Yersey, USA), for 30 
Chapter Two

minutes by $37^{\circ} \mathrm{C}$, at a flow rate of $5 \mathrm{ml} / \mathrm{minute}$. The perfusate was collected and centrifuged $\left(200 \mathrm{~g}, 10\right.$ minutes, $\left.20^{\circ} \mathrm{C}\right)$. Freshly isolated cells were washed twice with EC work mediurn, resuspended in EC culture medium and suspensions were seeded on frbronectin precoated, 6 well tissue culture dishes (Costar, Cambridge, USA) and cultured in a humidified. $5 \% \mathrm{CO}_{2}$ incubator at $37^{\circ} \mathrm{C}$.

\section{Cell culturing}

EC were cultured in a $\mathrm{CO}_{2}$ incubator at $37^{\circ} \mathrm{C}$ in $\mathrm{EC}$ culture medium. Confluent monolayers were passaged routinely in 1.3 dilution after treatment with $0.25 \%$ trypsin/0.2\% EDTA in PBS (150 mM NaCl, $8 \mathrm{mM} \mathrm{Na} 2 \mathrm{HPO}_{4} .2 \mathrm{H}_{2} \mathrm{O}, 1.6 \mathrm{mM}$ $\left.\mathrm{KH}_{2} \mathrm{PO}_{4}, \mathrm{pH} 7.3\right)$. All experiments were performed between passages 20 and 30 .

EC were tested for uptake of low density lipoprotein (LDL) by incubation of EC monolayers in 96 well culture dishes with $40 \mu \mathrm{g} / \mathrm{ml} 1$, 1'-dioctadecyl-1-3,3,3;3'tetramethyl-indo-carbo cyanine-perchlorate-acetylated LDL (Dil-ac-LDL) for 4 hrs at 37 ${ }^{\circ} \mathrm{C}$. Subsequently, monolayers were washed 3 times with PBS, fixed with $1 \%$ paraformaldehyde in PBS, and examined with a fluorescence reverse microscope.

\section{Antibodies and lectins}

The following Ab and lectins were used for staining. Mouse mAb RECA-1 (pan endothelial cell specific; 27), OX18 (anti-MHC class D), OX6 (anti-MHC class II), OX8 (NK and T cells, used as a non-relevant isotype-matched controly obtained through the European Collection of Animal Cel Cultures (Salisburey, UK), 1A29 ( anti-ICAM-1, donated by Dr. M. Miyasaka (29), 5F10 (anti-VCAM-I, donated by Drs. R. Lobb and P. Chisholm (30)), and 9B9 (anti-human ACE, crossreactive with rat ACE (Biotrack Incorp. USA). Polyclonal Ab used were rabbit Ab against vWF (DAKO, Denmark), and goat Ab against ACE (kindly donated by Dr. R.L. Soffer, (31)). The lectins used were biotin-labelled BS-I and isolectin BS-I-B4 (Sigma, Belgium). These lectins are derived from Bandeiraea or Griffonia simplicifolia and are specific for teminal $\alpha$ galactosyl and for $\mathrm{N}$-acetyl- $\alpha$-galactosaminyl, as well as for $\alpha$-gallactosyl residues 
respectively. Especially isolectin BS-I-B4 is used as an endothelial cell marker. Ab and lectins were used in pretested saturating concentrations.

\section{(Imuno)peroxidase staining}

Immunoperoxidase staining was performed on $6 \mu \mathrm{m}$ frozen heart tissue sections, and on cytocentrifuge preparations of heart EC, using a 2-step immunoperoxidase technique as previously described (27). Cytocentrifige preparations were made from suspensions of routinely trypsinized confluent EC cultures. EC were either fixed with $1 \%$ paraformaldehyde (PFA) in PBS for 30 minutes at $4^{\circ} \mathrm{C}$, washed 3 times with PBS and resuspended in EC working medium, or resuspended unfixed. Preparations were made in a cytocentrifuge (Cytospin3, Shandon, England) used at 680 rpm for 10 minutes. Frozen-tissue sections and cytocentrifuge preparations of unfixed. cells were aceton-fixed for $10 \mathrm{~min}$, and air-dried. Cytocentrifuge preparations and tissue-section preparations were incubated with the specific $\mathrm{Ab}$ or biotin-labelled lectins diluted in $0.05 \%$ BSA in PBS for 60 minutes in a humidified chamber at room temperature. The preparations were washed 3 times with PBS for 5 minutes and incubated with either peroxidase-conjugated second-step $\mathrm{Ab}$ ((rabbit $\mathrm{F}$ (ab)2 anti-mouse IgG, $100 \times$ diluted, Swine F(ab)2 anti-rabbit IgG, $100 \times$ diluted, (Dako, Denmark), or rabbit anti-goat IgG, $100 \times$ diluted (Nordic, The Netherlands)) supplemented with 3\% normal rat serum (NRS), or peroxidase-conjugated streptavidin (100 $x$ diluted; Amersham, U.K.) for 1 hour. Subsequently preparations were washed 3 times with PBS for 5 minutes and incubated for 10 minutes with a $0.05 \mathrm{mg} / \mathrm{ml}$ diaminobenzidin solution in PBS containing $0.5 \% \mathrm{H}_{2} \mathrm{O}_{2}$, washed 3 times in tap water and counterstained with haematoxylin. Preparations were routinely dehydrated and cover slipped using Entallan.

Quantification of percentages of positive cells occurred microscopically on cytocentrifuge preparations by counting a minimum total of 200 cells in at least two fields, or in case of low numbers of positive cells, a minimum of 10 positive cells. 


\section{lomunofluoresence staining}

Fluorescent staining was performed on viable confluent monolayers of heart EC in 96 well tissue culture plates. After a wash step with M199 containing $10 \%$ new born calf serum (NBCS), the cells were incubated with saturating concentrations of specific or isotype-matched control Ab diluted in M199 with $10 \%$ NBCS, for 60 minutes at room temperature. The cells were carefully washed 3 times in M199 medium with $10 \%$ NBCS, and incubated with a FTC-conjugated second step Ab (goat anti-mouse IgG, rat absorbed, $100 x$ diluted; Cappel $)$, for 30 minutes. After $3 x$ washing with M199 with $10 \%$ NBCS, monolayers were fixed in $1 \%$ PFA in PBS and examined under a Zeiss fluorescence reverse microscope.

\section{Flow-cytometry analysis}

For flow-cytometry immunofluorescent staining of EC surface antigens was performed in suspensions of routinely trypsinized confluent EC cultures. Cells showed more than $99 \%$ viability as tested by trypan blue exclusion. After a wash step with PBS with $0.5 \%$ BSA and $1 \%$ azide (PBSAA) the cells were incubated with the specific Ab diluted in PBSAA for 30 minutes at $0^{\circ} \mathrm{C}$. The cells were washed 3 times in PBSAA and incubated with a FITC conjugated second-step Ab (goat anti-mouse IgG, rat absorbed, $100 \mathrm{x}$ diluted, Cappel), for 30 minutes. After washing 3 times with PBSAA the cells were examined in flow-cytometry using a FACS-Sort (Becton Dickinson, Mountain View, CA, USA).

When immunofluorescent cell surface staining was combined with fluorescent DNA labelling, the cells were first immunostained as mentioned before. Subsequently they were fixed with $1 \%$ PFA for 30 minutes, washed 3 times and resuspended in a 10 $\mu \mathrm{g} / \mathrm{ml}$ propidium iodid (Calbiochem, La Jolla California. 537059) solution in PBS containing $10 \mu \mathrm{g} / \mathrm{ml}$ RNAse for $15-30$ minutes at $0^{\circ} \mathrm{C}$, and examined by two color flow cytometry in a FACS-Sort (Becton Dickinson). 
Cytokine stimulation

For cytokine stimulation experiments the RHEC lines were stimulated with either $400 \mathrm{U} / \mathrm{ml}$ human tumor-necrosis-factor (TNF)- $\alpha$ (kindly donated by Prof Dr W. Fiers) or $200 \mathrm{U} / \mathrm{ml}$ rat interferon (IFN)- $\gamma$ (kindly donated by Dr P van de Meide). Cytokines were diluted in EC culture medium and incubated on confluent monolayers of RHEC cultures for $32 \mathrm{hr}$. Experiments were performed in triplicate.

\section{Tissue piasminogen activator and von willebrand factor measurements}

tPA and VWF production were measured in the culture supernatant of confluent EC monolayers. Confluent monolayers had been incubated with EC culture medium alone $\left(5 \mathrm{ml} / 25 \mathrm{~cm}^{2}\right)$ or culture medium containing histamine $(3 \mu \mathrm{M})$ or phorbolmeristate-acetate (PMA; $30 \mu \mathrm{g} / \mathrm{ml})$. After 4, 8, 16, and 32 hrs supernatants were collected and stored at $-70^{\circ} \mathrm{C}$. APA and WWF were measured with ELISA as previously described $(32,33)$. Data for $\mathrm{tPA}$ were expressed in $\mathrm{ng} / \mathrm{ml}$, and for $\mathrm{VWF}$ in $\mathrm{U} / \mathrm{ml}, 100 \mathrm{U}$ being equivalent to the amount of wWF present in $1 \mathrm{ml}$ of pooled rat plasma.

For each time point, tPA values were compared for the three EC lines, using the Kruskall-Wallis test. Values of non-stimulated and stimulated cultures were compared using the Mann Whitney U-test. Differences were considered significant (two tailed) for $\mathrm{p}<0.05$ 


\section{$P G$ and TX measurements}

PG production was measured in culture supernatants of confluent momolayers Confluent monollayers were incubated with fresh EC culture medium (without FCS and ECGF) alone $\left(5 \mathrm{ml} / 25 \mathrm{~cm}^{2}\right)$ or with $\mathrm{AA}(80 \mu \mathrm{M})$, or with both $\mathrm{AA}$ and calcium ionophore A23187 (10 1 M) for 30 minutes. Supernatants were collected and stored at $-70^{\circ} \mathrm{C} . \mathrm{PG} \mathrm{I}_{2}$ (determined as the stable metabolite 6 -keto $\mathrm{F}_{1 \mathrm{a}}$ ) $\mathrm{PGF} \mathrm{F}_{2 \mathrm{a}}, \mathrm{PGE}_{2}$ and $\mathrm{TX}_{2}$ ( $T X \mathrm{~A}_{2}$, determined as the stable metabolite $\mathrm{TXB}_{2}$ ) were measured as previously described (34). In brief, supernatants were purified using C18 reversed-phase chromatography. The eluted PG/TX fractions were methoxymated, esterified with panaxyl bromide, and analyzed by high-performance liquid chromatography with fluorimetric detection.

Values of non-stimulated and stimulated cultures were compared using the Mann-Whitney U-test. Differences were significant (two-tailled) for $\mathrm{p}<0.05$

\section{Calcium mobilization studies}

To test whether the RHEC lines were responsive to various endothelial cellstimulating agents, cells were stimulated with either thrombin, histamine, bradykinin, or ATP, and cellular mobilization of calcium ([Ca $\left.{ }^{++}\right]$i) was measured using the calciumsensitive fluorescence probe fura-2 acetoxymethyl ester, according to Van Haaster et all (35) with minor modifications. In brief: confluent monolayers of RHEC lines were washed with buffer A (10 mM HEPES, $150 \mathrm{mM} \mathrm{NaCl}, 5 \mathrm{mM} \mathrm{KCl}, 1.8 \mathrm{mM} \mathrm{CaCl}$, $1 \mathrm{mM} \mathrm{MgCl} 2,1 \mathrm{mg} / \mathrm{ml}$ glucose, $4 \mu \mathrm{M} \mathrm{L-glutamin)} \mathrm{containing} 0.25 \%$ BSA, and incubated with $1 \mu \mathrm{M}$ fura-2 in buffer A with $1 \%$ BSA for 45 min at $37{ }^{\circ} \mathrm{C}$. Subsequently monolayers were washed and incubated with $\mathrm{EC}$ culture medium for $15 \mathrm{~min}$. Cultures were incubated with $0.05 \%$ EDTA until detachment of cells and resuspended in buffer A containing $0.25 \% \mathrm{BSA}$. Cellular mobilization of $\mathrm{Ca}^{+*}$ in $\mathrm{EC}$ suspensions after stimulation with different concentrations of either thrombin, histamine, bradykinin, or ATP was measured in cuvets using a spectrofluorometer (SLM Aminco) at $500 \mathrm{~nm}$ emission wave length. The change in ratio of fluorescence at 340 and $380 \mathrm{~nm}$ excitation 
before and after stimulation was used to calculate the [Ca+4] Calibration values for the calculation of $\left[\mathrm{Ca}^{++}\right]$i were collected after addition to the suspensions of $1 \%(\mathrm{w} / \mathrm{v})$ Triton $X-100$, followed by 1 mM EGTA according to the procedure of Grynkiewicz et al $(36)$.

\section{ET measurements}

ET production was measured in culture supernatant of confluent EC monolayers after 4 and $16 \mathrm{hr}$ using a radioimmunoassay-kit (Nichols Institute Diagnostics B.V., Wychen, The Netherlands). In brief: after acidification and extraction over C18 columns endothelin was measured in a sensitive and specific competitive proteinbinding radioimmunosssay (37).

\section{Tumorigenicity studies}

EC from the three different cell lines were routinely trypsinized, washed in PBS and resuspended in PBS to $8 \times 10^{7} \mathrm{cel} / \mathrm{s} / \mathrm{ml}$. The three EC lines were individually injected in volumina of 80 and $160 \mu \mathrm{l}$ intra cutaneously in the ventral side of the body of syngeneic male Lewis rats. Tumor growth was examined every 3 days for 1 month. Between 2 and 3 weeks the tumors from some of the animals were collected and snap frozen in isopentane or fixed in 4\% PFA and routinely paraffin-embedded.

\section{Electron microscopy}

EC suspensions from confluent monolayers were pelleted by centrifugation, fixed in $2.5 \%$ glutaraldehyde in $0.1 \mathrm{M}$ phosphate buffer for $30 \mathrm{~min}$. Fixed cells were resuspended in warm $4 \%$ agarose in PBS and cooled on ice for 20 minutes. Coagulated agarose with $\mathrm{EC}$ was fixed in $2.5 \%$ glutaraldehyde in $0.1 \mathrm{M}$ phosphate buffer for 20 min, washed in $0.1 \mathrm{M}$ phosphate buffer, fixed with $1 \%$ OsO4 for 1 hour and embedded in Epon. Ultrathin electron microscopy sections were counterstained with uranyl acetate and lead citrate, and examined in a CM10 Philips electron microscope. 


\subsection{Results}

\subsubsection{Production of EC Lines}

We used an ex vivo perfusion model to isolate heart EC. In an initial set of experiments we noticed that retrograde collagenase perfusion with an increased flow/pressure gave a higher cell yield (probably as a result of increased damage of the vascular integrity and thus better access for collagenase to digest matrix structures). However, this also led to increased contamination with non-endothelial cells (fibroblastis) easily leading to overgrowth of EC by these cells. An essential step in the production of cell lines was the low seeding of the rather pure EC isolates, which allowed establishment of EC lines from the surviving clones in the primary cultures. We therefore chose for a low perfusion flow rate of $5 \mathrm{ml} / \mathrm{min}$, half of that previously used (26). A set of 13 isolation experiments was done to produce lines. Cell isollates were seeded and formed small foci of proliferating cells in 1 week. After 2-3 weeks in more than $50 \%$ of the experiments some of the foci had grown to distinct cell clones, whereas other foci were senescent. Clones mostly had endothelial (cobble-stoned) morphology and, because of the low numbers of clones per surface area, they expanded mostly as individual and separate clones. Contaminating spindle-shaped fibroblast-like cells were frequently present. If distinct fibroblast clones appeared in primary cuitures, they were removed using a cell scraper. EC clones were allowed to grow further for another 1-2 weeks and then the primary cultures were passaged for expansion. During the first passages, uptake of Dil-ac-LDL was measured to identify the EC nature of growing clones (Fig. $1 \mathrm{~A} \& \mathrm{~B}$ ). When fibroblast contamination remained after passaging, these cells were seen to grow adjacent to EC clones, but mostly remained separated from EC clones. During trypsinization fibroblasts detached differently from EC clones (in general more quickly), and thus could be separated from EC by a wash step. Five out of the thirteen isolation experiments led to development of lines. Three out of these five lines met the defined EC criteria by being positive in DiI-ac-LDL uptake, and by expressing endothelial cell-specific antigen RECA-1 and VWF, as shown by immunostaining of the cells on cytocentrifuge preparations (Fig, 1C\&D). 
Two other lines did not show distinct RECA-1 expression and were excluded. The 3 selected lines were designated RHEC-3, RHEC-10, and RHEC-11. RHEC-3 was cultured for more than 100 passages, and RHEC-10 and -11 for more than 30 passages. The RHEC lines were free of mycoplasm and when studied ultra structurally, particularly to check for presence of virus, no cellular abnormalities or indications for the presence of virus were observed.
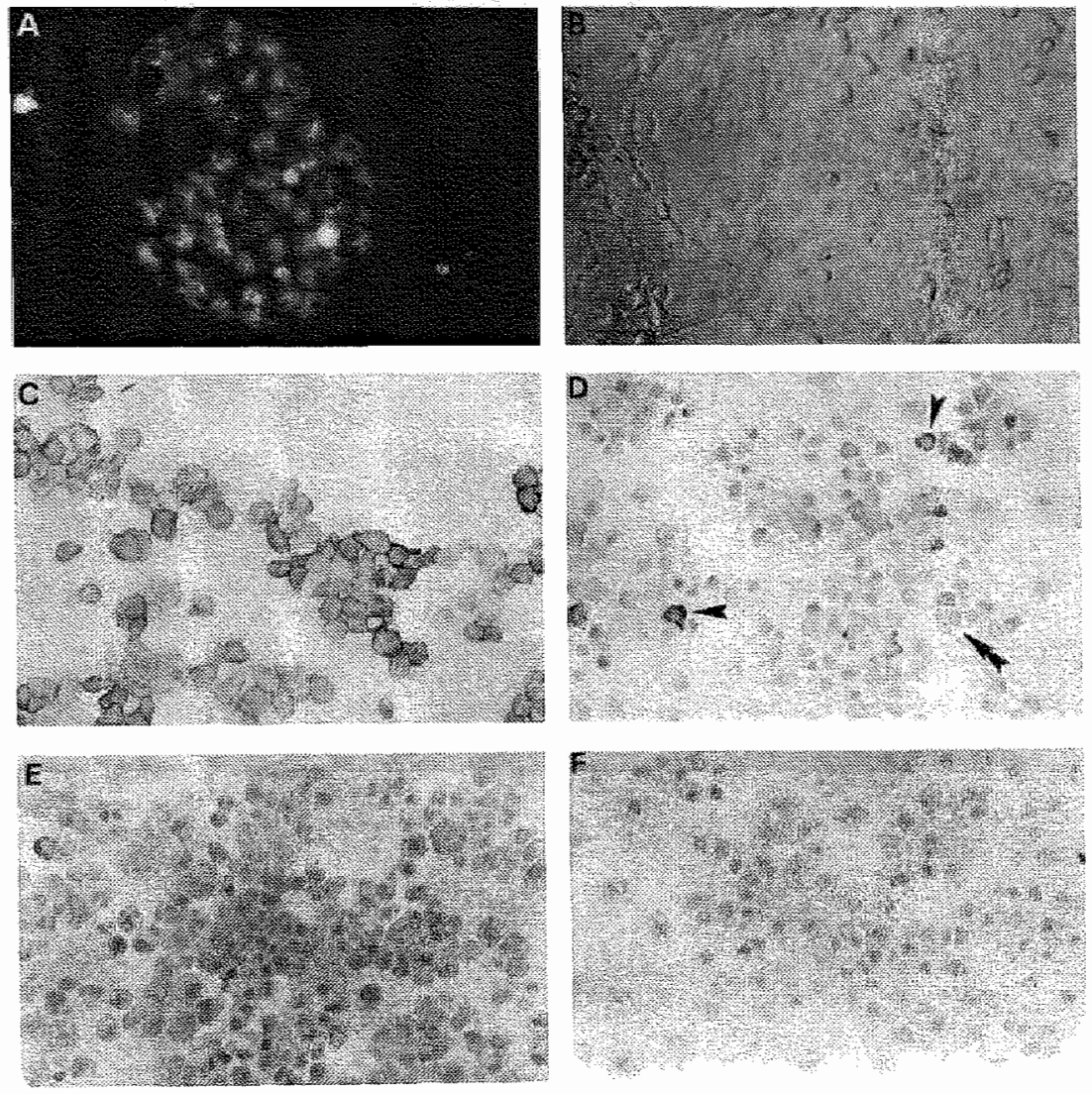

Figure 1: $A$ and $B$ show a primary culture of isolated rat heart EC. A) Clone of EC marked by uptake of Dil-acetylated LDL. Note the granular cytoplasmic staining pattern. B) Phase contrast microscopy showing the same EC clone surrounded by contaminating non-endothelial cells. $C$ and $D$ are cytocentrifuge preparations of PFA-fixed suspensions of RHEC lines stained by immunoperoxidase. C) RECA-1 staining of RHEC-3 showing all cells to express the antigen in variable intensity. D) Staining for WWF in RHEC-10. Only part of the cells in the RHEC lines express intracellutat WWF in a granullar staining pattern. Note the presence of strongly (single artow) and weakly (double arrow) positive cells. $E$ and $F$ are cytocentrifuge preparations of fresh suspensions of RHEC lines. Preparations were acetone-fixed and stained by immuno or lectimperoxidase. E) Staining of RHEC-11 with lectin GS-I-B4. All cells show diffuse staining. Fy Staining of RHEC-3 with mAb $9 B 9$ directed against ACE. All cells are stained in a fine spicular pattern. $x 625$. 


\subsubsection{Tumorigenicity of the RHEC Lines}

The mechanism of spontaneous immortalization of EC in primary cultures is unknown. To test whether the immortalized RHEC lines had tumorigenic potentials, as described for viral-transformed EC lines, the 3 lines were inoculated intracutaneously in syngeneic Lewis rats. Tumor dewelopment was checked by palpation every 3 days over a period of $\mathbb{1}$ month. All three RHEC lines developed distinct tumors in a dosedependent way at the site of inocculation. The size of the tumors varied per cell line, and reached a maximum of about $0.5-1 \mathrm{~cm}$ in diameter in approximately 3 weeks. The tumors subsequently developed signs of necrosis. Histologic examination of tumor tissues showed that all three RHEC lines developed vascular tumors that conld be classified as capillary to cavernous hemangiomas. In the hemangiomas clumps, or large lobular structures of poorly differentiated EC, sometimes with mitotic figures, were seen (Fig. 2 A\&B). Ab and lectin staining studies of frozen tumor material showed similar results for the 3 lines. The lobular tumor fields were diffusely positive for GS-IB4, whereas RECA-1 staining was seen in the tumor structures only in EC of intranodular blood vessels and along the peripheral cell layer lining blood sinuses and cavernosa (Fig. 2 B\&C). Expression of VWF was scarce or absent and, if seen, present in blood-lining EC. VCAM-1 and MHC class II were not expressed by EC in the hemangiomas, whereas ICAM-1 staining was occasionally observed locally in bloodlining endothelium. 

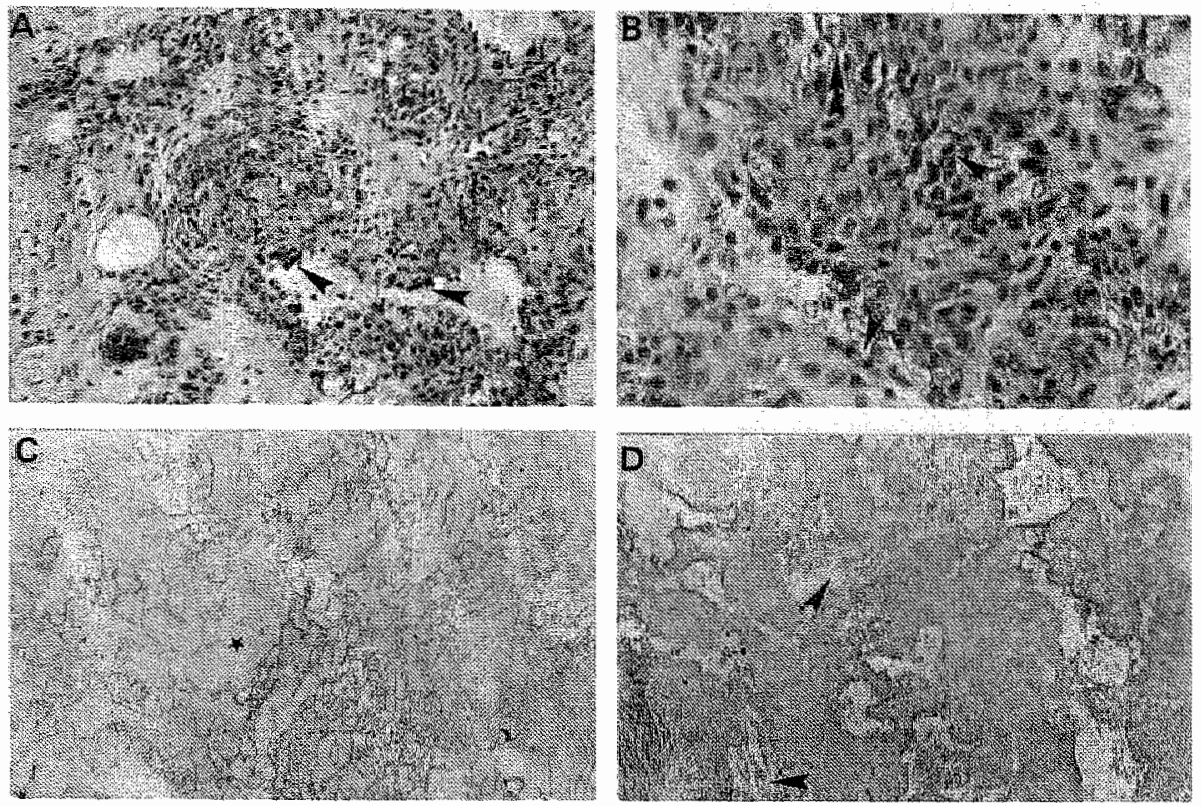

Figure 2: Haemangioma development of RHEC-3 at day 17 after intracutaneous innoculation. $A$ and $B$ are paraffin sections stained with $H \& E_{1} A$ ) In the subcutaneous tissue an endothelial cell tumor is seen with a lobular architecture. In and around the tumor cell fields small and large blood vessels are seen with a lining of plump EC along which adherent leukocytes can be seen (arrows). $\times 250$ B) In the dense tumor cell mass poorly differentiated $\mathrm{EC}$ with moderate cellular and nuclear polymorphism are observed. A few mitotic figures are seen (single arrows), and locally capillary formation is shown (double arrow) $x$ 625.C and $D$ are sections from frozen material, peroxidase-stained. C) RECA-1 staining, showing that in the haemangioma only the EC lining intranodal blood spaces and vessels are positive. EC in dense tumor frelds (asterisk) are negative. D) Lectin GS-I-B4 staining shows tumor cells are diffusely positive. Notice the absence of staining in non-endothelial vascular tissue (arrow). $x$ 250 . 
Chapter Two

\subsubsection{Phenotypic Characterization of the RHEC Lines}

Endothelial nature of the lines

\section{Phenotypic characterization of Rat-Heart-EC lines}

\begin{tabular}{lllll}
\hline Structure & $\begin{array}{l}\text { Cell } \\
\text { distribution }\end{array}$ & \multicolumn{3}{c}{ \% positive cells ${ }^{\mathbb{1}}( \pm$ S.E.) } \\
& RHEC-3 & RHEC-10 & RHEC-1 1 \\
\hline RECA-1 & Surface $^{2}$ & $>99$ & $>99$ & $>99$ \\
VWF & Intracellular & $14.7( \pm 7.6)$ & $8.1( \pm 6.5)$ & $12.9( \pm 7.7)$ \\
GS-I & N.D. & $>99$ & $>99$ & $>99$ \\
GS-I-B4 & N.D. & $>99$ & $>95$ & $>99$ \\
ACE 3 & N.D. & $>99$ & $>99$ & $>99$ \\
LCA & N.D. & $<1$ & $<1$ & $<1$ \\
ICAM-1 & Surface & $11.5( \pm 3.5)$ & $<1$ & $<1$ \\
VCAM-1 & N.A. & $<1$ & $<1$ & $<1$ \\
MHC-I & Surface & $>99$ & $>99$ & $>99$ \\
MHC-II & N.A. & $<1$ & $<1$ & $<1$ \\
\hline
\end{tabular}

\section{Table 1:}

1 Percentages of positive cells were measured in immunoperoxidase-stained cytocentrifuge preparations. Negative-controle staining, performind with second step only and with non-relewant isotype-matched mAb OX-8, was negative.

2 Cell surface expression was detected by irnmunofluorescence staining of viable EC monolayers.

${ }^{3}$ As tested with mAb $9 B 9$ against $A C E$.

N.A., not applicable; N.D., not done; RECA-1, Rat Endothelial Cell-specific Antigen; LCA, leukocyte-common-antigen; ICAM-I. Intracellular Adhesion Molecule-1; VCAM-1, Vascular Cell Adliesion Molecule-1; MHC-I/IT, Major Histocompatibility Complex antigen-I/II; VWF, von Willebrand Factor.

The RHEC lines were screened for expression of various EC markers. In addition to the uptake of DiI-ac- $-\mathrm{LDL}$, lines were tested for staining with $\mathrm{Ab}$ to ECspecific RECA-1, VWF, ACE, and with lectin GS-I and specific isolectin GS-I-B4 (table 1). RECA-1 was expressed by all cells in the RHEC cultures (indicated as $>99 \%$ positive). Granular intracellular expression of WWF was seen in some of the cells (10$15 \%$ ) in the three lines. Expression of $\mathrm{ACE}$ was detected using $\mathrm{mAb}$ and polyclonal $\mathrm{Ab}$ 
against human $A C E$ that cross-reacted with rat $A C E$. Staining with mAB $9 B 9$ showed fine spicular positivity of all cells in the RHEC lines (Fig. IE). Polyclonal anti-ACE showed $>95 \%$ positive cells in the 3 lines, with staining intensity varying from spicular to intense diffuse. All cells in the RHEC lines were positive for binding lectin GS-I and isolectin GS-I-B4 (a marker for EC; fig. IF). Only in RHEC-10 the intensity of cells stained with GS-I-B4 varied, and a small percentage negative cells was observed. When RHEC cultures were stained with $\mathrm{mAb} O X-1$, directed to a rat leukocyte common antigen, <1\% positive cells was found, demonstrating the non-leukocyte nature of the lines.

\section{Expression of adhesion molecules and MHC antigens.}

In addition to phenotypic markers defining EC nature of the cell lines, RHEC lines were tested for expression of ICAM-1 and VCAM-1 as well as for MHC class I and class II antigens. These molecules, which are important structures in the interaction between EC and leukocytes, and in particular lymphocytes, can be expressed by EC in various inflammatory and immunological settings. To test cell-surface expression of these molecules, viable EC monolayers were stained by immunofluoresence using specific monoclonal $\mathrm{Ab}$ (table 1 and fig. 3). Under standard culture conditions the RHEC lines showed surface positivity for MHC class I, but MHC class II and VCAM1 were not expressed. ICAM-1 could be detected only on part of the cells in RHEC-3. The percentages of positive cells calculated from immunoperoxidase-stained cytocentrifuge preparations are presented in table I. It shows that ICAM-1 is expressed only by RHEC-3 in approximately $12 \%$ of the cells.

To test whether adhesion molecule and MHC class II antigen expression were

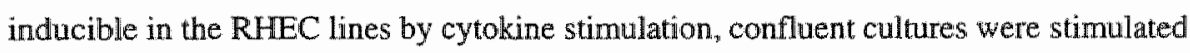
with either 400U/ml TNF $\alpha$ or $200 \mathrm{U} / \mathrm{ml}$ IFN $\mathrm{ICAM}$-1, VCAM-1, and MHC Class II expression were measured in cytocentrifuge preparations of cultures stimulated for 32 hr, a time point at which (as indicated by initial studies) the rather rapidly induced adhesion molecules as well as the more slowly induced MHC class II antigens could be 
detected. As shown in table 2, cytokine stimulation of RHEC-3 led to increased numbers of cells expressing ICAM-1, and it induced VCAM-1 and MHC class II in some of the cells. TNF $\alpha$ was most effective in adhesion molecule induction, whereas IFNy was more potent in MHC class II induction. RHEC-10 stimulation resulted only in a minor expression of MHC class $\Pi$. RHEC-11 showed a distinct induction of VCAM- 1 and MHC class 1 after stimulation. MHC class I was expressed by all cells in the lines in these experiments.

\section{Cytokine stimulation of RHEC lines}

\begin{tabular}{|c|c|c|c|c|}
\hline \multirow[t]{2}{*}{ Structure } & \multirow[t]{2}{*}{ Stimulation } & \multicolumn{3}{|c|}{ Expression at $32 \mathrm{hr}$} \\
\hline & & RHEC-3 & RHEC-10 & RHEC-11 \\
\hline \multirow[t]{3}{*}{$\mathrm{ICAM}-1$} & none & + & - & - \\
\hline & TNF $\alpha$ & $+t$ & - & - \\
\hline & IFNY & + & - & - \\
\hline \multirow[t]{3}{*}{ VCAM-1 } & none & - & - & - \\
\hline & TNFo & + & - & + \\
\hline & IFN $\gamma$ & \pm & - & + \\
\hline \multirow[t]{3}{*}{ MHC class II } & none & - & - & - \\
\hline & TNF $\alpha$ & \pm & - & - \\
\hline & $\mathbb{N} \mathbb{N} \gamma$ & + & \pm & + \\
\hline \multirow[t]{3}{*}{ MHC class I } & none & ++++ & $++t$ & ++++ \\
\hline & TNF $\alpha$ & $t+t$ & $t+t$ & +++ \\
\hline & IFNY & $+t+$ & +++ & $4+4$ \\
\hline
\end{tabular}

Table 2. Confluent monolayers of RHEC cultures were stimulated with eiber $400 \mathrm{U} / \mathrm{ml}$ TNFo or $200 \mathrm{U} / \mathrm{ml}$ IFNy for $32 \mathrm{hr}(\mathrm{n}=3)$. Expression was measured by immunostaining of cytocentrifuge preparations of paraforrialdehyde-fixed cells.

1 expression categories:,$-<1 \%$ positive cells:, $\pm 11-10 \% ;+, 10-30 \% ;++, 30-60 \% ;++, 60-99 \%$; 

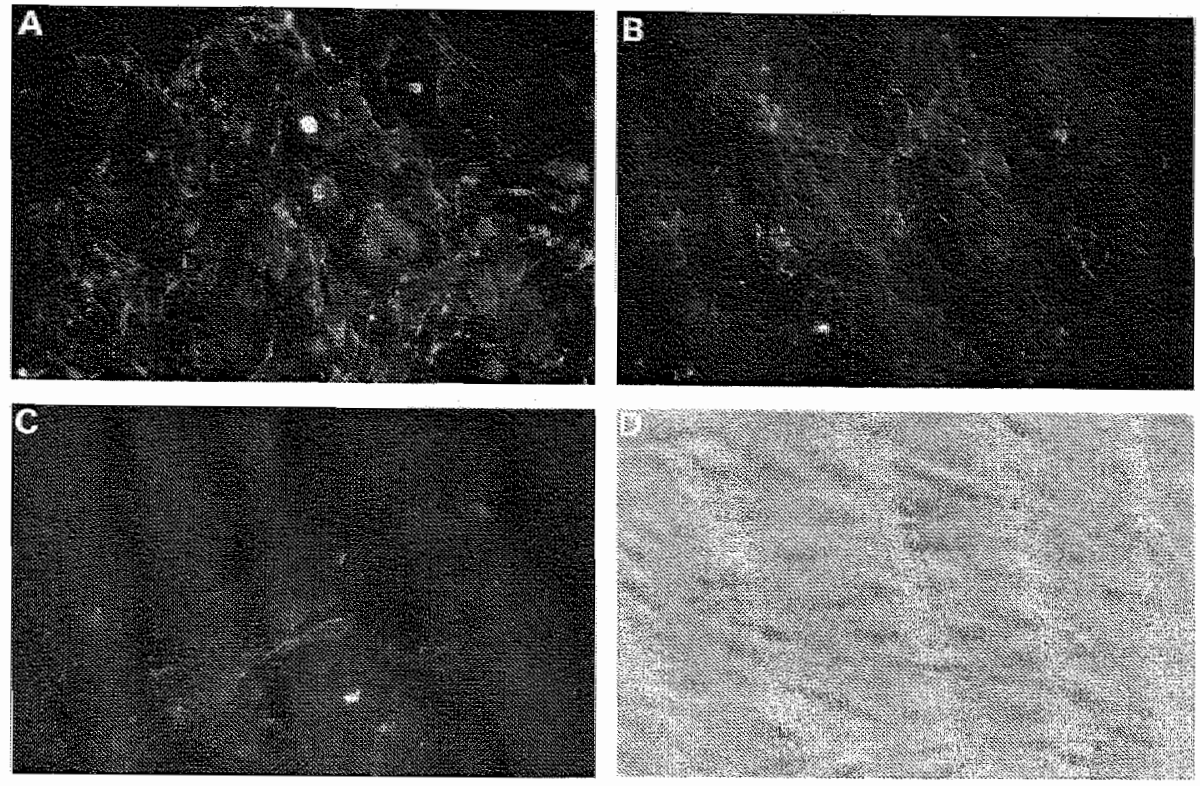

Figure 3: Monolayers of confluent viable RHEC lines stained by immunofluorescence. A) RHEC-11 stained with RECA-1. All cells show variable imtensity of cell-surface expression. B) Staining for MHC class I antigens on RHEC-10. All cells are positive in a staining pattern comparable to that of cells stained with RECA-1. C) ICAM-1 staining on RHEC-3. Only part of the cells express ICAM-1. D) Phase-contrast microscopy of a monolayer of RHEC-3 cells, $x 625$.

\section{ICAM-1 expression by RHEC-3 cells is not related to cell cycle stage.}

Although confluent RHEC monolayers were used for phenotypic studies, we noticed that some cells with mitotic figures were present, and thus that cell cycling occurred in confluent cell cultures. The fact that ICAM-1 expression under normal culture conditions was seen in only part of the RHEC-3 cells (Fig. 4A) led us to investigate whether expression was related to cell cycle stage. FACS analysis of RHEC-3 cells that had been DNA-labelled with propidium-iodid showed that the total cell population consisted of $\mathrm{G} 1, \mathrm{~S}$, and $\mathrm{G} 2$ cells. When RHEC-3 cells were doublestained for ICAM-1 and DNA, the gated population of ICAM-1 positive cells showed a cell cycle profile comparable with that of the total population (Fig. 4B) Apparently, ICAM-1 expression in RHEC-3 cells is not related to a particular cell cycle stage of the cells. 

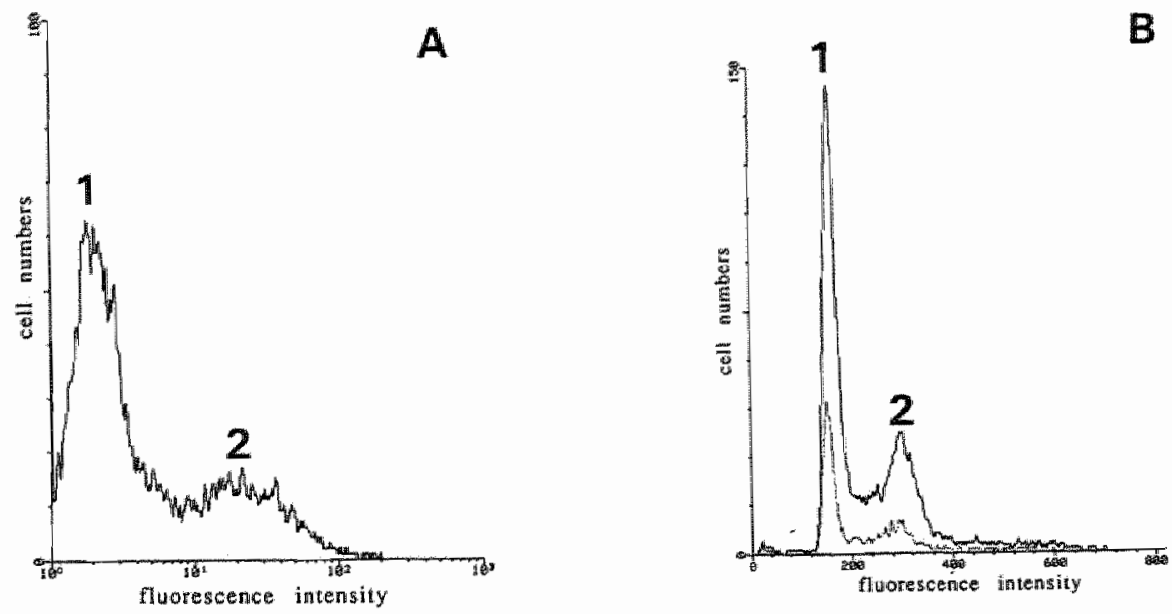

Figure 4: Flow-cytometry analysis of RHEC-3 cells. A) ICAM-1 immunofluorescence analysis showing that RHEC-3 consists predominantly of ICAM-1 negative cells (peak 1) and a small population of ICAM-1 positive cells (peak 2). B) The DNA profile of the total RHEC-3 population (upper black curve) and of the ICAM-1 positive RHEC-3 population (lower grey curve) was measured. The peaks 1 represent cells in the $G_{1}$ phase, the peaks 2 cells in the $G_{2}$ and $M$ phases. Cells between peak 1 and 2 are in the $S$ phase. As noticed, comparable DNA profiles are found for the total and for the ICAM-1 positive population. This indicates that ICAM-1 expression is random over the RHEC-3 cells in the warious cell cycle stages.

Phenotype of RHEC lines in comparison to heart vascular EC in situ.

To relate the phenotypic profiles of the RHEC lines to that of vascular EC in heart tissue, we did staining on normal heart-tissue sections for ICAM-1, VCAM-1, MHC class I and II molecules, and VWF. RECA-1 and lectin GS-I-B4 staining were used as a reference pattern identifying all vascular endothelium (Fig. 5A). MHC class I staining showed a similar pattern as that found for RECA-1 and GS-I-B4, indicating distinct endothelial MHC-I expression in the entire blood vasculature. MHC class-II molecules were not detected on vascular EC in normal heart. Class II positivity was noticed on a population of scattered cells of non-endothelial origin, most likely macrophages or dendritic cells (Fig. 5B). ICAM-1 was expressed by endothelium of 
some, predominantly small blood vessels in heart sections (Fig. 5C), whereas VCAM-1 was only occasionally seen on some EC of large vessels. Endothelium of all arteriolar and large venular vessels showed granular expression of vWF. This in contrast to the myocardial small vessels, only some of which showed WWF expression in section staining as described previously (27)(Fig. 5D). The data show that the phenotypic profiles of the three RHEC lines resemble the heterogenous heart endothelium in situ, and particularly the microvascular myocardial endothelium.
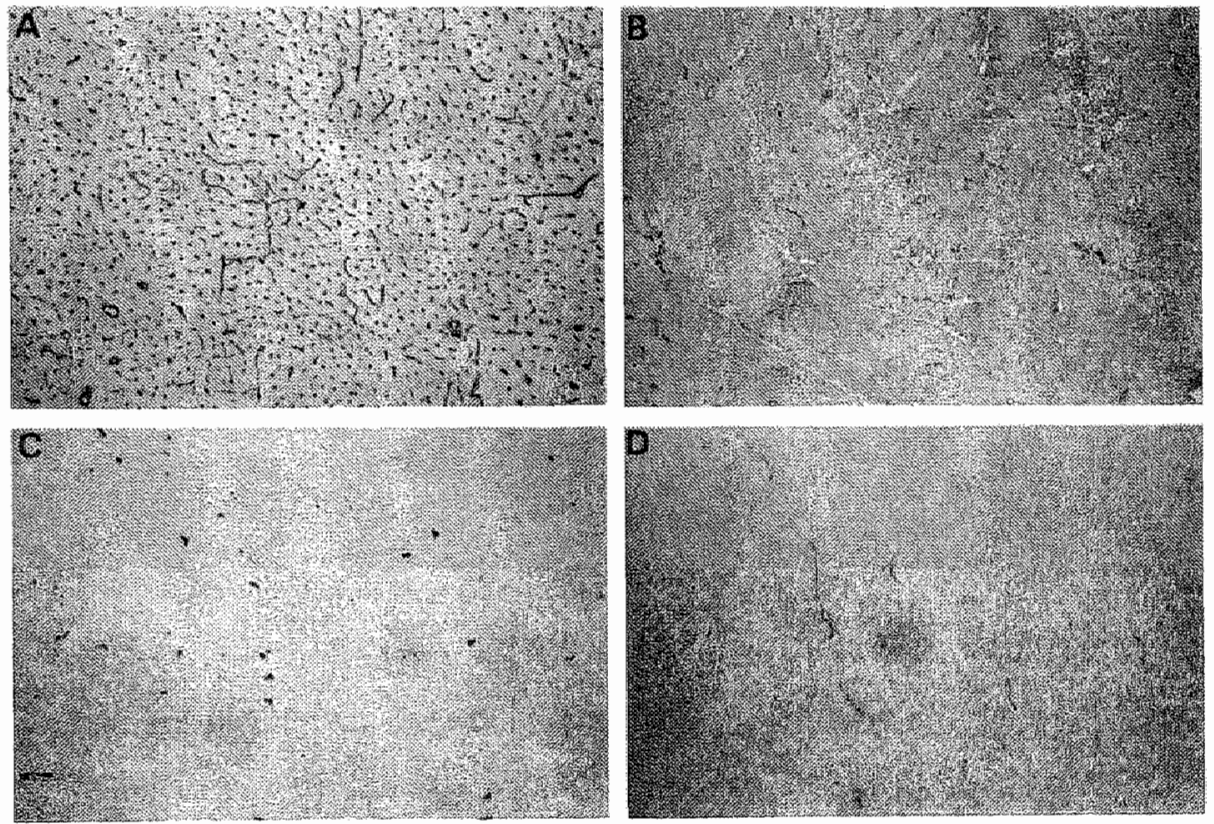

Figure 5: Immunoperoxidase staining on heart tissue-sections. A) RECA-1 staining marks all endothelium including that of the of the myocardial microwasculature as shown here. B) Staining for WWE indicates that (in comparison with RECA-1 staining) omly part of the microvascular EC express WWF. C) Staining for MHC class II antigens reveals that class II molecules are absent on heart endothelium. Notice class If staining of a population of scattered noti-ndothelial cells (most likely macrophages or dendritic cells). D) ICAM-1 staining shows that only a few of the myocardial blood vessels have ICAM-1 positiwe $\mathrm{EC}, \times 250$. 


\subsubsection{Functional Characterization of the RHEC Lines}

To address functional capacities of RHEC-3,10, and 11 , the lines were studied for production of a selected set of endothelial products, and for response to activating agents relevant to processes such as hemostasis, inflammation and vascular tone .

\section{Production of $t$-PA and VWF.}

Monolayers of RHEC lines were tested for production of t-PA and WWF in culture supernatants at $4,8,16$, and $32 \mathrm{hrs}$. Although all three the RHEC lines had gramular vWF storage, as shown by immunostaining, no vWF could be detected in the cell supernatants under normal culturing conditions. The RHEC lines constitutively produced distinct levels of t-PA (Table 3 ). To test whether activation could increase WWF and T-PA production, the RHEC lines were stimulated with $3 \mu \mathrm{M}$ histamine and $30 \mu \mathrm{g} / \mathrm{ml}$ PMA. Only PMA stimulation gave a minor production of vWF $(0.2-0.4$ U/mi) by RHEC-3 and RHEC-11 but not RHEC-10 over 32 hrs (data not shown). PMA also significantly increased t-PA production in all three RHEC lines, whereas histamine stimulation had no measurable effect on t-PA production (Table 3).

\section{PG andTX production.}

RHEC lines were tested for production of eicosanoids of the cyclooxygenase pathway, such as prostacyclin $\left(\mathrm{PGI}_{2}\right), \mathrm{PG} \mathrm{F}_{2}, \mathrm{PG} \mathrm{E}_{2}$, and $\mathrm{TX} \mathrm{A}_{2}$. In a previous set of dosemesponse experiments the production of eicosanoids by primary rat heart EC cultures upon stimulation with AA and calcium ionophore A23187 were measured (38). Already with low micromolar concentrations of AA ar increase in eicosanoid production was measured, reaching a maximum between $40-80 \mu \mathrm{M}$. A combination of A.A with A23187 in general gave similar but earlier production levels. Based on these results we tested the RHEC lines for production of prostanoids. To ensure maximal production, confluent EC cultures were stimulated for 30 min with $80 \mu \mathrm{M} \mathrm{AA}$, followed by analysis of PG and TX production in culture supernatants. As shown in Table 4, RHEC lines produced only low amounts of $\mathrm{PGF}_{2 \mathrm{a}}$ and $\mathrm{TX} \mathrm{A}_{2}$ under standard 
culture conditions, whereas incubation with $\mathrm{AA}$ induced $\mathrm{PGE}_{2}$ production and significantly increased $\mathrm{PGF}_{2 \mathrm{a}}$ and $\mathrm{TXA}_{2}$ production. Production of $\mathrm{PGI}_{2}$ could not be demonstrated. Incubation with AA in combination with calcium ionophore A23187 raised production levels of some of the eicosanoids, but no production of $\mathrm{PGI}_{2}$ by the RHEC lines was observed. 


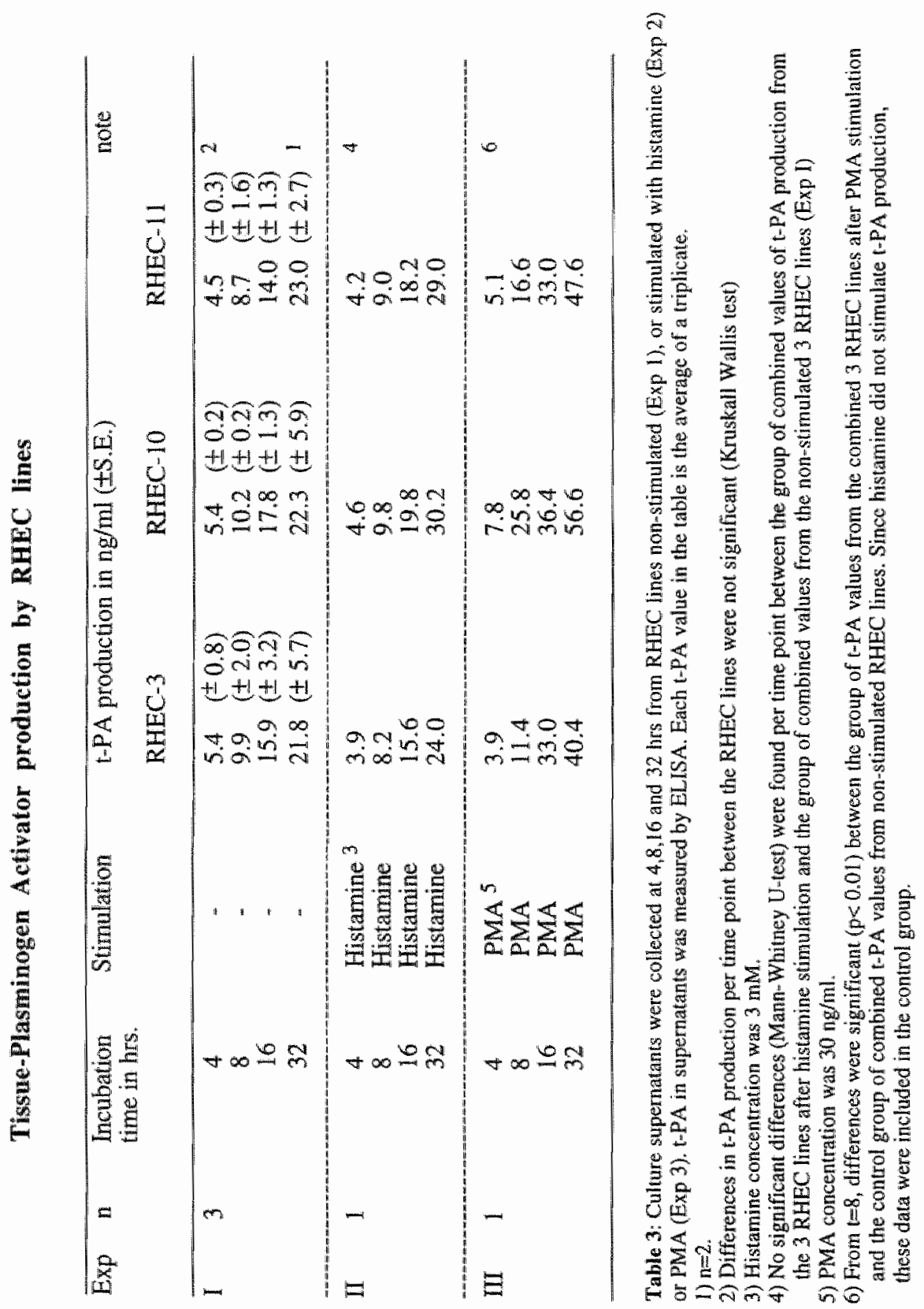




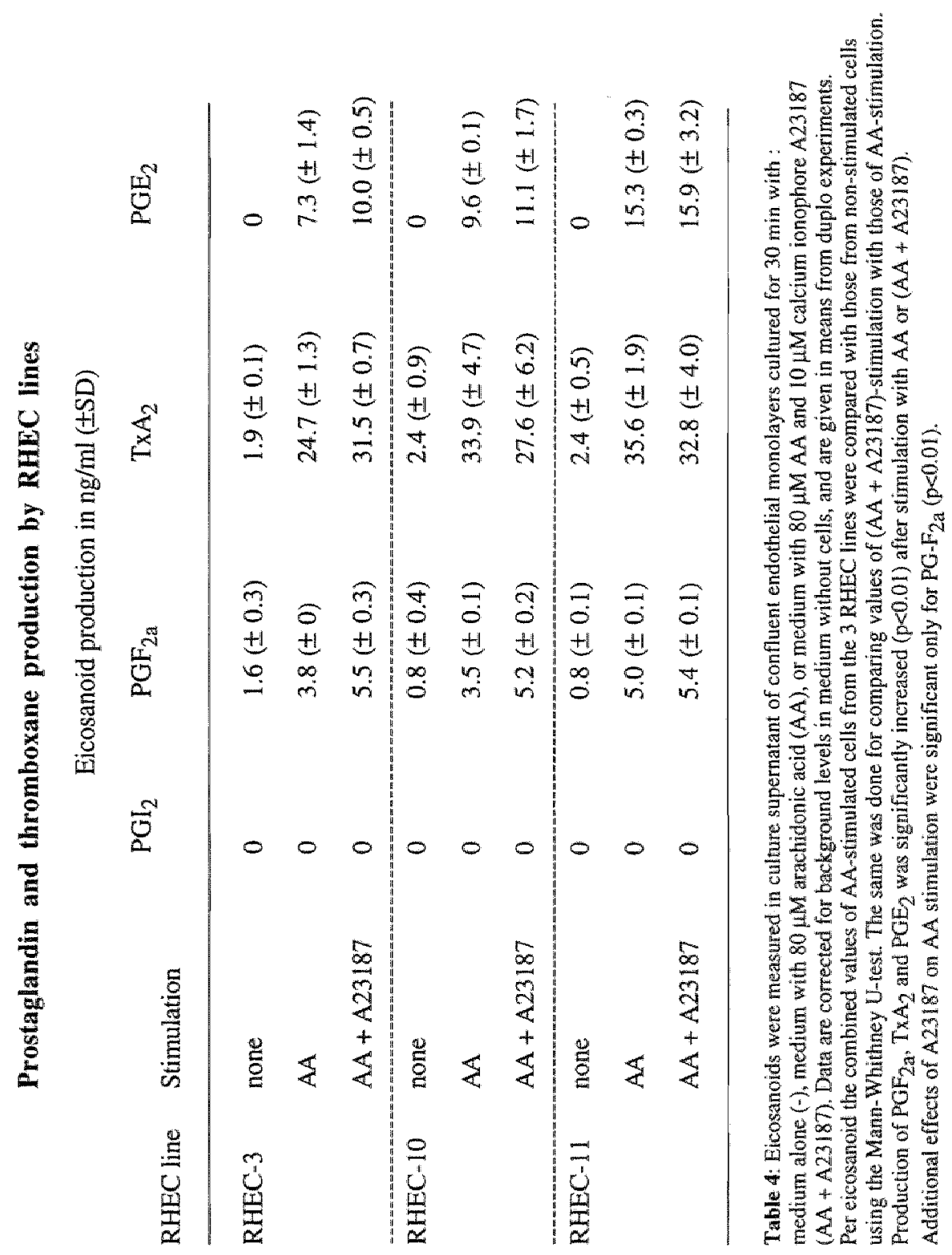




\section{ETproduction}

To test whether RHEC lines produced the endothelial vasoconstricting agent ET, supernatants of confluent cultures were collected at 4,8 , and $16 \mathrm{hr}$ and measured for ET quantities using a radioimmuno-assay. As shown in Table 5, the three RHEC lines constitutively produced small levels of ET. Over the time period of 16 hours, RHEC-3 was the highest producer of ET.

\section{Endothelin production by RHEC lines}

\begin{tabular}{|c|c|c|c|}
\hline \multirow[t]{2}{*}{ RHEC line } & \multicolumn{2}{|c|}{$\begin{array}{l}\text { Endothelin in } \mathrm{pg} / \mathrm{ml} \\
\text { culture supernatant }\end{array}$} & \multirow[b]{2}{*}{$\mathrm{t}=16 \mathrm{hr}$} \\
\hline & $\mathrm{t}=4 \mathrm{hr}$ & $t=8 \mathrm{hr}$ & \\
\hline $\mathrm{RHEC}-3$ & 6.4 & 3.8 & 21.9 \\
\hline RHEC-10 & 4.9 & 5.4 & 14.8 \\
\hline RHEC-11 & 4.4 & 5.4 & $\mathbb{1 1 . 9}$ \\
\hline
\end{tabular}

Table 5: Endothelin was measured by radio immuncassay in culture supermatant of RHEC lines in single experiments. Values were corrected for background levels in fresh culture medium $(<0.1 \mathrm{pg} / \mathrm{m})$ ).

\section{Activation of RHEC lines by endothelial cell-stimulating agents}

The RHEC lines were studied for responsiveness to agents with endothelial cell stimulating potentials. Therefore EC cultures were stimulated with thrombin, histamine, bradykinin, and ATP at physiological and higher concentrations, followed by fluorometric measurement of cellular mobilization of calcium ([Ca+ $\left.{ }^{++}\right]$in $\left.\mathrm{nM}\right)$. The 3 RHEC lines showed a dose-dependent response to stimulation with histamine in concentrations of 3-100 $\mu \mathrm{M}$. The lines also responded to stimulation with ATP concentrations of 10 and $100 \mu \mathrm{M}$, but no response was observed to thrombin and bradykin, even not to rather high concentrations of $10 \mathrm{nM}$ and $20 \mu \mathrm{M}$ respectively. In table 6 an experiment is presented jllustrating the dose-response effects of histamine and 
ATP stimulation for the three RHEC lines. Apparently the RHEC lines express functional receptors for histamine and ATP, but not for thrombin and bradykinin.

Calcium mobilization in RHEC lines by activating agents

\begin{tabular}{lccc}
\hline $\begin{array}{l}\text { Activating } \\
\text { agent }\end{array}$ & \multicolumn{3}{c}{$[\mathrm{Ca}++] \mathrm{i}(\mathrm{nM})$} \\
& RHEC-3 & RHEC-10 & RHEC-11 \\
\hline $\begin{array}{l}\text { Thrombin } \\
5 \mathrm{nM}\end{array}$ & 0 & 0 & 0 \\
$10 \mathrm{nM}$ & 0 & 0 & 0 \\
& & & \\
Histamine & 125 & 39 & 139 \\
$3 \mu \mathrm{M}$ & 424 & 288 & 367 \\
$50 \mu \mathrm{M}$ & 569 & 467 & 632 \\
$100 \mu \mathrm{M}$ & & & \\
Bradykinin & 0 & 0 & 0 \\
$2 \mu \mathrm{M}$ & 0 & 0 & 0 \\
$20 \mu \mathrm{M}$ & & & \\
ATP & 320 & 265 & 477 \\
$10 \mu \mathrm{M}$ & 474 & 492 & 553 \\
$100 \mu \mathrm{M}$ & & & \\
\hline
\end{tabular}

Table 6: Cellular $\mathrm{CA}^{++}$mobilization ([Cat+ $]$i) was measured in EC suspensions by fluorometry. Data are results from one experiment. 


\subsection{Discussilon}

We hawe produced and characterized three spontaneous endothelial cell lines from Lewis rat heart tissue. A modified isolation and culture technique was used to fawor EC line establishment. In previous studies (26) only few isolations led to EC cell line production (2 out of 60 ). In the experiments presented here a significant increase in the frequency of successful production of spontaneous EC lines was obtained, e.g. 3 out of 13 isolations $(23 \%)$ led to an established RHEC line. The high EC purity of isolated cells in combination with the low seeding in tissue culture plates appears an essential improvement for development of spontaneous EC lines. Apparently, it allows the few spontaneously immortalized EC in senescent primary cultures to expand and give rice to a permanent cell line.

The molecular mechanisms of spontaneous immortalization of $\mathrm{EC}$ are, are currently unknown. There is evidence that immortalization may result from genetic mutations with karyotypic alterations, such as chromosomal trisomy (26)(39). No ultrastructural evidence was found proving that EC immortalization was induced by virus infection. The fact that all three RHEC lines were tumorigenic and developed hemangiomas on in vivo injection, as do EC lines induced by viral transfection (40), may indicate that both mechanisms of immortalization have comparable cellular effects.

All EC in the RHEC lines expressed RECA-1, ACE, bound lectin GS-1-B4, and they were positive for Dil-ac-LDL uptake, demonstrating their EC nature. The facts that 1) within the lines only a small part of the cells showed vWF staining, and 2) that variable numbers of cells expressed adhesion molecules and MHC class II antigens after cytokine stimulation indicate the heterogeneity of the heart EC. It is not clear yet whether heterogeneity is a result of the presence of distinct $E C$ sub-populations or of intrinsic differentiation in an EC culture during growth to confluency. Long-term culturing of RHEC-3 for more than 100 passages, which allows growth competition between different populations, and thus selects for a particular subpopulation, did not alter percentages of cells expressing vWF. This suggests that heterogeneity within a line is the result of intrinsic differentiation within a RHEC culture. Heterogeneity, at least 
for ICAM-1 expression in RHEC-3, is not explained by a difference in cell cycle stage of EC within a culture, because FACS analysis of the subpopulation of RHEC-3 cells expressing ICAM-1 showed a cell cycle profile that was similar to that of the whole population. With respect to the phenotypic profiles found for the 3 RHEC lines, it is important that a close resemblance with heart endothelium in situ was noticed. All endothelia were RECA-1 and MHC-I positive, but MHC-II negative, and bound GS-IB4. The VWF was expressed by all large vessel endothelia but only by part of the myocardial microvascular endothelia. In previous studies (41) we described the absence or scarce presence of VWF in microvascular vessels of various rat organs including heart. For vWF, data from in witro studies show that indeed microvascular EC have, in contrast to macrovascular EC, scant or absent vWF granules (42). VCAM-1 expression is barely seen and ICAM-1 only by some microvascular and sometimes also macrovascular endothelium in the rat heart in situ. In this respect RHEC-3 is an interesting line because it is the only one that showed constitutive ICAM-1 expression by part of the cells. Another study demonstrated that in rat cerebro-microvascular EC lines, only a subpopulation of cells (about $30 \%$ ) constitutively expressed ICAM-1 (43). The RHEC lines responded to cytokine stimulation with rather different effects on induction of ICAM-1, VCAM-1, and MHC class II. In contrast to RHEC-3, which showed induction of ICAM-1, VCAM-1, and MHC class II, RHEC-10 was rather insensitive to cytokine stimulation ( i.e, only minor expression of MHC class II was observed). RHEC-11 expressed VCAM-1 and MHC class II on cytokine stimulation. Our phenotypic data suggest that the three RHEC lines form a set of $\mathbb{E C}$ lines representative for the heterogeneity of heart endothelium in wivo, and in particular for microvascular theart endothelium. We cannot exclude the possibility of an endocardial origin of EC in the RHEC lines, however, this is unlikely, becausethe initial heart perfusion route to isolate heart EC does not directly include endocardial endothelium.

The data on calcium mobilization by the RHEC lines upon stimulation show that the lines are functional in responsiveness to histamine and ATP, although for histamine a rather low effect was measured at the lowest (physiologic) concentration of $3 \mu \mathrm{M}$. As 
such, the observed $\mathrm{Ca}+$ mobilization demonstrates mainterance of histamine and ATP receptors by the lines, and suggests that effector mechanisms through these receptors are operable. The absence of response to thrombin and bradykinin suggests the absence of receptors. It is unlikely that detachment of EC cultures with EDTA, to obtain cell suspensions for measurements, is the cause of thrombin or bradykinin receptor loss. After similar de-attachment of HUVEC cultures, the EC suspensions still were responsive to stimulation (data not shown). Thus, most likely specific receptor loss resulted from long-term culturing and passaging of the lines. All the RHEC lines constitutively produced ET, albeit in low quantities compared with macrovascular HUVEC which produce about 10 times more ET in vitro (44). Studies comparing endothelin production between macrovascular and microvascular bovine EC showed a 10 to 30 times higher ET production by macrovascular cells $(45,46)$. The low level ET found for the RHEC lines thus supports their microvascular nature. Also, the high t-PA quantities produced by the RHEC lines indicate a microvascular nature of the cells. High t-PA, production is a property ascribed to microvascular $\mathbb{E C}(7,47)$. Macrovascular EC, such as HUVEC, produce much lower quantities of t-PA (7). Whereas for HUVEC, both histamine and PMA have been described to increased t-PA production $(24,48)$, the RHEC lines did not respond to $3 \mu \mathrm{M}$ histamine stimulation. Apparently this is not a result of the absence of histamine receptors, because histamine stimulation was shown to lead to Cat+ mobilization in all RHEC lines. Most likely as indicated by the low effect in the $\mathrm{Ca}^{++}$mobilization studies, the $3 \mu \mathrm{M}$ histamine concentration used in I-PA studies was not sufficient. However, PMA stimulation significanty increased in t-PA production in the RHEC lines, demonstrating a functional cellular regulation mechanism for $t-P A$. The lines did not secrete vWF under standard culture conditions, and PMA stimulation induced only low vWF production in RHEC-3 and 11. In this respect RHEC lines differ from primary HUVEC cultures which do respond to PMA stimulation with significant production of VWF (5). Whether the minor or absent production of WWF by the RHEC lines is physiologic a result of in vitro long-term culturing remains unknown. Studies with hybrid EC lines indicate that 
VWF production by EC lines can be easily lost during long-term culturing (49). Eicosanoids of the cyclooxygenase pathway were produced by all RHEC lines in similar profiles. Under standard culture conditions they produced only low amounts of $T_{X A_{2}}$ and $\mathrm{PGF}_{2} \alpha$, but no $\mathrm{PGE}_{2}$ and $\mathrm{PGI}_{2}$. Stimulation of the lines with $\mathrm{AA}$ or a combination of $\mathrm{AA}$ and $\mathrm{A} 23187$ significantly increased $\mathrm{TXA}_{2}$ and $\mathrm{PGF}$, and induced $\mathrm{PGE}_{2}$ production, as also observed with freshly isolated heart EC cultures (38), but $\mathrm{PGI}_{2}$ production could not be measured. Other investigators (38) showed that primary EC cultures from rat heart produced $\mathrm{PGI}_{2}$ upon incubation with arachidonic acid, but in relatively' low amounts compared with $\mathrm{TXA}_{2}$. Apparently the RHEC lines, because of immortalization or long-term culture conditions, lost the capacity to produce $\mathrm{PGI}_{2}$. In fact, the high $\mathrm{TXA}_{2}$ and low $\mathrm{PGI}_{2}$ production by primary cultures of heart $\mathrm{EC}$ after stimulation, as described by Linssen et al. (38), contrasts to data obtained with HUVEC, which on stimulation easily produce high amounts of $\mathrm{PGI}_{2}$ but no or low amounts of $\mathrm{TXA}_{2}(50)$. Whether these differences are related to organ specificity, micro or macrovascular origin of the cells, or culturing conditions is unknown and remains to be elucidated.

In conclusion, the applied isolation and culturing technique has been shown to be successful in the production of spontaneously immortalized EC lines from rat heart. The produced lines RHEC-3,10, and 11 share a series of phenotypic and functional EC characteristics; however, each line also has a unique characterization profile. As such, the lines may be considered representative of endothelial heterogeneity as observed in heart endothelium in situ. In general, the RHEC lines offer a series of unique tools for in vitro studies of various heart endothelial cell functions and mechanisms relevant to processes in inflammation, hemostasis, and immunology. 
Acknowledgments: The authors thank $A$. Gijsen for technical assistance, $P$. Lemmens for prostaglandin analysis, C. M van den Hoogen for $t-P A$ and $v W F$ analysis, H. van Rie for electron microscopy assistance, and P. Schiffers for endothelin measurements. We thank Dr. T. Tiebosch for pathological assistance in the tumorigenicity studies, Dr. J. G. M. C. Damoiseaux for assistance in FACS studies, Di. P. Frederik for electron microscopy expertise, $H$ van Rie for assistance in electron microscopical studies. Drs. J. Heemskerk and $\mathbb{R}$. van Gorp for assistance in calcium mobilization studies, Dr M. Miyasaka for donation of 1 A29, and Drs R. Lobb and P. Chisholm for donation of 5F 10.

\subsection{References}

1. Majno G, Palade GE. The effect of histamine and serotonin on vascular permeability; an electron microscopic study. Journal of Biophys Biochem 1961; 11: 571 .

2. Yanagisawa M, Kurihara H, Kimsura S, et al. A novel potent vasoconstrictor peptide produced by vascular endothelial cells. Nature $1988 ; 332: 411$.

3. Rees DD, Palmer RMJ, Moncada s. Role of endothelium-derived nitric oxide in the regulation of blood pressure. Proc Natl Acad Sci USA 1989: 86: 3375.

4. Auerbach $R$, Alby L, Grieves $J$, et al. Monoclonal antibody agaimst angiotensin-converting enzyme: its use as a marker for murine, bovine and human endothelial cells. Proc Natl Acad Sci USA 1982; 79: 7891.

5. Reinders JH, Groot de PG, Sixma JJ, Mourik van JA. Storage and secretion of von Willebrand factor by endothelial cells. Haemostatsis $1988 ; 18: 246$.

6. Lindhout $T$, Blezer R, Schoen P, Nordfang O, Reutelingsperger $C$, Hemker HC. Activation of factor $X$ and is regulation by tissue factor pathway inhibitor in small-diameter capillaries lined with human endothelial cells. Blood 1992; 79: 2909.

7. Hinsberg van VWM, Kooistra $T$, Emeis JJ, Koolwijk P. Regulation of plasminogen activator production by endothelial cells: role in fybrinolysis and local proteolysis. International Journal Radiation Biology 1991; 60: 246.

8. Whorton AR, Young SI, Data JL, et al Mechanism of bradykinin-stimulated prostacyclin synthesis in porcine aortic endothelial cells. Biochim Biophys Acta 1982; 721: 79.

9. Duijwestijn AM. Hamann A. Mechanisms and regulation of lymfocyte migration. Immunology Today 1989; 10:23.

10. Butcher EC. Cellular and molecular mechanisms that direct leukocyte traffic. American Journal of Pathology 1990; 136:1.

11. Cotran RS Pober IS. Effects of eytokines on vascular endothe lium: their role in immune injury. Kidney International $1989 ; 35: 969$.

12. Zimmerman GA, Prescott SM, Mc Intyre TM. Leukocyte-endothelial cell interactions. Immunology Today 1992; 13:

13. Roska AK, Geppert TD. Lipsky PE. Immunoregulation by vascular endothelial cells. Immunobiol 1984; 168: 470 .

14. Savage CO, hughes $\mathrm{CW}$, McIntyre BW, Picard JK, Pober JS, human CD4+T cells proliferate to HLA-DR+ allogeneic vascular endothelium. Transplantation 1993; 56:128.

15. Hughes CCW, Savage COS, Pober IS. The endothelial cells as a regulator of T-cell function. Immunol Rev 1990; 117: 85 .

16. Camussi $G$, Bussolino $F$, Salvidio $G$, Baglioni $C$. Tumor necrosis factor/cachetin stimulates peritoneal macrophages, polymorphonuclear neutrophils; and wascular endothelial cells to synthesize and release platelet-activating factor. Journal of Experimental Medicine 1987; 166: 1390.

17. Hebert CA, Luscinsikas FW, Kiely JM, et al. Endothelial and leukocyte forms of IL-8. Journal of Imanunology $1990 ; 145$ : 
18. Miossec $\mathrm{P}$, Cavender $\mathrm{D}$, ziff $\mathrm{M}$. Production of interleukin- 1 by human endothelial cells. Tournal of Immunology 1986; 136: 2486 .

19. O'Connel KA, Edidin M. A mouse lymphoid endothelial cell line immortalized by simian virus 40 binds lymphocytes and retains functional characteristics of normal endothelial cells. Journal of Immunogy 1990; 144: 521 .

20. Harder $\mathbb{R}$, Uhlig $H$, Kashan A, et al. Dissection of murine lumfocyte-endothelial cell interaction mechanisms by SV-40-transformed mouse endothelial cell lines: novel mecharisms mediating basal binding, and $\alpha 4$-integrin-dependent cytokine-induced adhesion. Exp Cell Res $1991 ; 197$ 259.

21. Tatsuta $T$, Naiot M, Oh-hara $T$, Sugawara $I$, Tsuruo T. Functional involvement of ICAM-1 in the adherence of resting versus activaied lymphocytes to high endothelial cells. Int Immunol 1992; 2: 165.

22. Laulajainen T. Julkunen I, Haltia A. Knutila S, Miettinen A, Holthofer H. Establishment and characterisation of a rat glomerular endothelial cell line. Lab Invest 1993; 69:183.

23. Ades EW, Hierholzer C, George V, Black J, Candal F. Viral susceptibility of an immortalized human microvascular endothellial cell line. Journal of Virological Methods 1992; 39: 83.

24. Fickling SA, Tooze JA, J. WGS. Characterization of human umbilical vein endothelial cell lines produced by transfection with early region of SV 40. Exp Cell Res 1992; 201:517.

25. Juillerat-Jeanneret L, Aguzzi A, Wiestler D, Darekar P, Janzer R-C. Dexamethasone selectively regulates the activity of enzymatic markers of cerebral endothelial cell lines. In Vitro Cell Dev Biol 1992; 28A: 537.

26. Linssen MCJG, Nieuwenhoven van FA, Duijwestijn AM, Glatz JFC, Vusse van der GJ. Continuous endothelial cells from adult rat heart. In Vitro cell Dev Biol 1993; 29:a: 611.

27. Dujjvestijn $A M$, Goor van $H_{n}$ Klatter $F$, Majoor $G D$, Bussel van $E$, Breda Vriesman van PJC. Antibodies defining rat endothelial cells: RECA-1 a pan endothelial specific monoclonal antibody. Laboratory Investigation 1992; 62: 459.

28. Maciag $T_{n}$ Cerendulo J, Isley $S$, Kellu PR, Forand R. An endothelial growth factor from bowine hypothalamus: identification and partial characterization. Proc Natl Acad Sci USA 1979; 76: 5674.

29. Tamatani T, Miyasaka M. Identification of monoclonal antibodies reactive with the raf homolog of ICAM- 1 and evidence for a differential involvement of ICAM- 1 in the adherence of resting versus activated lymphocytes to high endothelial cells. International Immunology $1990 ; 2: 165$.

30. May MJ, Entwistle G, Humphries MJ, Ager A. VCAM-1 is a CS-1 peptide-inhibitable adhesion molecule expressed by lymph node high endothelium. Journal of Cell Science 1993; 106: 109.

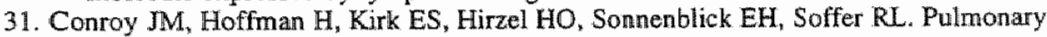
angiotensin-converting enzyme. Journal of Biol Chem 1976; 4828 .

32. Emeis JJ. Hoekzema R, Vos de A.F, Inhibiting interleukin-1 and tumour necrosis factor-a does not reduce the induction of plasminogen activator type-1 by endotoxin in rats in vivo. Blood 1995; 85: 115 .

33. Tranquillle N, Emeis IJ. The simultaneous acute release of tissue type plasminogen activator and von Willebrand factor in the perfused rat hindleg region. Thromb Haemostas 1990; 63: 454.

34. Engels W, Kamps M, Lemmens PJMR, Vusse vd G.J, Reneman RS. Determination of prostaglandins and thromboxane in whole blood by high performance liquid chromatography with fluorimetric detection. Journal of Chromatography 1988; 427: 209.

35. Haaster MCJ, Engels W, Lemmens PMMR, Hornstra Q, Vusse GJ van der, Heemskerk JWM, Differential release of histamine and postaglandin $\mathrm{D}_{2}$ in rat peritoneal mast cells: Roles of cytosolic calcium and protein tyrisine kinases. Biochin Biophys Acta 1995; 1265: 79.

36. Grynkiewicz $G$, Poenie M, Tsien RY. A new generation of Ca2t indicators with greatly improved fluorescence properties. Journal of Biol Chem $1985 ; 260: 3440$.

37. Schrey $G_{n}$ Es van PN, Schiffers. PMH, Leeuw de P. Renal arterial venous endothelin in hypertensive patients with or without renal artery stenosis. Blood Pressure 1994: 3: 370.

38. Linssen MCrG, Engels W, Lemmens. PJMR, et al. Production of arachidonic acid metabolites in adult rat cardiac myocytes, endothe lial cellis and fibroblast-like cellis. American Journal of Physiology 1993; 264: h973.

39. Cockerill GW, Meyer $G$, Noack L, vadas MA, Gamble JR. Characterization of a spontaneously transformed human endothelial cell lime. Laboratory Investigation 1994; 71: 497.

40. Garlanda $C$, Parravicini $C$, Sironi $M$, et al. Progressive growth in immunodeficient mice and host cell recruitment by mouse endothelial cells transformed by polyoma middle-sized $T$ antigen: implications for the pathogenesis of opputunistic vascular tumors. Proc Natl Acad Sci USA 1994: 91: 7291.

41. Duijvestijn A, Vlek L. Duistermaat L, Rie wan H, Breda Vriesman P. Chronic renal allograft rejection: the significance of non-MHC alloantigens. Transplantation International 1992; 5 suppl 1: $s 639$. 
42. Kem PA, Knedler A, Eckel RH. Isolation and culture of the microvascular endothelium from adopose tissue. Journal of Clinical lin westigation 1983; 71: 1822.

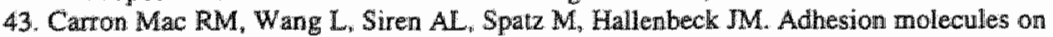
nomotensive and hypertensive rat brain endothelial cells. PSEBM 1994; 205 : 257.

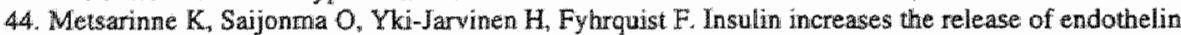
in endothelial cell cultures in vitro but not in vivo. Metabolism 1994; 7: 878 .

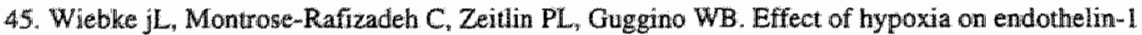
production by pulmonary wascular endothelial cells. Biochem Biophys Acta 1992; 1134: 105.

46. Glassberg MK, Nolop KB, Jackowski JT, W.M. A, Wanner A, Ryan US. Microvascular and macrovascular endothelial cells produce different constrictor substances. Journal of Appl Physiol 1992; 72: 1581 .

47. Levin EG, Del Zoppo GJ. Localization of tissue plasminogen activator in the endothelium of a limited number of vessels. American Journal of Pathology 1994; 144: 855 .

48. Hanss $M$, Collen $D$. Secretion of tissue-type plasminogen activator and plasminogen activator inhibitor by cultured human endothelial cells; modulation by thrombin, endotoxin and histamin. Journal of Lab Clin Med 1987; 109: 97.

49. Edgell C.J, Reisner HM, Graham JB. Endothelial cell hybrids and the supression of factor VII related antigen expression. Britisch Journal of Haematology 1980; 46: 613.

50. Vossen RCRM, Dam Mieras van MCE, Lemmens PJMR, Hornstra $G_{8}$ Zwaal RFA. Membrane fatty acids composition and endothelial cell functional properties. Biochem Biophys Acta 1991; 1083: 243 . 
Heart EC respond heterogeneously on cytokine stimulation in ICAM-1 and VCAM-1, but not in MHC expression A study with 3 rat heart endothelial cell (RHEC) lines

Josien G. Derhaag, Adrian M. Duijvestijn, and Peter J. C. van Breda Vriesman Department of Immunology, Cardiovascular Research Institute Maastricht, Maastricht University, P. O. box 616,6200 MD, Maastricht, The Netherlands

Published in Endothelium. 1997, vol. 5, p 307-319. 


\section{Abstract}

Cytokine-induced expression of ICAM-1, VCAM-1, and MHC class I and II was studied at different time points in microvascular endothelial cells (EC) of heart origin, using three different rat endothelial cell (RHEC) lines that were stimulated with TNF $\alpha$ and/or IFWy.

Each of the three RHEC lines responded to TNFa as well as to IFNץ; stimulation with combined cytokines led to increased or even synergistic effects. TNFa was most potent in inducing ICAM-1 and VCAM-1, whereas MHC class II was most effectively induced by IFN $\gamma$. The 3 RHEC lines responded similarly regarding induction of MHC class II and upregulation of constitutivily expressed MHC class I on the cells. However, the RHEC lines showed remarkable differences with respect to ICAM-1 and VCAM-1 induction, with each line having a unique expression profile. In RHEC-3, both ICAM-1 and VCAM-1 were well inducible, whereas in RHEC-10, no ICAM-1 and only some VCAM-1 could be induced. RHEC-11 showed minimal induction of ICAM-1, but strong induction of VCAM-1. For P-selectin induction, no such differences were found between the RHEC lines. These heterogeneous effects of cylokine stimulation could neither be explained by differences in mobilization of calcium nor by ultra-structural differences between the lines. Stimulation of the RHEC lines for ICAM-1 and VCAM-1 or MHC class II molecule induction resulted in expressing and non-expressing EC. Experiments with selected and subsequently cultured expressing and non-expressing cell populations for either ICAM-1, VCAM-1

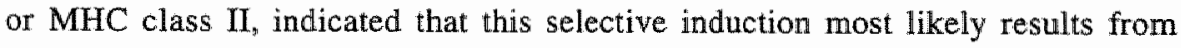
intrinsic regulation mechanisms in the cell cultures, and not from the presence of particular EC subpopulations within the lines.

We conclude that microvasculat heart endothelial cells, as represented by the 3 RHEC lines, demonstrate a selective heterogeneity in expression of ICAM-1 and VCAM-1, but not of MHC class I and I, upon cytokine stimulation. The consequences of this heterogeneity for leukocyte-endothelial cell interactions in heart inflammation and immune reactivity is discussed. 


\subsection{Introduction}

Vascular endothelial cells form the interphase between blood and tissue, and as such they play a major role in processes of arrest and extravasation of blood leukocytes in inflamed and immune reactive tissues. The interaction of leukocytes with endothelial cells is mediated through cell adhesion molecules expressed on both cell types. A series of relevant endothelial cell adhesion molecules has been described, such as P- and E-selectin, intercellular adhesion molecule 1 (ICAM-1) and vascular cell adhesion molecule 1 (VCAM-1). The endothelial $\mathbb{P}$ - and $\mathbb{E}$ - selectins are predominantly involved in the extravasation of neutrophils and monocytes through binding to a sialylated derivative of the Lewis $\mathrm{X}$ blood group determinants (Sle $\mathrm{X}$ ligands) on these cells $(1,2,3)$. ICAM-1 and VCAM-1 are both members of the immunoglobulin supergene family and play a major role in the adherence of lymphocytes and monocytes to endothellial cells $(4,5,6,7)$. The best known leukocyte ligands for ICAM-1 and VCAM-1 are the adhesion molecules LFA-1 (lymphocyte-function-associated-antigen 1) and VLA-4 (very-late-antigen 4) respectively, both members of the integrin family. By differential expression of the various adhesion molecules, vascular endothelial cells may regulate selective adhesion and extravasation of relewant leukacyte subsets in inflamed tissues $(8,9)$. In addition, in inflammatory processes with immune reactivity, vascular endothelial cells can be induced to de novo expression of MHC class II mollecules, and as such may function as antigen presenting cells in interaction with blood $T$ cells. In this process of antigen presentation by EC, adhesion molecules such as ICAM-1 and VCAM-1 are important for delivery of co-stimulatory signals $(10,11,12,13)$.

It has been shown that particular cytokines, such as TNFa, IL-1, and IFNy are potent stimulatory agents for induction and enhancement of adhesion and MHC molecules in endothelial cells $(8,14)$. In vitro studies, predominantly with human umbilical vein EC (HUVEC) cultures, have shown overlapping as well as more specific effects of stimulation with individual cytokines. For induction of the adhesion molecules E-selectin and VCAM-1, TNF $\alpha$ appears a potent cytokine $, 3,15$, 
$16,17,18)$, whereas for the induction of MHC class II molecules. IFN $\gamma$ plays a dominant role. With respect to induction or enhancement of ICAM-1, both cytokines have more or less similar induction capacities $(19,20)$. Interestingly, activation of EC by cytokines such as TNFor and IFNy occurs through different intracellular signalling pathways. Consequently, effects of EC stimulation with a combination of these cytokines may strongly differ from those of individual cytokine stimulation in expression levels of induced molecules and also in the kinetics of induction (14). It has been shown that not all EC respond similarly to cytokine stimulation and that differences such as species, strain, tissue, and blood vessel type are important in this respect $(21,22,23,24)$.

Our interest in inflammation and immune reactivity in heart diseases related to transplantation and autoimmunity, led us to emphasize the role of microvascular endothelium in these processes, using in vitro studies with rat EC cultures. Because endothelial cells express, as mentioned, tissue-specific characteristics, we wished to use $\mathrm{EC}$ of heart origin, and therefore developed a series of three rat heart endothelial cell (RHEC) lines. These lines were characterized previously and found representative for microvascular endothelial cells in vivo (25). In seeking the role of microvascular heart endothelial cells in blood leukocyte-endothelial cell interaction, RHEC lines were studied for induction of adhesion molecules and MHC antigens by cytokines. ICAM-1, VCAM-1, MHC class I and class II expression was measured at various time points after stimulation with TNF $\alpha$ and IFN $\gamma$ individually or in combination. Our results show that the three RHEC lines respond different upon cytokine stimulation in the expression of ICAM-1 and VCAM-1, but similar in the expression of MHC molecules and P-selectin. It was further studied whether these differences were related to different $\mathrm{Ca} 2+$ mobilization potentials or ultrastructure. What the consequences of these heterogeneous responses of heart EC upon cytokine stimulation may be for processes of inflammation and local immune reactivity in heart tissue is discussed. 


\subsection{Materials \& methods}

Heart Endothelial Cell Lines

We used the EC lines RHEC 3, RHEC 10 and RHEC 11 . These lines were produced as previous described $(25,26)$. They are derived from Lewis rats, and express the endothelial cell markers RECA-1, Angiotensin Converting Enzyme and won Willebrand Factor (vWF). In addition they bind EC specific isolectin GS-1-B4 and take up acetylated low-density-lipoprotein (25).

RHEC lines were routinely cultured in a $\mathrm{CO}_{2}$ incubator at $37^{\circ} \mathrm{C}$ in EC culture medium (40\% RPMI 1640 (Gibco BRL, Life Technologies B.V., the Netherlands), $40 \%$ M199 (Gibco), 20\% inactivated FCS (Integro, Belgium), bovine brain extract $(14.93 \mu \mathrm{g} / \mathrm{ml})$ prepared as described by Maciag $(27), 13 \mathrm{mM} \mathrm{NaHCO} 3,50 \mathrm{U} / \mathrm{ml}$ penicillin, $50 \mu \mathrm{g} / \mathrm{ml}$ streptomycin, $2 \mathrm{mg} / \mathrm{ml}$ Fungizone, $10 \mathrm{mM}$ Hepes, $20 \mathrm{U} / \mathrm{ml}$ heparin and $2 \mathrm{mM}$ L-glutamin). For passaging the cells, confluent monolayers were treated with trypsin $(0.25 \%) /$ EDTA $(0.2 \%)$ in Phosphate Buffered Saline (PBS, 150 $\mathrm{mM} \mathrm{NaCl}, 8 \mathrm{mM} \mathrm{Na}_{2} \mathrm{H}_{2} \mathrm{PO}_{4}, 1.6 \mathrm{mM} \mathrm{KH}_{2} \mathrm{PO}_{4}, \mathrm{pH} 7.3$ ) for 1 minute. Trypsin was neutralized with EC Work medium (90\% M199, $10 \%$ inactivated FCS, $50 \mathrm{U} / \mathrm{ml}$ penicillin, $50 \mu \mathrm{g} / \mathrm{ml}$ streptomycin and $2 \mathrm{mM} \mathrm{L-glutamin}$ and $25 \mathrm{mM}$ Hepes). Cell viability was always $>95 \%$, as assessed by Trypan blue exclusion.

\section{Stimulation of Endothelial Cell Monolayers}

\section{ICAM-1, VCAM-1 and MHC Induction}

Incubation of the endothelial cells with cy tokines was performed on confluent. monolayers with $2.5 \mathrm{ml}$ of culture medium in 6 well culture dishes for the time periods: $0,4,8,16,32$, and 64 hours. Recombinant human TNFo (a gift from Prof. Dr. W. Fiers, Gent, Belgium) was used in a $400 \mathrm{U} / \mathrm{mll}$ concentration. Recombinant rat IFNy (a gift from Dr. P. van de Meide, TNO Rijswijk, The Netherlands), was used in a $200 \mathrm{U} / \mathrm{ml}$ concentration. In these stimulation experiments the cell lines were treated with either control culture medium, culture medium with TNFo, culture medium with IFN $\gamma$ or culture medium with combined TNF $\alpha$ and IFN $\gamma$. In 64 hours stimulation 
experiments, the culture medium with cytokines was refreshed after 32 hours. Longterm incubation (32-64 hr) of the endothellal cell monolayers with the cytokines did not result in induction of proliferation, as shown by the unchanged total cell numbers of stimulated cultures. Reorganization in endothelial cells was studied morphologically in EC monolayers. After IFNy stimulation the EC of the intact monolayer appeared more elongated in all cell lines.

At the end of the stimulation, endothelial cells were harvested using trypsin/EDTA (see above) and cell suspensions were used for cytocentrifuge preparations or FACS analysis. Experiments were performed in triplo, with cells of passage 20 to 30 .

\section{P-selectin Induction}

Confluent monolayers of the endothelial cells were incubated with PMA ( 30 $\mu \mathrm{g} / \mathrm{ml})$, TNF $\alpha(400 \mathrm{U} / \mathrm{ml})$, histamine $(50 \mu \mathrm{M})$ or the $\mathrm{Ca} 2+$ ionophore $\mathrm{A} 23187(10 \mu \mathrm{M})$ dissolved in $2.5 \mathrm{ml}$ of culture medium in 6 well culture dishes for the time periods: 15 min, 30 min, $1 \mathrm{hr}$ and $4 \mathrm{hr}$. Control incubations were carried out with culture medium in the absence of agonists. At the end of the incubation period the cells were harvested by treatment with $0.05 \%$ (w/v) EDTA and cell sulspensions were used for cytocentrifuge preparations. Induction of E-selectin was not studied because antibodies against rat E-selectin were not available.

\section{Cytocentrifuge Preparations}

Cytocentrifuge preparations were made from EC fixed with $1 \%$ paraformaldehyde (PFA) in PBS for 30 min at $4^{\circ} \mathrm{C}$ and washed 3 times with PBS and resuspended in EC culture medium, or unfixed endothelial cell suspensions. Preparations were made in a Cytocentrifuge (Cytospin 3, Shandon, England) in a 10 min run at 690 RPM. Preparations were stored in an exsiccator at room temperature for maximally 10 days. 


\section{Antibodies and Imumurostaining}

The following murine monoclonal antibodies (Mab) were used: OX18 directed against MHC class I antigen, OX6 directed against MHC class II antigen, OX8 used as non-relevant control Mab cobtained through the ECACC, Salisbury, UK), 1 A29 an anti ICAM-1 Mab, donated by Dr. Miyasaka (28), 5F10 an anti VCAM-1 Mab, donated by Drs. R. Lobb and P. Chisholm (29). Detection of P.. selectin occurred with a polyclonal rabbit antibody against human CD62P (P-selectin) cross reactive with rat P-selectin (Pharmingen, Germany). For detection of vWF a rabbit polyclonal antibody A082 (DAKO. Denmark) directed to wWF was used (DAKO, Denmark).

Immunoperoxidase staining was performed on cytocentrifuge preparations of either $1 \%$ PFA fixed or unfixed endothelial cells. Preparations of fresh EC were aceton-fixed for 10 minutes, and air dried before use. A 2-step immunoperoxidase technique was used, as described previously (30). Briefly, the cytocentrifuge preparations were incubated with the above mentioned antibodies or control antibodies, at pretested saturating concentrations, for 60 minutes in a humidified chamber at RT. Dilutions were made in PBS containing $0.05 \%$ BSA $(0.05 \%$ PBSA). The preparations were washed 3 times with PBS and incubated with peroxidaseconjugated second step antibodies (rabbit $F(a b)_{2}$ anti-mouse $\operatorname{IgG}_{\text {, }}$ or swine $F(a b)_{2}$ anti-rabbit IgG, (Dako, Denmark), supplemented with $3 \%$ normal rat serum (NRS)), for 30 minutes. Subsequently preparations were washed 3 times with PBS for 5 minutes and incubated with a $0.05 \mathrm{mg} / \mathrm{ml}$ solution of diaminobenzidin (DAB) in PBS containing $0.05 \% \mathrm{H}_{2} \mathrm{O}_{2}$ for 10 minutes, and subsequently washed 3 times in water and counter-stained with haematoxylin. Preparations were routinely dehydrated in ethanol, and cover slipped with Entallan, (Merck, Germany). Quantification of percentages of positive cells occurred microscopically on cytocentrifuge preparations by counting a minimum total of 200 cells over at least 2 fields, or in case of low numbers of positive cells, a minimum of 10 positive cells. 
Immunofluorescence staining was performed on viable confluent monolayers of heart endothelial cells in 96 well tissue culture plates as earlier described (25). Briefly, the cells were incubated with saturating concentrations of specific or nonrelevant control antibodies in M199 containing $10 \%$ NBCS, for 60 minutes at room temperature. Subsequently the cells were washed and incubated with FITCconjugated second step antibody (goat anti mouse IgG, rat absorbed, Cappel, Organon Teknika, the Netherlands) for 30 minutes. After washing the cells were fixed in $1 \%$ PFA and examined under a Zeiss fluorescence reverse microscope.

\section{Flow Cytometer Analysis}

Immunofluorescent staining was performed in suspensions of routinely trypsinized confluent endothelial monolayers of either non-stimulated or stimulated cultures. $5 * 10^{5}$ cells were incubated for 30 minutes on ice with saturating amounts of monoclonal mouse antibodies $\mathrm{OX} 8, \mathrm{OX} 18$ or RECA-1, then washed three times in $0.5 \%$ PBSA and incubated for 30 minutes with a $100 \mathrm{X}$ diluted. FITC-conjugated goat anti-mouse IgG antibody (rat absorbed, Cappel, Organon Teknika, the Netherlands). Flow cytometry analysis was performed with a FACS-Sort (Becton Dickinson, Mountain View, CA, USA). Data were collected from $1^{*} 10^{5}$ cells.

\section{Electron Microscopy}

EC suspensions from confluent monolayers were fixed in $2.5 \%$ glutaraldehyde in $0.1 \mathrm{M}$ phosphate buffer for $30 \mathrm{~min}$. Fixed cells were resuspended in warm $4 \%$ agarose in PBS and cooled on ice for 20 minutes. EC in coagulated agarose were post-fixed in $2.5 \%$ glutaraldehyde in $0.1 \mathrm{M}$ phosphate buffer for 20 minutes, washed in $0.1 \mathrm{M}$ phosphate buffer, fixed with $1 \% \mathrm{OsO}_{4}$ for 1 hour, and embedded in Epon. Ulthrathin sections for electron microscopy were counter-stained with uranyl acetate and lead citrate and examined with a CM10 Philips electron microscope. 


\section{Calcium mobilization studies}

Cellular mobilization of calcium was measured using the calcium sensitive fluorescent fura-2 acetoxymethyl ester (fura-2) according to van Haaster (31) with minor modifications. In brief: confluent monolayers of RHEC were washed with buffer A (10mM HEPES, $150 \mathrm{mM} \mathrm{NaCl}, 5 \mathrm{mM} \mathrm{KCl}, 1.8 \mathrm{mM} \mathrm{CaCl} 2,1 \mathrm{mM} \mathrm{MgCl}_{2}$, $1 \mathrm{mg} / \mathrm{ml}$ glucose $(\mathrm{w} / \mathrm{v})$ and $4 \mu \mathrm{M} \mathrm{L}$-glutamine), containing $0.25 \%$ (w/v) BSA and incubated in buffer supplemented with $1 \mu \mathrm{M}$ fura-2 with $1 \% \mathrm{BSA}, 37^{\circ} \mathrm{C}$, for 45 minutes. Subsequently monolayers were washed and incubated with EC culture medium for 15 minutes. Cells were detached by incubation with $0.05 \%$ EDTA, and resuspended in buffer $\mathrm{A}$. Mobilization of $\mathrm{Ca}^{2+}$ in suspensions of $\mathrm{EC}$ was determined by stimulation with either $1-3 \mu \mathrm{M}$ ionomycin, $25 \mu \mathrm{M}$ histamine, or $30 \mu \mathrm{g} / \mathrm{ml}$ PMA, using a spectrofluorometer (SLM Aminco) at a $500 \mathrm{~nm}$ emission wave length. Changes in ratio of fluorescence at 340 and $380 \mathrm{~nm}$ were used to calculate levels of $\left[\mathrm{Ca}^{2+}\right] \mathrm{i}$, according to the procedure of Grynkiewicz et al (1985). Calibration values for the calculation of $\left[\mathrm{Ca}^{2+}\right]_{\mathrm{i}}$ were obtained by the addition of $1 \%(\mathrm{w} / \mathrm{v})$ Triton $\mathrm{X}$ 100, followed by $1 \mathrm{mM}$ EGTA.

\section{EC Selection}

Selection of endiothelial cells that were positive or negative for expression of either MHC class II, ICAM-1, VCAM-1 occurred with magnetic beads coated with sheep anti-mouse antibodies (Dynabeads M-450; Dynal, ITK Diagnostics BV, the Netherlands). Briefly, a monolayer of RHEC was stimulated with standard concentrations (see above) of TNF $\alpha$ and IFN $\gamma$ for 16 or 32 hours. The cells were routinely trypsinized and incubated in suspension with mouse $\mathrm{mAb}$ directed to rat MHC class II antigens (OX-6, 1:400 diluted), or against ICAM- $\mathbb{1}(1 \mathrm{~A} 29,1: 50$ diluted), or against VCAM-1 (5F10, 1:500 diluted) for 30 minutes at $4^{\circ} \mathrm{C}$. The cells were washed 3 times with PBS, and $1 * 10^{7}$ cells were incubated with $1.4 * 10^{8}$ magnetic beads in $0.2 \mathrm{ml} 0.5 \%$ PBSA for 30 minutes on ice. The amount of beads used per incubation was based on an estimated 4-20 beads per selected cell. During 
the incubation, the suspensions were frequently rotated. Magnetic bead-labelled cells were separated from non-labelled cells, in a $4 \mathrm{ml}$ volume, using a magnet for two minutes. The positively selected population consisted of more than $99 \%$ cells labelled with beads. In the negatively selected EC population no cells labelled with beads were observed, and staining for false negative cells (by incubation with second-step antibodies) showed less than $0.1 \%$ positive cells. Both positively and negatively selected populations were cultured for 10 passages. At passages 3 and 10, monolayers were stimulated with TNF $\alpha$ and IFN $\gamma$ for 16 or $32 \mathrm{hr}$, and EC were subsequently tested for the selected phenotype by immunoperoxidase staining of either MHC class II, ICAM-1 or VCAM-1 on cytocentrifuge preparations.

\subsection{Results}

Basal Expression of ICAM-1, VCAM-1 and MHC Molecules in RHEC Lines.

In a first series of studies we tested the basal expression of ICAM-1, VCAM-1 and MHC class I and II molecules in the three EC lines RHEC-3, RHEC10 , and RHEC-11, Cytocentrifuge preparations of routinely cultured RHEC lines were stained with monoclonal antibodies to ICAM-1, VCAM-1, MHC class I and MHC class II using an immunoperoxidase technique. As shown in table 1, only RHEC-3 expressed ICAM-1, whereas MHC class I was expressed by all three RHEC lines. Interestingly, ICAM-1 expression in RHEC-3 was present on part (12.3\%) of the cells only. In none of the 3 RHEC lines expression of VCAM-1 or MHC class II was observed during standard culture conditions. 


\section{Adhesion molecule and MHC antigen expression} of the RHEC lines under standard culture conditions

$\begin{array}{lcll}\text { ICAM-1 } & 12.3 \pm 3.3 & <1 & <1 \\ \text { VCAM-1 } & <1 & <1 & <1 \\ \text { MHC class I } & >99 & >99 & >99 \\ \text { MHC class II } & <1 & <1 & <1\end{array}$

Table 1: Percentages of positive cells were measured on immunoperoxidase stained cytocentrifuge preparations of paraformaldehyde-fixed cells. ICAM-1, Intercelluiar Adhesion Molecule-1; VCAM- 1 , Vascular Cell Adhesion Molecule-1; MHC, Major Histocompatibility Complex antigen. Data are from 3 experiments. Absence of expression or less than $1 \%$ expression is categorized as $<1 \%$. Positivity of all cells, or less than $1 \%$ negative cells is categorized as $>99 \%$.

Heterogeneous Induction of Adhesion Molecules of the Immunoglobulin Superfamily on the RHEC Lines upon Cytokine Stimulation

To investigate whether the RHEC lines could be induced to ICAM-1 and VCAM-1 expression by inflammatory cytokines, RHEC cultures were stimulated with TNF $\alpha$ and IFN $\gamma$ individually or in combination for periods from 4 to $64 \mathrm{hr}$. Stimulation occurred with saturating concentrations of the cytokines $(400 \mathrm{U} / \mathrm{ml}$ for TNFo and $200 \mathrm{U} / \mathrm{ml}$ for IFN $\gamma$ ) as tested in initial experiments (data not shown).

ICAM-1 induction (fig. 1) was observed in RHEC-3 and RHEC-11, but not in RHEC-10. In RHEC-3 induction of ICAM-I was obtained with TNF $\alpha$ as well as with IFN $\gamma$. Stimulation with combined TNF $\alpha$ and IFN $\gamma$ was more effective in ICAM-1 induction (e.g., higher percentages of positive cells were measured) than the individual cytokines, but effects were not additive (see also fig. $2 \mathrm{c}$ ). The kinetics of ICAM-1 induction were different for the two cytokines, e.g., TNF $\alpha$-induced expression was already maximal at $16 \mathrm{hr}$, whereas IFN $\gamma$ expression slowly inclined during the $64 \mathrm{hr}$ time period. In RHEC-11, ICAM-1 induction was minimal, and only seen after stimulation with combined TNF $\alpha$ and IFN $\gamma$. 


\section{RHEC lines respond heterogeneously upon cytokine stimulation}

\section{in ICAM-1 and VCAM-1 but not in MHC expression}

AHEC 3
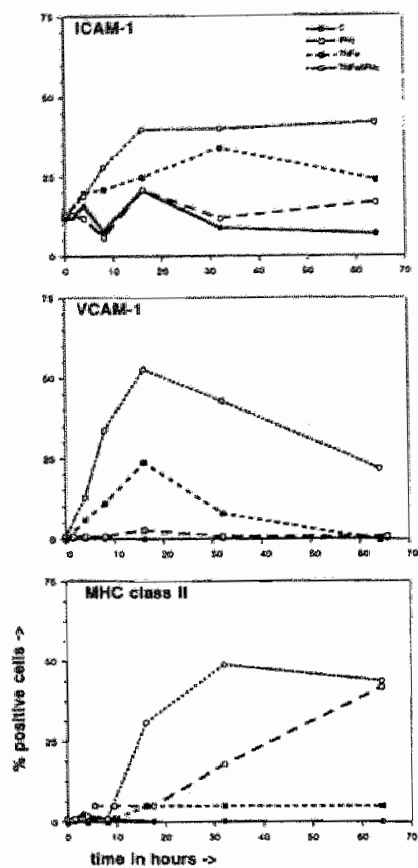

FHec 10
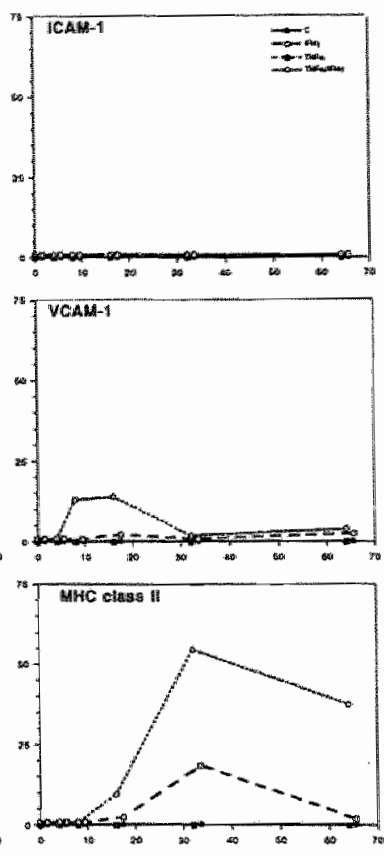

RHEC: 11
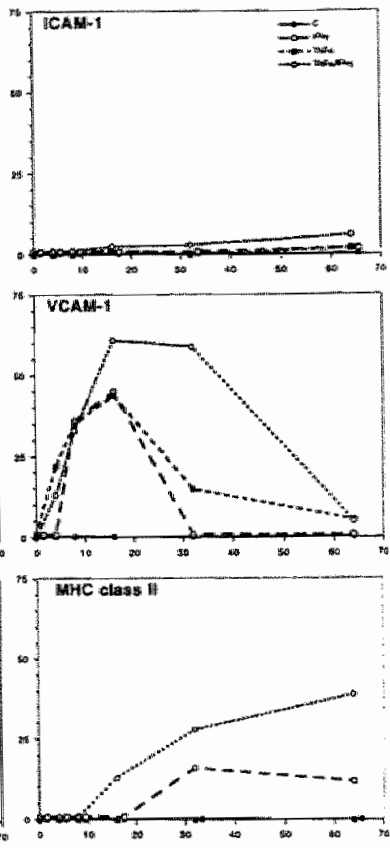

Figure 1: Expression of ICAM-1, VCAM- 1 and MHC class II in the RHEC lines after cytokine stimulation. RHEC-3, RHEC 10 and RHEC 11 cells were stimulated with either TNF $\alpha$, IFNy, or a combination of both (TNFox + IFNy). Control incubations were executed with culture medium without cytokines. Expression was measured at $4,8,16,32$, and 64 hr of stimulation, by immunoperoxidase staining on cytocentrifuge preparations. One representative experiment out of 3 is presented.

Figure $2 \rightarrow$ : Cell surface staining of RECA-1. ICAM-I and MHC class II in RHEC cultures. Monolayers of endothelial cells were stimulated for 32 hours with the combined cytokines TNFor and IFN $\gamma$. Viable, non-fixed, monolayers were stained by immunofluorescence. A: Phase contrast microscopy showing a confluent monolayer of RHEC 10. B: RECA-1 staining of RHEC II showing expression of this $\mathbb{E C}$-specific antigen by all cells. C: Staining for ICAM-1 showing ICAM-1 cell surface expression in RHEC 3. D: MHC class II induction in RHEC 11. In C and D only part of the cells are stained.

Bars $16 \mu \mathrm{mr}$. 
Induction of VCAM-1 (fig. 1) by cytokine stimulation was observed in all three RHEC lines with a maximum at $16 \mathrm{hr}$. But, as also shown for ICAM-1 induction, each cell line responded differently. RHEC-1.0 was the poorest responder in this respect, it showed a minor expression after IFN $\gamma$ stimulation, whereas stimulation with the combined TNF $\alpha$ and IFNy gave an increased, but still rather low expression. VCAM-1 was well inducible in RHEC-3 and RHEC-11 by either TNF $\alpha$ or IFN $\gamma$. RHEC-3 responded best to TNF $\alpha$, whereas for RHEC-11 effects of TNF $\alpha$ and IFN $\gamma$ were rather similar. VCAM-1 induction by TNF $\alpha$ was observed at an earlier time point than with IFN $\gamma$ (4 versus $8 \mathrm{hr}$ ). The strongest induction was observed after combined TNF $\alpha$ and IFN $\gamma$ stimulation (see also fig. 3a), with even synergistic effects in RHEC-3.

To define whether the heterogeneity among the RHEC lines in ICAM-1 and VCAM-1 induction also existed for acutely inducible P-selectin, RHEC cultures were stimulated with either PMA, TNF $\alpha$, histamin or calcium jonophore A23187 for 15 min to $4 \mathrm{hr}$. In none of the RHEC lines increased P-selectin levels could be observed after stimulation.
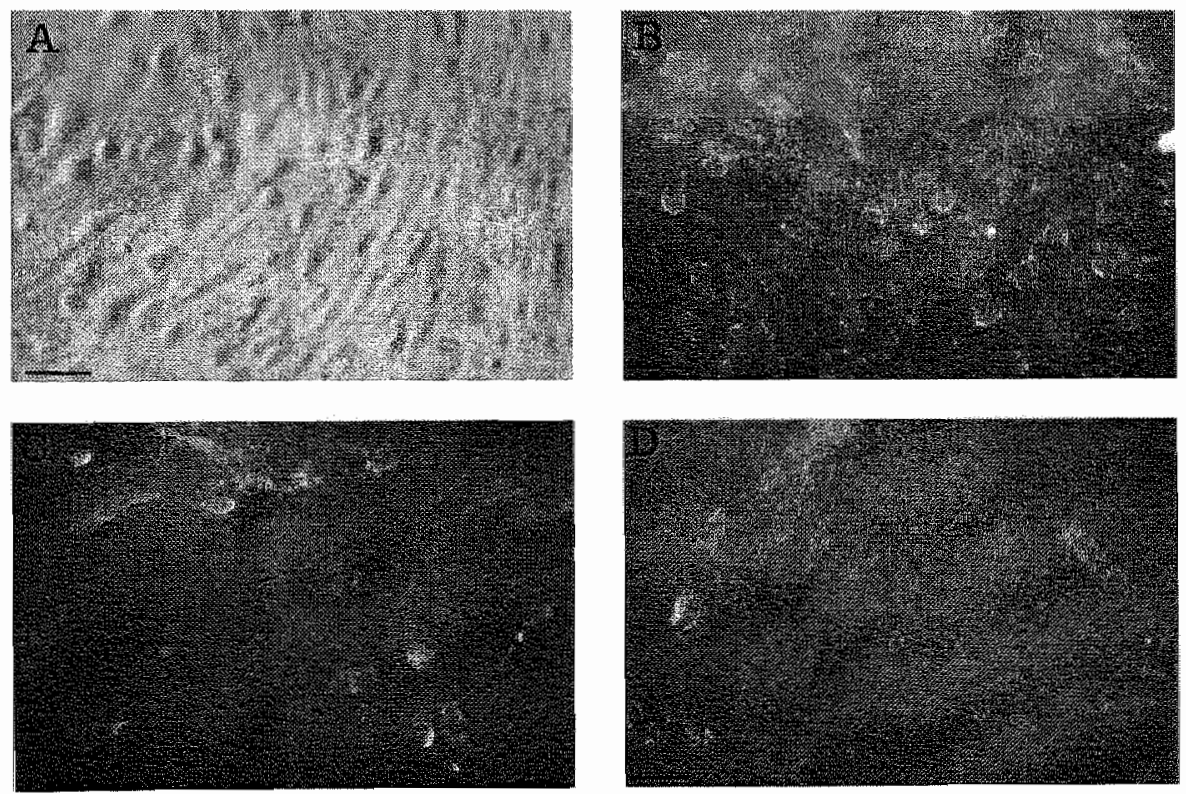

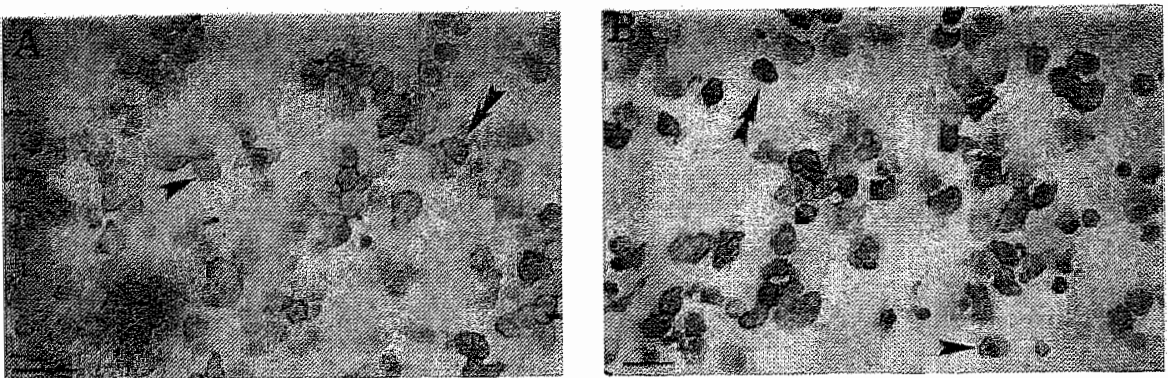

Figure 3: Immunoperoxidase staining for $\mathrm{VCAM}-1$ and $M H C$ class II on cytocentrifuge preparations of RHEC lines after stimulation with a combination of TNF $\alpha$ and IFNy for $32 \mathrm{hr}$. A: VCAM-1 staining is seen on part of RHEC 3 cells (arrows). B: MHC class II staining of RHEC 3 showing part of the cells express the antigen. Staining of cells varied from weakly positive (single arrows) to strongly positive (double arrows).

Bars $40 \mu \mathrm{m}$.

Similar Enhancement of MHC class I and II Expression in the RHEC Lines upon Cytokine Stimulation

In addition to adhesion molecule expression we investigated the induction of MHC class I and MHC class II antigens in the RHEC lines. For MHC class I studies the RHEC lines were stimulated with combined TNF $\alpha$ and IFN $\gamma$ for 32 hours, and FACS analysis was used to detect changes in constitutively expressed MHC class I antigens. All three cell lines showed similar enhanced MHC class I expression after cytokine stimulation. MHC class I enharicement was a specific effect, since no enhancement of expression was observed for pan endothelial cell-specific antigen RECA-1. In fig. 4 the RHEC-10 data, which are representative for the three RHEC lines, are shown.

In all three RHEC lines MHC class II expression, which was absent without stimulation, was induced by IFN $\gamma$. In most experiments expression was observed from $16 \mathrm{hr}$ of stimulation and inclined to maximal levels at 32 or $64 \mathrm{hr}$. TNF $\alpha$ stimulation did not, or in very low levels, induce MHC class II expression in the RHEC lines. However, stimulation with combined TNF $\alpha$ and IFN $\gamma$ gave a strong synergistic effect in all three lines (see also fig. $2 \mathrm{~d}$ and $3 \mathrm{~b}$ ). This clearly demonstrate that although TNFo stimulation alone has only a minor effect on MHC class II 
expression, it has a strong costimulatory effect with IFNy. In contrast with the heterogeneous induction of ICAM-1 and VCAM-1 by cytokines, MHC class I and class II induction was similar for all 3 RHEC lines.

\section{MHC class I upregulation after TNF $\alpha /$ IFN $\gamma$ stimulation}
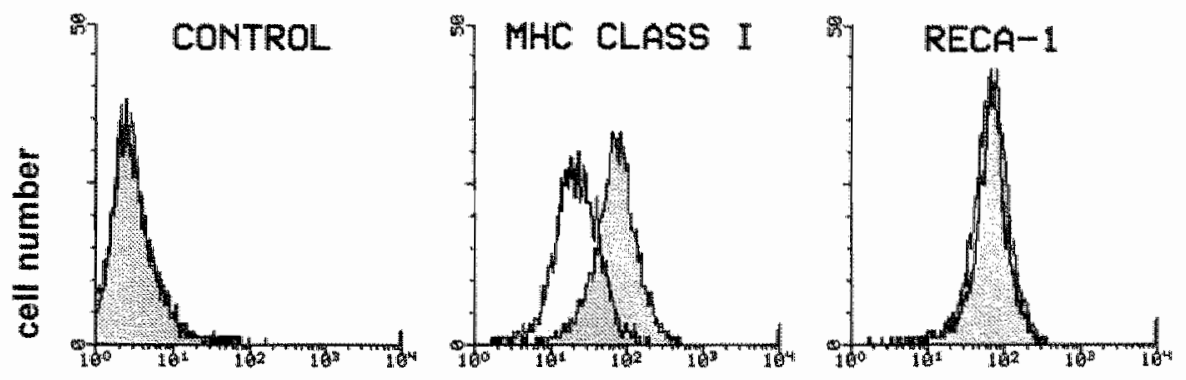

\section{fluorescence intensity}

Figure 4: Expression of MHC class I antigens by RHEC-10 after 32 hr of stimulation with combined TNF $\alpha$ and IFN $\gamma$ was measured by FACS amalysis (one out of two similar experiments is shown). White histograms: expression profile under non-stimulation conditions. Grey histograms" expression profile after $32 \mathrm{hr}$ of cytokine stimulation.

Left panel: $\quad$ Control staining with non-reactive class-matched antibody (OX 8) under stimulation and non-stimulation conditions. Profiles are identical.

Middle panel: Constitutive MHC class I expression under non-stimulated and stimulated conditions. Expression is enhanced by cytokine stimulation.

Right panel: Constitutive RECA-1 expression under non-stirivulation and stimulation condition. Curves have an identical profile, showing the absence of upregulation of RECA- $\mathbb{1}$ by cytokine stimulation.

RHEC Lines Respond Similarly in Calcium Mobilization and Protein kinase $C$ activation

Since in cell activation calcium mobilization and/or protein kinase $C$ activation are important processes in signal transduction, we studied whether the RHEC lines differed in this respect. Calcium mobilization was studied by stimulation with the calcium ionophore ionomycin and addicionally with histamin. Ionomycin stimulation elicited rather similar increase in intracellular calcium $\left(\left[\mathrm{Ca}{ }^{2+}\right]_{i}\right)$ in the 
three cell lines (range 1892 to $2086 \mathrm{nM}$ ). Comparable results were obtained with the 3 cell lines upon histamin stimulation (one experiment, $\left[\mathrm{Ca}^{2}+\right]_{\mathrm{i}}$ range: 1176 to 1982 nM). PKC activation was studied indirectly, by measuring the inhibitory effect of PKC activation on $\mathrm{Ca}^{2+}$ mobilization by histamin. As such, PKC activation obtained by preincubation of RHEC cultures with PMA, led to decreased $\mathrm{Ca}^{2+}$ mobilization by histamin, with similar results for the three RHEC lines ([Ca $\left.{ }^{2+}\right]_{i}$ range: 486 to 1177 nM). The data show that with respect to $\mathrm{Ca}^{2}+$ mobilization and $\mathrm{PKC}$ activation the 3 RHEC lines have rather similar potentials.

\section{The RHEC Lines Show no Defined Ultrastructural Differences}

To study whether the heterogeneous phenotype of EC in the RHEC lines was related to ultrastructural cellular differences, we studied suspensions of RHEC cultures by electron-microscopy (Fig. 5). Most cells of the RHEC lines showed a ruffled cell membrane with variable numbers of small processes. The nuclei showed an active state with present nuclei and a preponderance of euchromatin over heterochromatin. The cytoplasm of the cells frequently showed a cytocentre with an active Golgi apparatus. Cells contained many polyribosomes, endoplasmatic reticulum, and numerous mitochondria. Phagolysosomes were observed in variable numbers, sometimes with multi-laminar membranous material. Weible Palade bodies were not noticed (Fig. 5a). Heterogeneity in the EC of the RHEC lines was observed in the shape of the cells, and the numbers of cytoplasmatic vesicles. EC were variable in cell size, large cells showed extensive cytoplasmatic protrusions. Vesicles in EC varied in size and contained heterogeneous amorphous material. Sometimes numerous lipid droplets were observed (Fig. 5b). Occasionally in present small clusters of cells, contacts between cells with zonulae occludens could be noticed (Fig. 5c), indicating intensive contact between these EC. The data indicated that each of the RHEC lines consisted ultrastructurally of a rather heterogeneous population of EC, but no defined subpopulations of EC could be identified. 


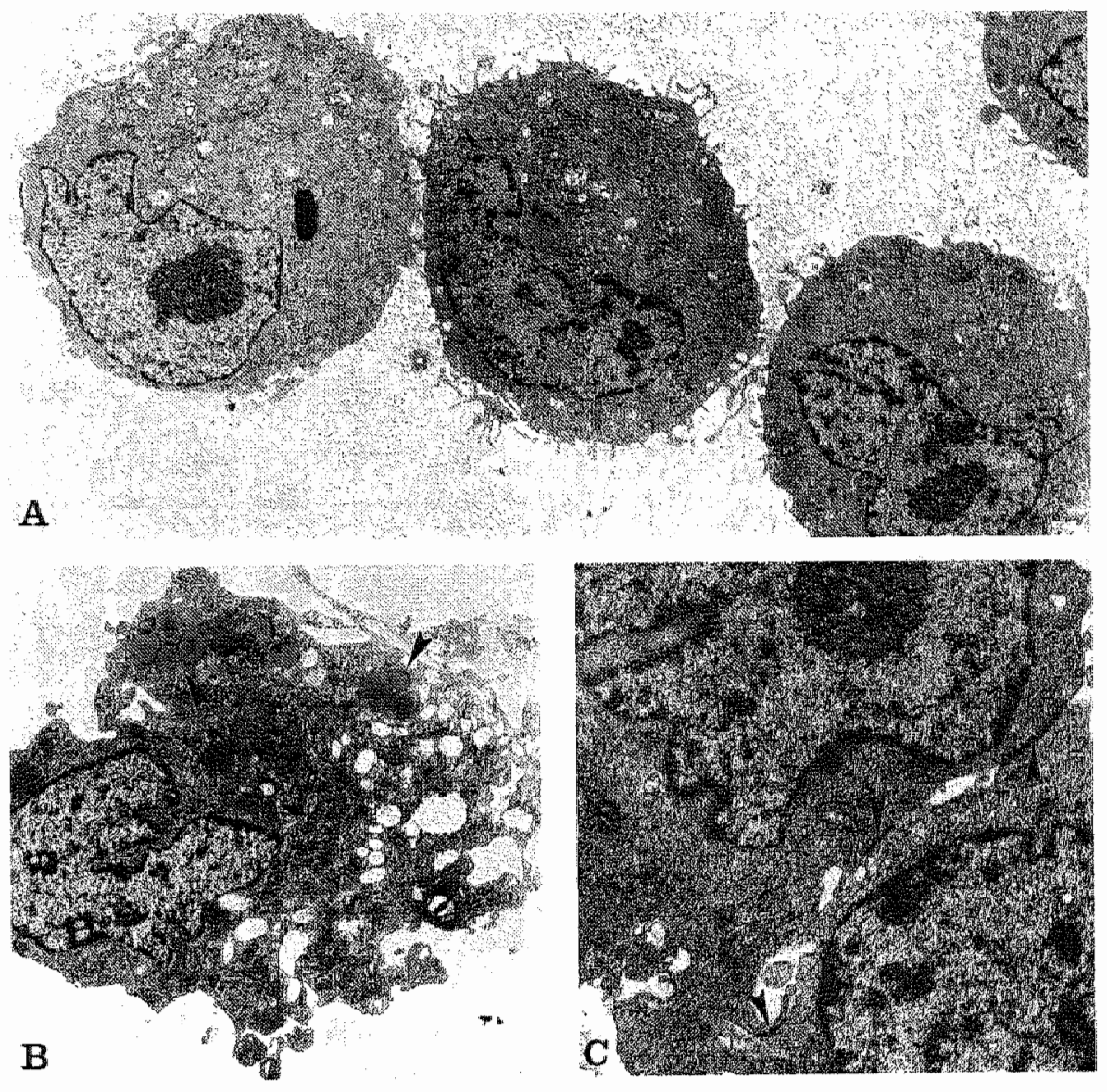

Figure 5: Electronmicroscopy of RHEC cells. A: Cells from RHEC 11. Notice the ruffled cell membranes and small processes, bar $0.2 \mu \mathrm{M}$. B: Cells from RHEC 10, vesicles with lipid droplets can

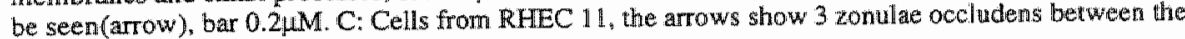
cells, bar $0.9 \mu \mathrm{M}$. 
Chaprer Three

Heterogeneous Expression of ICAM-1, VCAM-I and MHC class II Seems

not a Result of Specific Subpopulations of EC

As shown, cytokine stimulation gave a different pattem of ICAM-1, VCAM-

1 , and MHC class II expression in the cell lines. In addition stimulation did not lead to induction of these molecules on all cells of a RHEC culture. We wished to determine whether this was due to the presence of responsive and non-responsive EC subsets in the RHEC lines. Therefore, after combined TNF $\alpha$ and IFN $\gamma$ stimulation, positive and negative EC for either ICAM-1, VCAM-1, or MHC class II were selected, using magnetic beads to sort out specific antibody-labelled EC. The selected expressing and non-expressing populations were subcultured and tested at passage 3 4 and 10 for induction of ICAM-1, VCAM-1 and MHC class II respectively on stimulation with combined TNFio and IFNy.
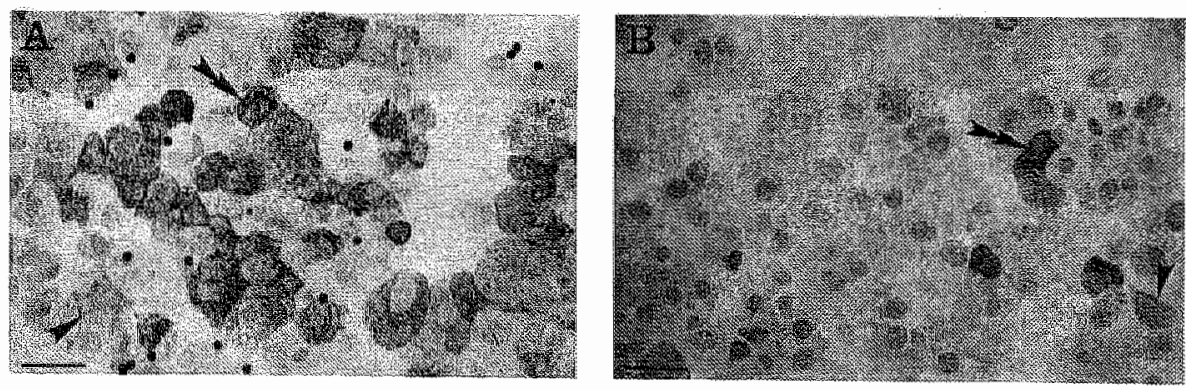

Figure 6: Immunoperoxidase staining on cytocentrifuge preparations of selected RHEC-11 cells after stimulation with a combination of TNFC and IFNy for $32 \mathrm{hr}$. A: MHC class II staining of RHEC 11 cells that had been selected 3 passages earlier for MFC cllass II expression (see text). Most cells express MHC class II after cytokine stimulation. Small black dots are remaining magnetic beads from the isolation procecture. B: MHC class II staining of RHEC 11 cells that had been selected 3 passages earlier for absence of MHC class II expression after cy tokine stimulation. A low but distinct $\%$ of cells express MHC class II. Staining of cells varied from weakly positive (single anows) to strongly positive (double arrows).

Bars $40 \mu \mathrm{m}$. 


\section{Effect of RHEC pre-selection on cytokine induced expression of \\ ICAM-1, VCAM-1, and MHC class II}

\begin{tabular}{|c|c|c|c|c|c|c|c|}
\hline \multirow[b]{3}{*}{$\begin{array}{c}\text { Passage } \\
\text { after } \\
\text { selection } \\
\end{array}$} & \multirow[b]{3}{*}{$\begin{array}{c}\text { Cytokine } \\
\text { stimulation }\end{array}$} & \multicolumn{4}{|c|}{$\begin{array}{c}\text { RHEC 3 } \\
\text { experiment }\end{array}$} & \multicolumn{2}{|c|}{$\begin{array}{l}\text { RHEC } 11 \\
\text { experiment }\end{array}$} \\
\hline & & \multicolumn{2}{|c|}{$\%$ ICAM-1 + cells } & \multicolumn{2}{|c|}{$\%$ VCAM-1 + cells } & \multicolumn{2}{|c|}{ \% MHC-II + cells } \\
\hline & & $\begin{array}{l}\text { ICAM-1 + } \\
\text { population }\end{array}$ & $\begin{array}{l}\text { ICAM-1- } \\
\text { population }\end{array}$ & $\begin{array}{l}\text { VCAM-1 + } \\
\text { population }\end{array}$ & $\begin{array}{l}\text { VCAM-1 - } \\
\text { population }\end{array}$ & $\begin{array}{l}\text { MHC-II" } \\
\text { population }\end{array}$ & $\begin{array}{l}\text { MHC-II" } \\
\text { population }\end{array}$ \\
\hline $\mathrm{po}^{2}$ & yes & $>99 \%$ & $<1 \%$ & $>99 \%$ & $<1 \%$ & $>99 \%$ & $<190$ \\
\hline \multirow[t]{2}{*}{$\mathrm{p} 3-4$} & no $0^{3}$ & $55 \%$ & $12 \%$ & $<0.1 \%$ & $<0.1 \%$ & $<0.1 \%$ & $<0.1 \%$ \\
\hline & yes & $96 \%$ & $38 \%$ & $75 \%$ & $32 \%$ & $95 \%$ & $13 \%$ \\
\hline \multirow[t]{2}{*}{$\mathrm{p} 10$} & no & $13 \%$ & $15 \%$ & $<0.1 \%$ & $<0.1 \%$ & $<0.1 \%$ & $<0.1 \%$ \\
\hline & yes & $97 \%$ & $57 \%$ & $45 \%$ & $41 \%$ & $79 \%$ & $51 \%$ \\
\hline
\end{tabular}

Table 2: Data are from a representative experiment.

${ }_{1}$ Cytokine stimulation occured with combined TNE $\alpha$ and IFN $\gamma$ for $16 \mathrm{hr}$ (ICAM-1 and VCAM-1 experiments) or $32 \mathrm{hr}$ (MHC class II experiments).

${ }^{2} \mathrm{p} 0$ values were measured directly after the magnetic bead selection step. In the negative selected $\mathrm{EC}$ populations these values were calculated from cytocentrifuge preparations immunoperoxidase-stained with second step antibodies only. In the positive selected EC populations the values were calculated from the numbers of free, non bead-rozetted, EC.

${ }^{3}$ RHEC 3 shows already low ICAM-1 expression (see table 1) under normal (non-stimulated) conditions.

The selection procedure yielded ICAM-1, VCAM-1, and MHC class II positive and negative populations with a purity of $>99 \%$. Upon subsequent culturing of these populations without cytokines, VCAM-1 and MHC class II expression completely disappeared from the positively selected populations, and ICAM-1 expression diminished to basal levels (about 10-15\% positive cells). Re-stimulation of the populations with cytokines at passage 3-4 and subsequently at passage 10 showed that the selection phenotype of VCAM-1 or MHC class II positive and negative populations gradually diminished during culturing, and at passage 10 had returned to 
rather pre-selection expression levels. (Table 2 and Fig. 6) Similar results were obtained with the ICAM-1 negative population, but not with the ICAM-1 positive population, which at passage 10 after selection still showed very high ICAM-1 expression upon cytokine stimulation. When the expression levels of vWF were compared between MHC class II positive, MHC class II negative, and non-selected EC, no differences were found (about 13\% positive cells, data not shown). Apparently WWF expression did not co-select and remained randomly distributed over the selected populations. In another approach to define the presence of particular subpopulations in the RHEC lines, EC of RHEC 3 were cloned by limiting dilution. Two clones selected from the 0.5 cell/well plate were tested for response on stimulation with combined IFN $\gamma$ and TNF $\alpha$ for 16 and $32 \mathrm{hr}$. These clones 1D4 (and 1C5 expressed RECA-1 and MHC class I but no ICAM-1, VCAM-1 or MHC class II under standard culture conditions. After 16 and $32 \mathrm{hr}$ of cytokine stimulation both clones expressed VCAM-1 (highest at $16 \mathrm{hr}$ ) and MHC class II (highest at $32 \mathrm{hr}$ ). But, expression levels were comparable with RHEC 3 levels before cloning. The same was found for ICAM-1 expression in clone 1D4, but not for 1C5. Cytokine stimulation of $1 \mathrm{CS}$ led to expression of ICAM-1 on $>99 \%$ of the cells. These results indicate that at least for VCAM- 1 and MHC class II the heterogeneous induction in the RHEC lines is likely not due to cytokine-responding and non-responding subpopulations. 


\subsection{Discussion}

To obtain insight in the role of vascular endothelial cells in leukocyte-EC interactions in heart inflammatory and immune reactive processes, we studied the induction of cell adhesion molecules of the immunoglobulin superfamily, andthat of MHC antigens by cytokines in heart EC cultures in vitro. For these studies, a series of 3 rat heart endothelial cell (RHEC) lines were selected, that were representative for heterogeneous heart microvascular endothelium in vivo (25). Our data show that all three heart EC lines respond to the cytokines TNF $\alpha$ and IFN $\gamma$. With respect to induction of the adhesion molecules ICAM-1 and VCAM-1, the strongest effects were obtained with TNF $\alpha$, e.g. peak expression was higher and reached earlier than with IFN $\gamma$. This was not due to suboptimal cytokine concentrations, because 2 and 4 times (800 U/ml) higher IFN $\gamma$ concentrations did not increase expression (data not shown). The effectiveness of pro-inflammatory cytokines such as TNF $\alpha$ on induction of cell adhesion molecules in the microvascular heart $\mathrm{EC}$ has also been described for macrovascular EC in vitro, such as HUVEC (8). Apparently, pro-inflammatory cytokines can be considered most relevant for induction of cell adhesion molecules on microvascular EC, as shown in this study, as well as on macrovascular EC in local acute inflammation.

In none of the RHEC lines adhesion molecule induction was found in the wholle $\mathrm{EC}$ population. Such heterogeneity was also observed by others in microvascular EC of mouse heart and human dermal origin $(22,23)$. In this respect microvascular theart EC respond differently than macrovascular $E C$, such as HUVEC. in which cytokine stimulation has been described to induce adhesion molecule expression in the whole cell population (32). Our stimulation experiments using combinations of TNF $\alpha$ and IFNy clearly demonstrated the importance of IFN $\gamma$ as a co-stimulatory cytokine for adhesion molecule induction. This immune regulatory cytokine, which is produced by activated $\mathrm{T}$ cells and natural killer (NK) cells, increased the induction of ICAM-1 by TNFa and in two of the three RHEC lines had a synergistic effect on TNFo-induced VCAM-1 expression. 
Interestingly, the 3 RHEC lines differed from each other in their specific ICAM-1 and VCAM-1 expression profiles upon cytokine stimulation. RHEC-3, which had a basal ICAM-1 expression, was inducible to relatively high levels of both ICAM 1 and VCAM-1, whereas RHEC-11 showed very poor ICAM-1 but high VCAM-1 induction. Surprisingly, RHEC-10 was not at all inducible to ICAM- $\mathbb{1}$ expression, and only minorly to VCAM-1 expression. The latter was not due to a non responsiveness of RHEC 10 to cytokine stimulation (e.g. due to absence of cytokine receptors on the EC), as demonstrated by the fact that IFN $\gamma$ stimulation induced MHC class II expression. Also, TNFa synergistically increased this expression in this cell line. The different responses of the 3 endothelial cell lines in ICAM-1 and VCAM-1 induction upon cytokine stimulation, contrasted with the responses of the 3 lines in MHC molecule induction. MHC class I molecules, constitutively expressed by EC, were similarly upregulated in all 3 RHEC lines. Also MHC class II expression profiles after cytokine stimulation did not differ between the 3 RHEC lines. A synergistic effect of TNF $\alpha$ on IFN $\gamma$-induced MHC class II expression was noticed. This indicates that different, e.g. opposite synergistic effects are obtained with IFN $\gamma$ versus TNF $\alpha$ in ICAM-1/VCAM-1 and MHC class II induction respectively. Such specific effects of cytokine combinations in stimulation of $\mathrm{EC}$, and its implication for inflammatory conditions have also been described by others. For example, Leeuwenberg et al., showed that IFN $\gamma$ prolonged the effect of TNF $\alpha$ on E-selectin expression (14), whereas a similar effect was shown for $\mathbb{L}_{-}-4$ in combination with TNF $\alpha$ for VCAM-1 expression (33). We showed that the different responses of the RHEC lines could not be explained by differences in $\mathrm{Ca}^{2}+$ mobilization or $\mathrm{PKC}$ activity. Also ultrastructurally no indications were found pointing at differences between the cell lines. In fact the data together, including the similar responses of the cell lines in P-selectin expression, suggest that the heterogeneity in ICAM-1 and VCAM 1 is a specific characteristic of the heart EC population. The fact that the induction of adhesion molecules and MHC class II antigens was shown in only part of the EC population, and the obserwation that wWF and also ICAM-1, in RHEC 3 (25) 
was never seen in all EC in standard cultures, demonstrate a phenotypical heterogeneity of EC within a RHEC line. Previously we have shown that this heterogemeity is probably not related to differences in cell cycle stage of the EC in confluent cultures (25). The experiment with selected either ICAM-1, VCAM-1 or MHC class II positive and negative populations showed that, except for the selected ICAM-1 positive EC population, the selected profile was slowly lost during subsequent culturing. Also the cloned cell population from RHEC 3 still showed heterogeneity in adhesion molecule and MHC molecule expression upon cytokine stimulation. Apparently this heterogeneity within a RHEC line results from linespecific intrinsic regulation mechanisms, and not from the presence of particular subpopulations of EC in the RHEC lines. Such programmed heterogeneity among EC in vitro cultures has also been described by others $(22,23,24)$, and was also noticed in microvascular $\mathrm{EC}$ in the normal rat heart in wivo (25). We noticed in immunofluorescence microscopy studies of confluent monolayer cultures of RHEC lines that the expression of ICAM-1, VCAM-1, or MHC class II was mostly seen in foci or strands of cells. In fact, this may be relevant for understanding how in vivo such reactivity of $E C$ in the microvascular endothelium occurs. A possible explanation for the remarkable differences in expression profiles between the 3 lines could be their origin from different hearts. However, this is not likely because the rats used were from the Lewis inbred strain. We think it is more likely that such heterogeneity is related to the primary cultures representing endothelial isolates from various locations in the heart micro-vasculature.

One may expect that in settings of inflammation and local immune reactiwity in heart tissue the selective differences of vascular EC as demonstrated here, has an impact on leukocyte-endothelial cell interactions in local inflammatory and immune processes. For example, if upon cytokine stimulation microvascular heart EC develop different phenotypes regarding expression profiles of MHC and adhesion molecules, this may imply different functions of EC in processes such as leukocyte infiltration and antigen presentation to blood $T$ cells. With respect to leukocyte infiltration, 
differential expression of ICAM-1 or VCAM-1 may regulate preferential local adhesion and infiltration of specific leukocyte subpopulations. MHC class III expression in combination with costimulatory molecules such as ICAM-1 and/or VCAM-1 is required for antigen presentation to T helper cells (12). However, antigen presentation by MHC class II in the absence of such costimulatory adhesion may render $T$ cells anergic, or apoptotic. In general our data suggest that heart microvascular EC in vivo display heterogeneous differentiation profiles, which in inflammation and immune reactivity leads to different phenotypes with respect to adhesion and MHC molecule expression. As such this knowledge contributes to understanding how local EC can control different types and effects of leukocyte-EC interactions in heart tissue.

Acknowledgements: The authors would like to thank A. Gijsen and M. Maes for technical assistance. We thank Dr. J. Damoiseaux for assistance in FACS studies, Dr. J. Heemskerk and M. Feijge for assistance in calcium mobilization studies, P. Bomans for electron microscopy assistance, Drs. R. Lobb and P. Chisholm for donation of 5F10, Dr. M. Miyasaka for donation of 1A29, Prof. Dr. W. Fiers and Dr. $P$. van de Meide for donation of TNF $\alpha$ and IFN $\gamma$ respectively. 


\section{5 References}

1. Hakkert BC, Kuijpers T, Leeuwenberg JEM, Mourik wan JA, Roos D. Neutrophil and monocyte adherence 10 and migration across monolayers of cytokine activated endothelial cells: contribution of CD 18, ELAM-1 and VLA-4. Blood 1991; 78: 2721.

2. Lawrence MB, Springer TA. Neutrophils roll on E-selectin. The Journal of Immunology 1993; 151: 6338.

3. Bevilaqua MP, Nelson RM. Selectins. Journal of Clinical Inwestigation 1993:91: 379.

4. Elices MJ, Osborne L, Takada Y, al e. VCAM-I on activated endothelium interacts with leukocyte integrin VLA-4 at a distinct of the VLA-4/fibronectin binding site. Cell 1990;60:577.

5. Springer TA. Traffic signals for lymphocyte recirculation and leukocyte emigration: the multi step paradigm. Cell 1994; 76: 301 .

6. Kuypers TW, Harlan IM. Monocyte endothelial interactions insights and questions. Journal of Lab Clin Med 1993; 122: 641.

7. Carlos TM, Harlan JM. Leukocyte endothelial adhesion molecules. Blood 199:; 84:2068.

8. Sluiter W, Pietersma A, Lamers IMII, J.F. K. Leukocyte achesion molecules on the vascular endothelium: Their role in the pathogenesis of cardiovascular disease and the mechanism underlying their expression. Journal of Cardiovascular Pharmacology 1993; 22: 337 .

9. Bevillaqua MP. Endothelial-leukocyte adhesion molecules. Annu Rev Immunol 1993; 11: 767 .

10. Dougherty GI, Murdoch S, Hogg N. The function of human intercellular adhesion molecule 1 (ICAM-1) in the generation of an immune response. European Journal of Immunology 1988 ; 18: 35 .

11. Makgoba MW, Sanders ME, Ginther Luce GE, et al. Functional evidence that intercellular adhesion molecule 1 (ICAM-1) is a ligand for LFA-1 dependent adhesion in T cell mediated cytotoxicity. European Journal of Immunology 1988; 18: 637 .

12. Steinman $\mathrm{RM}_{*}$ Young $\mathrm{JW}$. Signals arising from antigen presenting cells. Current Opinion in Immunology 1991; 3: 361 .

13. Damle $\mathrm{NK}$, Klussman $\mathrm{K}$, Leytze $\mathrm{G}$, et al. Costimulation of $\mathrm{T}$ lymfocytes with integrin ligands intercellular adhesion molecule-1 or wascular adhesion molecule-1 induces functional expression of CTLA-4, a second receptor for B7. Journal of Immunology 1994; 152: 2686.

14. Leeuwenberg JFM, Damme van J, Maeger T, Jeunhomme TMMA, Buurman WA. Effects of tumor necrosis factor on the interferon- $\gamma$-induced major histocompatibility complex class II antigen expression by human endothelial cells. European Journal of Immunology 1988; 18" 1469.

15. Smith CW, Anderson DC, Taylor, Rossen RD, Entman ML. Leucocyt adhesion molecules and myocardial ischemia. Trends in Cardiovascular Medicin 1991; 1: 167.

16. Palluy O, Morliere L, Gris J, Bonne C, Modat G. Hypoxia/reaxygenation stimulates endothelium to promote neutrophil adhesion. Free Radic Biol Med 1992; 13:21.

17. Osborn $L$, Hession $C$, Tizard $R$, al e. Direct expression cloning of vascular cell adhesion molecule1, a cytokine-induced endothelial protein that binds to lymfocytes. Cell 1989; 59: 1203 .

18. Pober JS, Cotran RS. Cytokines and endothelial cell biology. Physiol Rev 1990; 70; 427.

19. Carlos TM, Harlan JM. Membrane proteins involved in phagocyte adherence to endotheliurn. Immunological Review 1990; 114:

20. Fougerolles de AR, Stacker SA, Sclswarting R, Springer A. Characterization of ICAM-2 and evidence for a third counter receptor for LFA-1. Journal of Experimemtal Medicine 1991; 174: 253.

21. Linke AT, Male DK. Strain specific variation in constitutive and inducible expression of MHC class II, class I and ICAM-1 on rat cerebral endothelium. Immunology 1994; 82: 88.

22. Gumkowski F. Kaminska G, Kaminki M, L.W. M. Auerbach R. Heterogeneity of mouse vascular endothelium. Blood Vessels 1987; $24: 11$.

23. Petzelbauer P, Bender JR, Wilson J, Pober JS. Heterogeneity of dermal microvascular endothelial cell antigen expression and cytokine responsivemess in situ and in cell culture. the Journal of Immunology 1993; 151: 5062 .

24. Wang IM, Kumar S, Pye D, Vanagthoven AJ, Krupinski J, Hunter RD. A monoclonal antibody detects heterogeneity in vascular endothelium of tumours and rormal tissues. Int J Cancer 1993; 54: 363 .

25. Derhaag J, Duijwestijn A. Emeis J, Engels. W, Breda Vriesmain van P. Production and characterization of spontaneous rat-heart endothelial cell lines. Laboratory Inwestigations 1996: 74: 437 .

26. Linssen MCJG, Nieuwenhoven van FA, Dujjwestijn AM, Glatz JFC, Vusse van der GJ Continuous endothelial cells from adult rat heart. In Vitro cell Dev Biol 1993; $29 \mathrm{a}: 611$.

27. Maciag T, Cerendulo J, Isley $S$, Kellu PR, Forand R. An endothelial growth factor from bovine hypothalamus: identification and parial characterization. Proc Natl Acad Sci USA 1979; 76: 5674. 
28. Tamatani $T$, Miyasaka $M$. Identification of monoclonal antibodies reactive with the rat homolog of ICAM-1 and evidence for a differential involvement of ICAM- 1 in the adherence of resting versus activated lymphocytes to high endothelial cells. International Immunollogy 1990;2:165.

29. May MJ, Entwistle G, Humphries MJ, Ager A. VCAM-1 is a CS-1 peptide-inhibitable adhesion molecule expressed by lymph node high endothelium. Journal of Cell Science 1993; 106: 109.

30. Duijwestijn AM, Goor van $\mathrm{H}_{*}$ Klatter $\mathbb{F}$, Majoor GD, Bussel wan E, Breda Vriesman van PJC. Antibodies defining rat endothelial cells: RECA-1 a pan endothelial specific monoclonal antibody. Laboratory Investigation 1992; 62: 459 .

31. Haaster van MCJ, Engels W, Lemmens PJMR, Hornstra G, J. VydG, Heemskerk JWM. Differential release of histamin and prostaglandin D2 in rat peritoneal mast cells: roles of cytosolic calcium and protein tyrosine kinases. Biochem Biophys Acta 1995; 1265: 79.

32. Wedgwood $\mathrm{JF}$, Hatam $L_{\mathrm{s}}$ Bonagura VR. Effect of interferon $\gamma$ and tumor necrosis factor on the expression of class I and class II major histocompatibility molecules by cultured umbilical vein endothelial cells, Cellular Imunology $1988 ; 111: 1$.

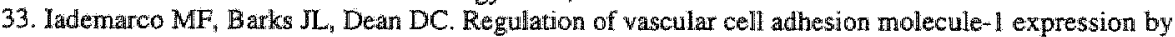
IL-4 and TNFo in cultured endothelial cells. Journal of Clinical Investigation 1995; 95: 264. 


\section{A dual role for $\mathrm{EC}$ in cytomegalovirus infection?}

\section{A study of cytomegalovirus infection in a series of rat endothelial cell lines}

Renée C. R. M. Vossen* Josien G. Derhaag\#, Marlea E. P. Slobbe van Drunen*" Adrian M. Duijvestijn\# Maria C. E. van Dam Mieras and Cathrien A. Bruggeman*.

* Department of Medical Microbiology, Maastricht University, P. O. Box 5800 , 6202 AZ Maastricht, and \#Department of Immunology, Maastricht University, Maastricht, The Netherlands, and \$Department of Natural Science, Open University, Heerlen, The Netherlands.

Published in: Virus Research 1996, Vol. 46, p. 64-74. 


\section{Abstract}

Severall clinical findings point to the involvement of microvascular endothelial cells (EC) in cytomegalovinus-related pathology. In this study the interactions of cytomegalovirus (CMV) with microvascular EC was investigated in an in vitro rat model. A series of rat endothelial cell lines, considered representative for the heterogeneity of heart microvasculat endothelium in wiv, were infected with rat CMV (RCMV). The course of infection and production of infectious virus were examined using immunofluarescence staining and plaque titration assays, and was compared with the infection of fully permissive rat fibroblasts. These endothelial cell lines displayed differences in susceptibility to CMV infection. Two endothelial cell lines (RHEC 50 and 191)were practically non-permissive, while four endothelial cell lines (RHEC 3, 10,11 and 116) were partly permissive for CMV infection. In contrast to CMV infection on fibroblasts, only limited infection of the permissive endothelial cell lines was observed without spreading of CMV infection through the monolayer, although infectious virus was produced. Detachment of infected EC and recovery of the monolayer with time was observed. The detached $\mathrm{EC}$ were able to transmit CMV infection to fibroblast monolayers, but not to endathelial cell monolayers. Our in vitro results demonstrate differences in permissiveness for RCMV between the series of rat endothelial cell lines, which is suggestive for endothelial heterogeneity to $\mathrm{CMV}$ infection in vivo. Our findings indicate that $\mathrm{EC}$ are relatively resistant to $\mathrm{CMV}$ infection and that, upon infection, the endothelial monolayer may dispose of the virus via detachment of the infected cells. This points to a dual role for the endothelium in CMV infection in vivo: a barrier for CMV infection (by the endothelial monolayer) on the one hand and spreading of CMV infection (by detached infected cells) on the other hand. 


\subsection{Introduction}

Infection of healthy individuals by cytomegalovirus (CMV) is usually asymptomatic. However, in immunocompromised individuals, like AIDS patients and transplant recipients, CMV infection causes life-threatening complications. A variety of symptoms like retinitis, vasculitis and gastrointestinal ulcers is observed in these patients with acute CMV infection. Furthermore, chronic CMV infection has been associated with atherosclerosis and transplant associated atherosclerosis $(1,2,3)$.

During the acute phase of the infection, especially in the severely immunocompromised host, microvascular endothelial cells (EC) have been described to be infected in several organs $(4,5)$. Furthermore, circulating $C M V$ infected cells of endothelial origin are found in the peripheral blood of organ transplant recipients during acute CMV infection (6). These circulating EC harbor infectious vinus and it is speculated that they may be involved in dissemination of CMV throughout the body when they become trapped in capillaries (6).

The clinical observations listed above can be simulated and studied in an in vivo rat model. Infection of immunocompromised rats with rat CMV (RCMV) leads to a generalised infection with virus in most organs and to comparable symptoms as described in severe immunocompromised HCMV-infected patients (7). A recent study of acutely infected immunocompromised rats (8) describes the appearance of gastrointestinal bleedings (as observed in AIDS patients) and direct endothelial damage in the microvasculature. Furthermore, by using a rat model to study the pathogenesis of interstitial lung disease after bone marrow transplantation, endothelial damage is found to be one of the multiple factors in the development of clinical symptoms (9).

The in vivo data described above suggest a role for $\mathrm{EC}$ from the microvasculature in CMV-associated pathology. To establish the link with the in vivo system it is attractive to study the interactions of CMV with EC in more detail in an in vitro rat model. Recently, six continuous microvascular endothelial cell lines, derived from the rat heart microvasculature, have been isolated and characterized $(10,11)$. These rat heart endothelial cell lines (RHEC) exhibit common endothelial markers but show differential 
phenofypic and functional characteristics; differential expression of activation markers such as VCAM-1, ICAM-1 and MHC-II, differences in the production of prostaglandins, tissue plasminogen activator and its inhibitor. This series of cell lines have been shown to be representative for the heterogeneity of heart microvascular endothelium in vivo (10, 11).

In the present study, the interaction of rat CMV with these rat endothelial cell lines was investigated. The results indicated that these cell lines display heterogeneity with respect to RCMV permissiveness. In addition, limited CMV infection without spreading of the virus through the endothelial cell monolayer as well as detachment of infected EC from the monolayer was observed. Our results in combination with in wivo findings suggest a barrier function of the endothelial monolayer for CMV infection in wivo. On the other hand, detached infected EC may be involved in CMV dissemination.

\subsection{Materials \& methods}

Virus and cell culture

Rat cytomegalovirus (RCMV, Maastricht strain) was cultured in rat embryonal fibroblasts (REF) in minimum essential medium (EMEM, ICN Biomedicals, Zoetermeer, the Netherlands), containing $2 \%$ fetal calf serum (FCS) (Biowithacker, Verviers, Belgium), $200 \mathrm{mM}$ L-glutamine (Serva, Heidelberg, Germany) and non-essential aminoacids (ICN Biomedicals, Zoetermeer, The Netherlands). At 100\% cytopathic effect, the culture supernatant was clarified by centrifugation for $10 \mathrm{~min}$ at $500 \mathrm{xg}$. RCMV preparations were stored at $-70^{\circ} \mathrm{C}$ and infectivity titers were determined by plaque assay on REF monolayers as described below.

Spontaneously transformed endothelial cell lines (originally isolated from rat heart) were cultured in RPMI 1640/M199 (1/1,v/v)(Gibco BRL, Breda, The Netherlands), containing 20\% FCS (Integro, Zaandam, The Netherlands), $200 \mathrm{mM} \mathrm{1-}$ Glutamine, $10 \mathrm{U} / \mathrm{ml}$ heparin (ICN Biomedicals, Zoetermeer, The Netherlands), $2 \mathrm{~m} / 1$ endothelial growth supplement (12), $50 \mu \mathrm{g} / \mathrm{ml}$ gentamicin. The following cell lines were used between passage 20 and 35: RHEC 3,10,11 described by Derhaag (10) and RHEC 
50,116 and 191 described by Linssen (11). All cell lines have been characterized as EC by staining with von Willebrand Factor and internalization of Dil-ac-LDL as described $(10,11)$.

\section{Infection of cells}

RHEC or REF were cultured in 96 well culture plates (Costar, Badhoevedorp, The Netheriands) till $95 \%$ confluency. The cells were washed twice with phosphate buffered saline (PBS) and incubated in infection medium (Iscove's modified Dulbeco medium (IMDM, ICN Biomedicals, Zoetermeer, The Netherlands) containing $15 \%$ FCS for RHEC and EMEM containing $2 \%$ FCS for REF) for $4 h$, and washed again with PBS. The cells were inoculated at m.o.i. of 1 or 0.2 or 0.02 with RCMV diluted in infection medium or with infection medium alone. A m.o.i. of 1 means that 1 plague forming unit ( $\mathrm{PFU}$, viral titre as determined by plague titration assay on rat fibroblasts)of $\mathrm{CMV}$ is applied per cell. The cells were either incubated with RCMV for $60 \mathrm{~min}$ at $37^{\circ} \mathrm{C}$ or centrifuged with RCMV for $45 \mathrm{~min}$ at $700 \times \mathrm{g}$ at $20^{\circ} \mathrm{C}$, followed by washing and incubation with infection medium. Enhancement of HCMV infection of human fibroblasts by centrifugational infection was previously described (13). At the indicated times after infection $(1,3,5,7$ or 13 days) viral antigens were detected by immunofluorescent staining as described below. Infected and uninfected cells were examined daily for appearance of cytopathic effect.

To investigate if soluble factors in culture supernatants of non-infected RHEC monolayers may influence the CMV permissiveness of RHEC, culture supernatants of every cell line were prepared by incubating the RHEC monolayers with infection medium for $24 \mathrm{~h}$. The permissive cell lines (RHEC 3, 10, 11 and 116) were pre incubated for $4 \mathrm{~h}$ with the culture supernatants obtained from non-permissive cell lines (RHEC 50 and 191), followed by infection with RCMV and subsequent incubation for 24 h with the same culture supernatants. Concomitantly, non-permissive cell lines were incubated with the culture supernatants obtained from permissive cell lines. Infection with RCMV (m.o.i. = 1) and detection of virall antigens was performed as described above. 
To investigate their susceptibility to second RCMV infection, RHEC monolayers were infected with RCMV (m.o.i. = 1) as described above and viral antigens were detected by immunofluorescence staining at the indicated times after infection (day 13, 15, 17 and 19 post infection (p.i.)). Non-infected RHEC monolayers were used as controls.

\section{Detection of viral antigens by immunofluorescence}

At the indicated timed, culture supernatants were removed and cells were fixed with $3 \%$ formaldehyde in PBS for $15 \mathrm{~min}$ at room temperature. The cells were permeabilised in $0.05 \%$ Nonidet P40 in PBS for 10 in at RT. After blocking with PBS containing $1 \%$ bovine serum albumin (BSA), cells were incubated with a mixture (1:1) of mab 8 and 35 against nuclear $(41,46$ and $91 \mathrm{kD}$ ) and cytoplamic $(29 \mathrm{kD}) \mathrm{RCMV}$ antigens (14)diluted 1 in 350 in PBS containing 0.1\% BSA, followed by a second step incubation with FITC labeled rabbit anti mouse IgG (TTK, Uithoorn, The Netherlands) dihuted 1 in 80. As a control for non-specific staining, infected and non-infected cells were incubated with an anti human CMV mab of the same subclass non reactive with RCMV. For total nuclei staining, 4,6-diamino-2-phenilindole (DAPI $0.5 \mathrm{ng} / \mathrm{ml}$ ) in PBS containing 2.3\% 1.4-daizo-bicyclo-(2,2,2)-octane (DAPCO) was added to the wells. Positive FITC fluorescent cells and total nuclei were counted in triplicate wells (3. microscopic fields per well) using a Zeiss axiovert 100 inverted microscope equiped for epifluorescence, and percentage infection was calculated.

\section{Detection of detachment of infected cell}

At indicated times after infection of RHEC the culture supernatant was recovered under gentle agitation and fixed with $3 \%$ formaldehyde. Cytospin preparations were made at $600 \mathrm{rpm}$ for $8 \mathrm{~min}$ using a Shandon cytofuge. Infected cells were detected by immunofluorescence staining as described above. Only intact stained nuclei were counted, excluding cellular debris. 
Detection of infectious virus production.

Infectious virus production by plague titration assay is based on lytic viral infection in permissive REF. REF were grown to $95 \%$ confluency in 24 well plates (Greiner, Frickenhausen, Germany) and were incubated with serial dilutions of the RHEC or REF supernatants in infection medium. After $1 \mathrm{~h}$ at $37^{\circ} \mathrm{C}$, the cells were refreshed with $0.6 \%$ agarose (Seakem, FMC, Rockland, ME, USA) containing basal eagle medium (BME, Gibco BRL, Breda, The Netherlands), $2 \%$ FCS and $50 \mu \mathrm{g} / \mathrm{ml}$ gentamicin. After 7 days incubation, the cells were fixed with $3.7 \%$ formaldehyde and stained with $0.5 \%$ cristal violet. The plagues were counted and expressed as infectious plaque forming units per milliliter (PFU/ML)

\section{Detection of infectious virus transmission}

Transmission of infectious virus is measured based on viral antigen detection. REF and RHEC were grown to 95\% confluency in 96 well culture plates. At indicated times after infection, the culture supernatant of infected RHEC was harvested under gentle agitation and centrifuged at $400 \mathrm{xg}$ for $10 \mathrm{~min}$ at room temperature. The cell fraction was obtained and resuspended in an equal amount of infection medium. The cell fractions were incubated with either REF monolayers or with new RHEC monolayers for detection of viral transmission from detached RHEC to REF or new RHEC monolayer, respectively. After $24 \mathrm{~h}$ incubation, REF and RHEC were fixed with $3 \%$ formaldehyde and infection was measured by immunofluorescence staining as described above. 


\subsection{Results}

RCMV Infection of Rat Endothelial Cell Lines and Rat Fibroblasts.

Although in wivo data show that EC from the microvasculature are involved in CMV associated pathology, most in witro results have been obtained using EC from the macrovasculature. In this study we used a series of six microvascular endothelial cell lines, which have been shown to be representative for the heterogeneity of rat heart endothelium in vivo $(10,11)$. These rat endothelial cell lines (RHEC) were infected with RCMV at m.a.i. of 1 and 0.2 with and without centrifugation. Centrifugation is known to cause enhancement of CMV infection (13). After removal of the inoculum, the cell lines were supplied with fresh medium and fixed at day $1,3,5,7$, or 13 p.i. The cell lines showed distinct differences in viral antigen expression as determined by immunofluorescence staining (Fig. 1).

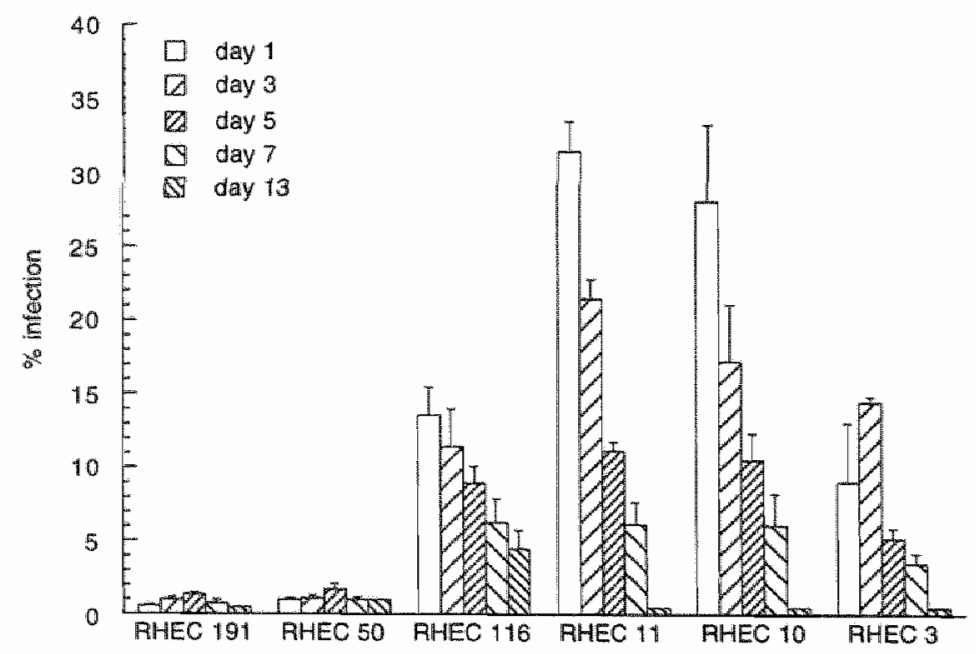

Figure 1: Infection of six rat heart endothelial cell lines (RHEC) with RCMV. The cell monolayers were centrifugational infected with RCMV at m.o.i. of 1 . At the indicated time post infection, the amount of infected cells, expressed as percentage of the total cells in the monolayer, is shown as detected by innuunofluorescence staining. Data are shown from one experiment (performed in triplicate) representautve of six experiments performed. 
Without centrifugation, a low level of viral antigen expression was found in RHEC 10 and 11 monolayers ( $<2 \%$ infection) while infection of RHEC 3, 50, 116 and 191 was below the detection limit (data not shown). After centrifugational infection (m.o.i. $=1$ ), viral antigen expression at day 1 p.i. was detected in $30 \%$ of RHEC 10 and RHEC 11 monolayers, in $14 \%$ of RHEC 116 and in $9 \%$ of RHEC 3 (Fig. 1). Only a few infected cells were detected in RHEC 50 and RHEC 191 monolayers $(0.8 \%)$. When using a lower virus titer (m.o.i. $=0.2$ ) comparable differences between the cell lines were found with much lower levels of infection. These differences in CMV permissiveness did not correlate with the previously studied differential characteristics of these cell lines (10). Foci of infected EC developed starting at day 2 p.i. These infected cells were rounded and emerged from the monolayer while staying adhered (Fig. 2). Enlarged nuclei and clustering of infected cells were detected in RHEC 116, and more pronounced in RHEC 3, 10 and 11. Such morphological changes were not observed in RHEC 50 and 191 or in uninfected cells. 

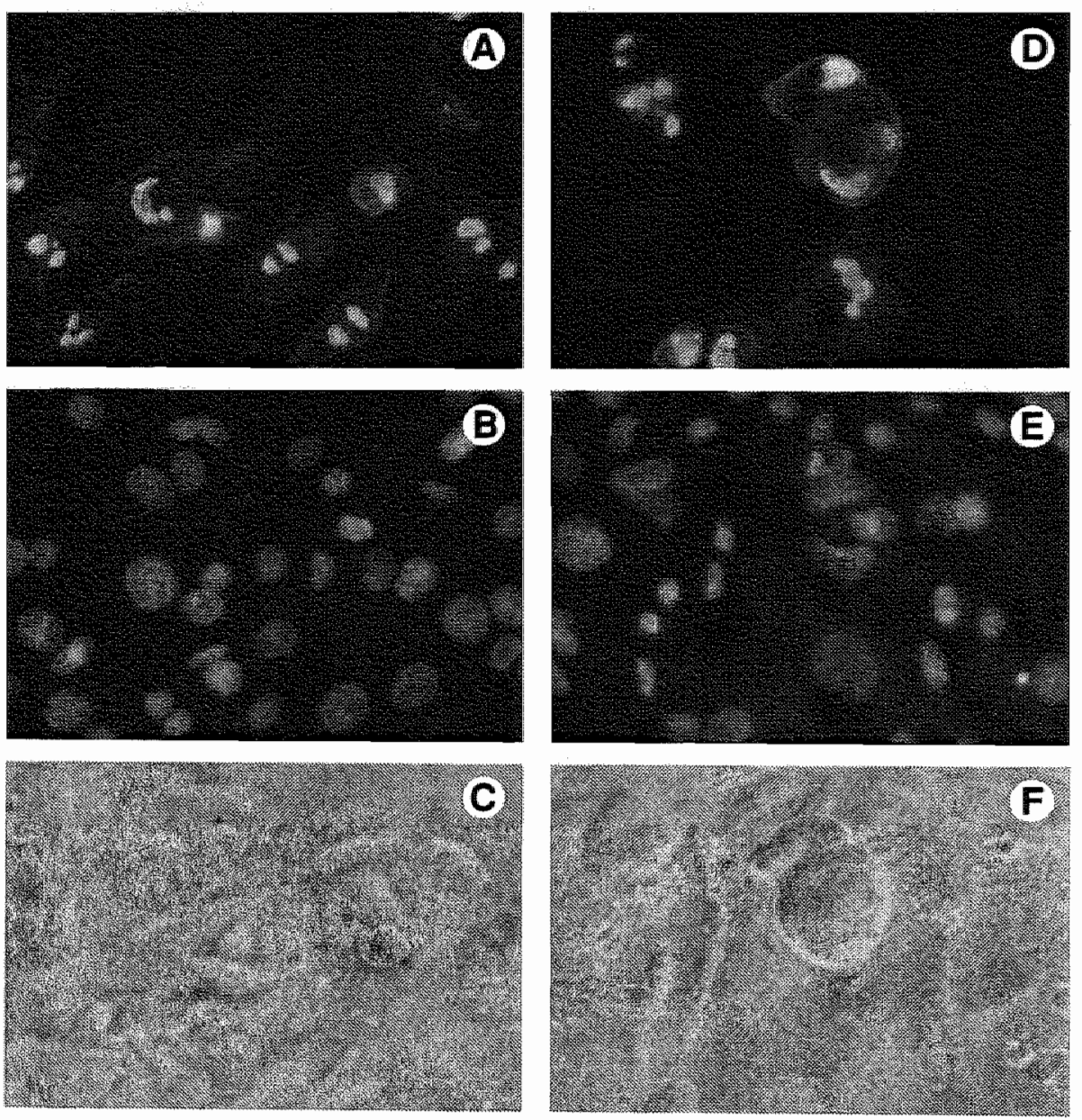

Figure 2: Morphological changes induced by RCMV infection of a rat endotheliall cell line. The monolayer of RHEC 3 is shown at day $1(A, B, C)$ and at day $3(D, E, F)$ after centrifugational infection (m. o. $i_{0}=1$ ): RCMV positive antigens are indicated $(A, D)$, total nuclei $(B, E)$ and the monolayer morphology $(C, F)$. Notice the enlargement of the nuclei, and rounding up and clustering of the infected cells at day 3. Original magnification $x 400$. 
The number of infected EC in the monolayer tended to decline, which is in contrast to infected rat embryonal fibroblasts (REF) monolayers in which the number of infected cells increases with time. At day 13 p.i. only a few infected cells were detectable within the monolayer of all endothelial cell lines. This may be due to detachment of infected cells from the monolayer, as infected cells were detected in cytospot preparations of the culture supernatants of RHEC $3,10,11$ and 116. At days 1 and 3 post RCMV infection only a few detached cells were found in the culture supernatant, while detached infected cells (30-40\%) were observed at days 5 and 7 (data not shown). It can not be rulled out that lysis of CMV infected cells may also contribute to a relative decrease of the number of infected cells in the endothelial monolayer.

RCMV infection of REF (infected at m.o.i. of 1, 0.2, 0.02 ) differed from that of RHEC in that the infection rate in REF was much higher (depending on viral input) and that almost $100 \%$ infection of the monolayer was reached in time (Table 1). Detached infected cells were observed in cytospin preparations from 1 and 0.2 . detachment of the whole monolayer, due to complete infection, was observed at day 4 p.i. for m.o.i. of 1 and 0.2 and at day 5 for m.o.i. of 0.02

\section{Infection course of rat embryonal fibroblasts (REF)}

$$
\text { m.o.i. }=1 \quad \text { m.o.i. }=0.2 \quad \text { m.0.i. }=0.02
$$

\begin{tabular}{llll}
\hline Day 1 & $74(4)$ & $52(1)$ & $19(2)$ \\
Day 2 & $93(3)$ & $88(3)$ & $58(3)$ \\
Day 3 & $95(3)$ & $94(2)$ & $66(3)$ \\
Day 4 & $\mathrm{X}$ & $\mathrm{X}$ & $83(4)$ \\
Day 5 & $\mathrm{X}$ & $\mathrm{X}$ & $\mathrm{X}$
\end{tabular}

Table 1: The infection level of the monolayer (expressed as percentage infection; number of infected cells per total cells) is shown at the indicated time after centrifugational infection with RCMV at mo.i. of $1,0,2$ or 0.02 , as detected by immumofluorescence staining From day 4 post infection at mo.i. of 1 and 0.2 and from day 5 at m.0. $\hat{1}$. of 0.02 the whole REF monolayer was detached, indicated by an $X$, and a high level of RCMV infected cells were detected in the culture medium. Data are expressed as percentage infection (SED). Data are shown from one experiment (pwerformed in triplicate) representative of two experiments performed. 
Production of Infectious Virus by Rat Endothelial Cell Lines and Rat Fibroblasts.

To study whether infectious virus was produced by RHEC, the culture supernatant was obtained from infected RHEC monolayers at different time points post infection. Infected REF monolayers were used as control. Infectious virus production of RHEC was compared with that of REF using a plaque titration assay on REF monolayers. As shown in Fig. 3, infectious virus was produced by RHEC 3, 10, 11 and 116 monolayers, while only low amounts of virus $(<2300 \mathrm{PFU} / \mathrm{ml}$ ) was recovered from RHEC 50 or 191 monolayers. In comparison, extracellular infectious virus production of REF was much higher and started earlier than that of RHEC (Fig. 3).

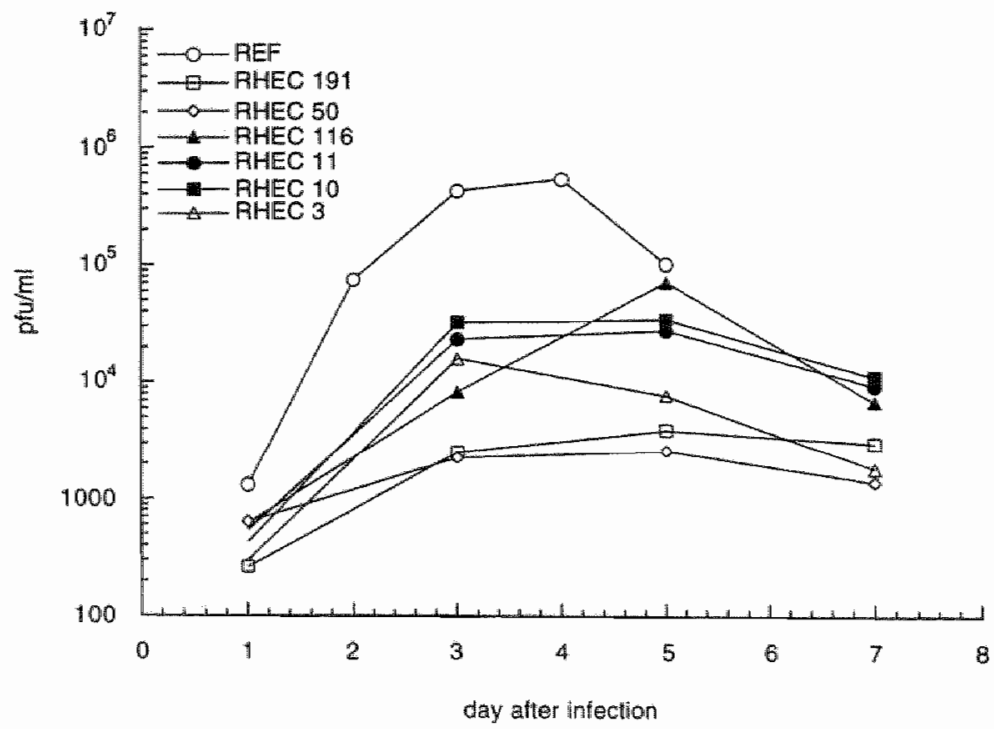

Figure 3: Comparison of infectious virus production by RHEC and REF monolayers. At the indicated time after infection, the release of infectious virus in the culture supernatants of RHEC and REF was measured by plaque titration assay on REF monolayers. Data are shown from one experiment representatiwe of three experiments performed. Infectious virus production by REF was detected earlier and with a higher virus titer compared to that of RHEC. 
Investigation of the Differences in Susceptibility to CMV Infection of Rat Endothelial Cell Lines.

To investigate whether soluble factors released by the rat endothelial cell lines are responsible for the differences in permissiveness for RCMV, the influence on CMV infection of culture supernatants, obtained from the different RHEC monolayers, was investigated. For this purpose, permissiwe cell lines (RHEC 3, 1011 and 116) were incubated with culture supernatants obtained from uninfected non-permissive cell lines (RHEC 50 and 191). Non-permissive cell lines were also incubated with supernatants from uninfected permissive cell lines. No influence of culture supernatants on the infection levels were observed in all experiments (data not shown) suggesting that factors constitutively released by RHEC are not involved in the observed differences in CMV permissiveness.

To investigate whether detached cells from the CMV infected RHEC monolayer were able to transmit CMV to other cells, the following experiments were perforned. At different time points after infection, detached RHEC were incubated with REF and new RHEC monolayers and the infection of these REF and RHEC monolayers was monitored by immunofluorescence staining. As shown in Fig. 4, detached RHEC were able to infect REF monolayers, indicating that the detached EC contain infectious virus. However no infection of the RHEC monolayers was observed (data not shown). Also stimulation of RHEC monolayers by centrifugation did not have any effect. It is likely that the amount of infectious virus in detached RHEC is high enough to infect fully permissive REF monolayers, but too low for infection of new RHEC monolayers. These results suggest that, although detached EC can play a role as a transport vehicle of infectious virus, transmission of the infection to other cells may be limited depending on the cell type.

Contrary to fibroblast monolayers, which detached completely after CMV infection, we observed no spreading of CMV through the endothelial monolayer but detachment of the infected EC, which suggests recovery of the endothelial monolayer from CMV infection. We therefore investigated whether endothelial monolayers, that had 
previously been infected by $\mathrm{CMV}$, showed an altered susceptibility to CMV infection. For this purpose RHEC monolayers were tested 2 weeks after the first infection, when the amount of infected cells in the monolayer had decreased to less than $2 \%$ (see Fig. 1). RHEC at day 12 p.i. and previously uninfected RHEC at days 1 or 12 after confluency were infected with RCMV (m.o.i. = 1). We found that re-infection of previously infected RHEC monolayers resulted in a comparable infection level as in primary infected RHEC (data not shown). This indicates that the permissiveness for CMV infection of the endotheliat monolayer is not influenced by a previous infection chalienge, suggesting recuperation of the monolayer.

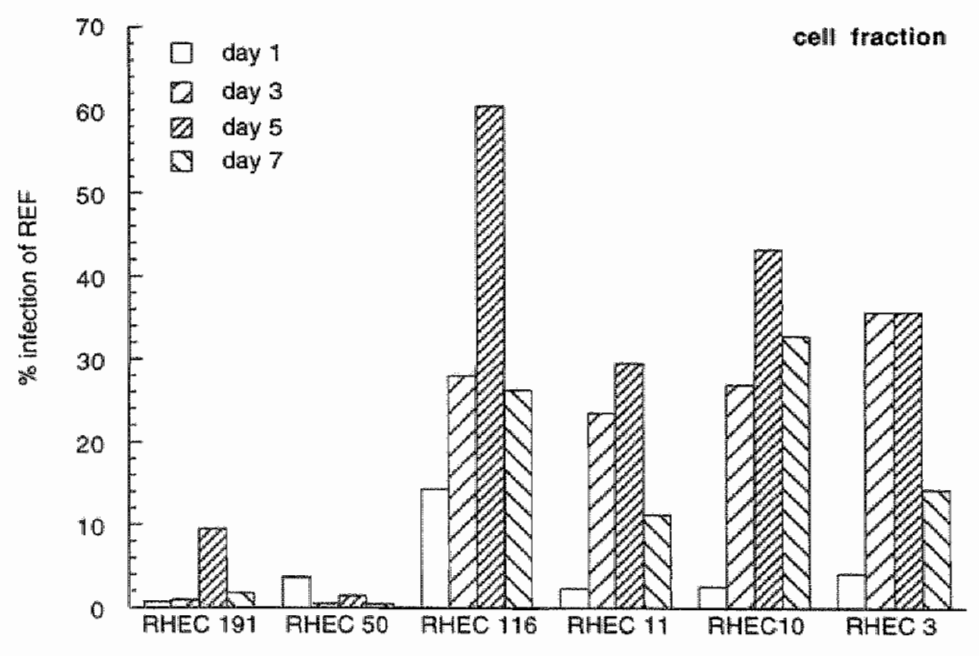

Figure 4: Transmission of CMV infection by detached infected RHEC. At the indicated time, virus transmission of detached infected RHEC to REF was measured by incubation of REF monolayers with the cell fraction of infected RHEC culture supernatants. REF infection was detected by immunofluorescence staining. Data are shown from one experiment representative of two experiments performed. 


\subsection{Discussion}

Microvascular EC have been suggested to play a rolle in CMV-related pathology. Therefore, it was attractive to investigate the interactions of CMV with microvascular endothelium in vitro. We used a series of six rat heart endothelial cell hines, which are considered representative for heterogeneity of the heart endothelium in vivo. We observed that these cell lines displayed differential susceptibility to RCMV infection and that, contrary to monolayers of fibroblasts, endothelial monolayers did not reach a $100 \%$ infection level, despite the fact that infectious virus could be obtained from the culture supernatants. In addition, most of the infected EC detached from the monolayer. From these intriguing observations, we hypothesize that $\mathrm{EC}$ can resist a CMV infection to a certain extent and, in addition, infected endothelial monolayers dispose of the virus via detachment of the infected cells. This points to a barrier function of the inner lining of blood vessels in vivo. Such a defensive role for EC against CMV infection is also suggested by experimental results obtained in the in vivo rat model (15). In this model it was observed that removal of the endothelial lining of the vessel by balloon denudation resulted in CMV infection of the exposed smooth muscle cells, while infection of smooth muscle cells was not observed when these cells were covered with intact endothelium.

Previous in vitro studies learned that, irrespective of the source, EC only be infected to a limited extent." There is no satisfying explanation for the low permissiveness of EC for CMV, but several factors seem to be involved such as the virus strain used and the origin of the cells. Several laboratory strains of human CMV reach only $5-15 \%$ infection in human umbilical vein EC (HUVEC), Towne strain (16), Kerr strain (17), $A D 169$ (18), and EC of neural origin appear more susceptible than large vessel HUVEC (19). In addition, HUVEC seems more permissive to low passage clinicial CMV isolates and to endothelial propagated virus(20,21).

Until now mostly large vessel EC originating from human umbilical cords were used to study the virus-endothelial cell interactions in vitro, but according to in vivo findings it would be appropriate to use EC from the microwasculature in such investigations. By using a series of six different endothelial cell lines, originating from 
the rat heart microvasculature $(10,11)$, we observed distinct differences in susceptibility to RCMW infection. The rat endothelial cell lines RHEC 50 and 191 were practically nonpermissive, while RHEC $3,10,11$ and 116 were partly permissive for RCMV infection. Why the endothelial cell lines show such a variation in susceptibility to infection with RCMV is an intriguing question especially considering the common origin of the cells (heart microvasculature). In addition to the observed differences in phenotypic and functional characteristics $(10,11)$ these endothelial cell lines displayed also heterogeneity with respect to CMV permissiveness. Our observations are suggestive of endothelial heterogeneity for CMV infection in the heart microvasculature and possibly in other organs in vivo.

Several factors may contribute to the observed differences in endothelial permissiveness for RCMV: (i) limited entrance of CMV due to variable expression of endothelial receptors for binding or fusion of $\mathrm{RCMV}$; (ii) differences in viral gene expression or viral replication; and (iii) a release of endothelial factors which may interfere with CMV infection.

The first option, differences in CMV binding or fusion, is suggested by several studies with human CMV showing that cells express various host cell receptors for CMV: class I HLA (22), CD13 (23), the gH receptor (24), and annexin II (25). The variability in permissiveness for RCMV found in the different rat endothelial cell lines could thus be due to differences in receptor expression.

The second option, interference with expression of viral DNA in EC, is suggested by observations in other cell types. Restriction of CMV replication in vitro by differentiation-specific negative regulators of the expression of CMV immediate early proteins (26) may point to this option.

Finally, the secretion by the endothelium of factors which may interfere with the infection process, is suggested as the third option. Although our experiments with culture supernatants suggested that constitutively released (stable) factors are not involved in the differential permissiveness observed, it can not be ruled out that inhibition of infection of neighbouring EC via cell-cell contact occurs. Such a phenomenon has been described 
recently for herpes virus (HSV-1) infection in polarized MDCK cells, suggesting a role for tight junctions in HSV-1 infection (27).

Our results indicate only limited CMV infection of the rat endothelial cell lines and, in spite of production of infectious virus, no spreading of CMV infection in all endothelial monolayers comparable with that seen in fibroblasts. Furthermore, our observations suggest that the endothelial monolayer is able to recover from the CMV challenge ( 2 weeks after infection) after detachment of the infected cells. From this we conclude that in our in vitro system the endothelial monolayer may constitute a barrier to CMV infection.

The observed detachment of infected EC from the monolayer may be caused by an altered interaction of the cells with extracellular matrix proteins as is described for human CMV infection (28). Our in vitro finding is in agreement with the in wivo observation that circulating infected EC are found in immunocompromised patients with an active CMV infection (6). It has been speculated that these circulating infected EC may contribute to CMV dissemination throughout the body (6). Our in vitro results, however, indicate that transmission of CMV infection from the detached infected cells is limited to fully permissive cells like fibroblasts, whereas the endothelial monolayer seems resistant. This suggest that on the one hand limited permissiveness to CMV infection and detachment of infected cells would contribute to a barrier function of the EC, but on the other hand a role for circulating infected $\mathrm{EC}$ in $\mathrm{CMV}$ dissemination throughout the body can not be ruled out. To elicit a possible role in dissemination, further investigations of the interactions of these detached infected EC with other cell types are necessary. 
Acknowledgements: The authors thank Dr. Marieke Dormans-Linssen for the RHEC 50,116 and 191 cell lines, and Annemie Gijssen for technical assistance with culturing RHEC 3,10 and 11 .

\subsection{References}

1. Bruggeman CA, Dam-Mieras van MCE. The possible role of cytomegalovirus in atherogenisis. In: $\mathbb{L}$ Melnich (Ed) Progress in Medical Virology, Karger, Basel 1991; 1.

2. Hayry PJ, Alatali S, Myllamiemi M, Raisanen-Sokolowski A, Lemstrom KB. Cellular and molecular biology of chronic rejection. Transplantation Proceedings 1995; 27:71.

3. Melnick JL, Adam E, Debakey ME. Cytomegalovirus and atherosclerosis. European Heart Journal $1993 ; 14: 30$

4. Meyerson D, Hackman RC, Nelson JA, McDoughall JA. Widespread presence of histologically occult cytomegalovirus. Hum Pathology 1984; 15: 430.

5. Roberts WH, Sneddon JM, Waldman J. Stephens RE. Cytomegalovirus infection of gastrointestinal endothelium demonstrated by simultaneous nucleis acid hybridization and immunohistochemistry. Arch Pathol Lab Med 1989; 113: 461.

6. Grefte JMM, Giessen van der M, Son van WJ, The TH. Circulating human cyiomegalovirus (HCMV)-infected endothelial cells in patients with an active HCMV infection. Joumal of Infection diseases 1993; 167: 270 .

7. Stals FS, Eosman $F$, Boven van CP, Bruggeman CA. An animal model for therapeutic intervention studies of CMV infection in the immuno-comprimised host. Arch Virol 1990; 114: 91.

8. Persoons MCJ, Stals FS, Dam-Mieras wan MCE, A. BC. Multiple organ involvement during experimental cytomegalovirus infection is associated with disseminated vascular pathology. 1996; subminted.

9. Stals FS, Steinhof $\mathrm{G}_{\mathrm{.}}$ Wagenaar $\mathrm{SS}$, et al. Cytomegalowirus induces interstitial lumg diseases in allogeneic bone marrow transplani recipients rats independent of acute graft versus host response. Laboratory Investigation $1996 ; 74: 452$.

10. Derhaag J, Duijwestijn A, Emeis J, Engels W, Breda Vriesman van P. Production and characterization of spontaneous rat-heart endothelial cell lines. Laboratory Investigations 1996; 74: 437.

11. Linssen MCJG, Nieuwenhoven van FA, Duijvestijn AM, Glatz JPC, Vusse van der GJ. Continuous endothelial cells from adult rat heart. In Vitro cell Dev Biol 1993; 29 a: 611.

12. Maciag T, Cerendulo J, Isley S, Kellu PR, Forand R. An endothelial growth factor from bovine hypothalamus: identification and partial characterization. Proc Natl Acad Sci USA 1979; 76: 5674.

13. Hudson JB. Further studies on the mechanism of centrifugal enhancement of cytomegalovirus infectivity. Journal of Virological Methods 1988; 19:97.

14. Bruning JH, Bie de WHM, Dormans PHJ, Meijer $H_{\text {. Broggeman } C A}$. The development and characterization of monoclonal antibodies against rat cytomegalowirus induced antigens. Arcg Virol $1987 ; 94: 55$.

15. Persoons MCJ, Daemen MJAP, Bruning JH, Bruggeman CA. Active cytomegalovirus infection of arterial smooth muscle cells in immunocomprimised rats. A clue to herpes-associated atherogenenisis. Circulation Research 1994; 75: 214.

16. Smiley HL, Mar E. Cytomegalovirus infection and viral induced transformation of human endothelia] cells. Journal of Medical Virology $1988 ; 25: 213$.

17. Span AHM, Boven var CPA, Bruggeman CA. The effect of cytomegalovirus infection on the adherence of polymorpho-nuclear leucocytes to endothelial cells. European Joumal of Clinical Investigation 1989; 19:542. 
18. Geelen var AGM, Slobbe van Drunen MEP, Muller AD, Bnggeman CA, Dam-Mieras van MCE. Membrane related effects in endothelial cells induced by human cytornegalovirus. Arch Virol 1995 ; 140: 1601 .

19. Lathey $\pi_{*}$ Wiley CA, Verity MA, Nelson JA. Cuitured human brain cappilary endothelial cells are permissive for infection by human cytomegalovinus. Virology 1990; 176: 266.

20. Ho DD, Rota TR, Andrews CA. Hirsch MS. Replication of human cytomegalovirus in endothelial cells. Journal of Infection diseases 1984; 150:956.

21. Waldman Wj, Snaddon JM, Stephens RE, Roberts WH. Enhanced endothelial cytopathogenicity induced by a cytomegalovirus strain propagated in endothelial cells. Journal of Medical Virology 1989: 28: 223.

22. Grundy JE, McKeating JA, Ward PJ, Sanderson HR, Griffiths PD. B2 microglobulin enhances the infectivity of cytomegalowirus and when bound to virus enables class I HLA molecules to be used as a virus receptor. Journal Gen Virol 1987; 68: 793.

23. Soderberg $C_{\text {f }}$ Giugni TD, zaia JAL S., Wahlberg JM, Moller E. CD13 (Human aminopeptidase N) mediated human cytomegalovirus infection. Journal of Virology 1993; 67: 6576.

24. Keay S, Merigan TC. Rasmussen $\mathrm{L}$. Idemtification of cell surface receptors for the 86-kilodalton glycoprotein of human cytomegalovirus. Proc Natl Acad Sci USA 1994; 86: 1.0100.

25. Wright JF, Kurosky A, Wasi S. An endothelial cell-surface form annexin II binds human cytomegalovirus. Biochem Biophys Res Commun 1994; 198: 983.

26. Taylor-Wiedeman J, Sissons P, Sinclair J. Induction of endogenous human cytomegalovirus gene expression after differentiation of monocytes from healthy carriers. Journal of Virology $1994 ; 68$ : 1597.

27. Hayashi $\mathrm{K}$. Role of tight junctions of polarized epithelial MDCK cells in the replication of herpes simplex virus type I. Joumal of Med Virol 1995; 47: 323.

28. Pande $H$, Terramani T, Tressel T, Churchill MA, Hawikins GG, Zaia JA. Altered expression of fibronectin gene in cells infected with human cytomegalovirus. Journal of Virology 1990; 64: 1366. 


\section{Effects of antibody reactivity to MHC and non-MHC} alloantigens on graft endothelial cells in heart allograft rejection

Josien G. Derhaag, Adrian M. Duijuestijn, Jan G. M. C. Damoiseanx and Peter J. C. van Breda Vriesman.

Department of Immunology, $\mathrm{CARIM}_{*}$ Maastricht University, P. O. Box 616 , $6200 \mathrm{MD}$, Maastricht, The Netherlands

Submitted for publication. 


\section{Abstract}

To gain insight in the pathogenesis of vascular lesions in heart allograft rejection, we investigated effects of allosera reactive with $\mathrm{MHC}$ or non-MHC alloaritigens on graft endothelial cells (EC) in a rat transplantation model.

Anti MHC and anti non-MHC allosera were obtained from BN (RT. In) reciplents of a Lewis (RT.11) or congenic LEW.1N (RT.1n) heart allograft respectivily. Reactivity with endothelial alloantigens was studied in vitro using a series of 3 rat-heart endothelial-cell (RHEC) lines of Lewis origin. Phenotypic studies of $\mathrm{MHC}$ and non-MHC alloantigen expression "complement activation, and adhesion molecule induction on EC were performed by immunostaining and FACS analysis. Complement-mediated cytotoxicity of allosera was studied using a $51 \mathrm{Cr}$ release assay.

Both anti MHC allosera and anti non-MHC allosera showed reactivity with all 3 RHEC lines. EC stimulation with TNF $\alpha$ and IFN $\gamma$, resulted in upregulation and induction of MHC class I and II antigens respectively, but not of non-MHC alloantigens. Anti MHC allosera showed distinct complement-mediated cytotoxicity for EC which was increased after cytokine stimulation. With anti non-MHC allosera only low cytotoxicity was measured which was not increased by cytokine stimulation. In both anti MHC and anti non-MHC allosera allospecific IgG had similar subclass profiles, but allospecific IgM was only detected in anti MHC allosera. Complementmediated cytotoxicity of anti MHC allosera appeared effected mainly by IgM but not IgG alloantibodies. Anti MHC allosera activated complement of both guinea pig (GP) and rat origin. Anti non-MHC allosera led only to $\mathrm{C} 3$ expression of GP origin. No indications were found that alloantibody reactivity or complement activation led to EC activation processes relevant to ICAM-1 or VCAM-1 induction.

Our data show that in heart allograft rejection MHC but also non-MHC alloantigens on EC are target structures in the alloantibody response. Complementmediated cytotoxicity for graft $\mathrm{EC}$ is effected by $\mathrm{IgM}$ alloantibodies and appears to play a role in rejection of MHC but not of non-MHC mismatched heart allografts. Whether alloantibody reactivity with endothelial MHC or non-MHC alloantigens can provoke other endothelial effects relevant to graft vasculopathy requires further investigation. 


\subsection{Introduction}

Successful heart transplantation (Tx) is hampered by graft malfunctioning and eventually graft loss as a result of the recipient's immune response against graft alloantigens. The endothelium of the graft vasculature is considered a major target tissue in the rejection process because of it's direct and continuous contact with the circulating immune reactants of the recipient. Since adequate $\mathrm{EC}$ functioning is required for good graft performance and survival, interference by immune reactants with vascular homeostatic processes of $\mathrm{EC}$ contributes to the pathogenesis of graft rejection.

In allogeneic transplantation MHC class I and class II antigens are considered the most important target structures in the recipient's immune response directed to the graft. The immune reactants formed in this response are of cellular and humoral (antibody) nature $(1,2,3,4)$ and may readily interact with constitutively expressed MHC class I and, in settings of immune reactivity , induced MHC class II antigens on graft EC.

Most studies on immunological processes in allograft rejection are dealing with acute rejection, and emphasize cellular effector mechanisms and in particular the important role of $T$ cells $(5,6,7)$. Antibodies have been considered to play a minor role in acute aliograft rejection and consequently their precise effects are poorly defined. However, increasing interest in vascular rejection processes, due to it's significance in chronic rejection, has focussed on the role of anti-EC antibodies in development of graft vasculopathy. It appears that in this respect antibody reactivity with EC effects various processes in the graft vasculature. Recently it has been shown that antibodies can activate or perturb EC (B), triggering processes that lead to alterations in endothelial integrity. For instance complement activation on EC by $\mathrm{Ab}$ results in production of substances relevant for coagulation processes $(9,10,11)$ and the induction of endothelial cell adhesion molecules for leukocytes $(12,13)$. This induction of adhesion molecules such as ICAM-1, VCAM-1 and E-selectin appears to result from autocrine stimulation by newly formed endothelial $\mathrm{IL}-1 \quad(13,14)$. 
Complement activation also leads to the formation of split products of early complement components such as $\mathrm{C} 3 \mathrm{a}$ and $\mathrm{C} 5 \mathrm{a}$ which influence recruitment and effector functions of platelets and leukocytes (15). This series of antibody effects provokes local inflammatory processes contributing to development of vasculopathological lesions.

Alloantibody reactivity with EC may also have other effects relevant for development of graft vasculopathy. When alloantibodies on EC activate complement, this may lead to formation of the membrane attack complex (MAC or C5b-9) and subsequent EC lysis. In fact, next to such complement-mediated cytotoxic effects of alloantibodies, anti-EC alloantibodies facilitate EC destruction through the processes of anti-body-dependent-cell-mediated-cytotoxicity (ADCC) $(16,17)$. Whereas MHC molecules can be considered the most dominant antigens in alloantibody reactivity with graft EC, a series of studies have demonstrated that also non-MHC alloantigens are involved in rejection processes (18). Such alloantibody reactivity with endothelial non-MHC alloantigens appears associated with vasculopathy, and in particular with graft arteriosclerotic lesions $(19,20)$.

To define whether in heart allograft rejection alloantibodies to endothelial MHC and non-MHC alloantigens play a role in the development of graft vasculopathy, we used a heart allograft model in the rat in combination with in vitro cultures of heart EC. Allosera reactive with graft MHC or non-MHC alloantigens were obtained from BN recipients of an allogeneic (LEW) or congenic (LEW.1N) heart respectively. These sera were tested for endothelial cell reactivity, complement activation, and complement-mediated cytotoxicity on non-stimulated and cytokinestimulated cultures of 3 Rat-Heart-Endothelial-Cell (RHEC) lines from LEW origin. In addition, alloantibodies reactive with EC were isotyped and it was tested whether reactivity with EC led to induction of the adhesion molecules ICAM-1 and VCAM-1. Our data show that in heart allograft rejection graft EC express, in addition to constitutively expressed MHC class I and inducible class II antigens, non-MHC alloantigens that are targets in the alloantibody response. Both anti MHC and anti 
non-MHC allosera show low complement activation and cytotoxic effects with nonstimulated $\mathrm{EC}$, but a distinct increase of the effects is measured for anti MHC allosera with cytokine-stimulated (MHC class II expressing) EC. We demonstrated that these effects are dependent on the presence of alloantibodies of the IgM type, which appear to be absent in anti non-MHC allosera. No evidence was found that alloantibody reactivity leads to activation of $\mathrm{EC}$ mechanisms effecting adhesion molecule induction. The results are discussed in the context of development of graft vasculopathy in allograft rejection. 
Chapter Fove

\subsection{Materials \& methods}

\section{Animals}

Lewis, (LEW; RT.-1l), Brown Norway $(B N ; R T .-1 n)$ and congenic Lewis $1 N$ (LEW.1N, RT. $1^{\mathrm{n}}$ ) rats were obtained from the Central Animal Facility of Maastricht University. Male rats in the age of 8 to 12 weeks were used. Animals were bred under specified pathogen free conditions and had free access to food and water.

\section{Heart transplantation and allosera collection}

Hearts were routinely transplanted heteratopically in the abdomen. In short: the donor heart aorta and artery pulmonalis were end to side anastomized to the recipient aorta abdominalis and vena cava inferlor respectively $(21,22)$. Transplantations were considered technically successful when heart beat was more than 250 beats/min on the second day after transplantation (Tx). Transplanted hearts were considered rejected when heart beat was absent or less than $100 / \mathrm{min}$. The following heart $\mathrm{Tx}$ were executed for allosera production:

1: $\quad$ LEW $\rightarrow \mathrm{BN},(\mathrm{MHC}$ and non-MHC) -mismatched;

bloodsamples were collected at the day of rejection (7-8 days after $\mathrm{Tx}$ ).

2: LEW. $1 \mathrm{~N} \rightarrow \mathrm{BN}$, non-MHC mismatched; bloodsamples were collected at day $8,16,21$ days after $\mathrm{Tx}$, and the day of rejection (29-35 days after $\mathrm{Tx}$ ),

3: $\quad$ BN $>$ BN, matched non rejected hearts; bloodsamples were collected at day 8 and 29 after $T x$.

Bloodsamples were prepared for sera and stored at $-70^{\circ} \mathrm{C}$ until use. Unless mentioned otherwise the sera used were from the day of rejection.

\section{Endothelial cells}

For in vitro EC studies $3 \mathrm{EC}$ lines from LEW heart origin were used. These Rat Heart Endothelial Cell lines RHEC 3, RHEC 10, and RHEC 11 were prepared as previously described (23). EC were routinely cultured in EC culcure medium (40\% RPMI 1640 (Gibco BRL, Life Technologies B.V., Breda, the Netherlands, $40 \%$ M199 
(Gibco BRL), $20 \%$ inactivated FCS (Integro, Belgium), $0.5 \mu / \mathrm{ml}$ bovine brain extract (14.93 $\mathrm{mg} / \mathrm{ml}$ ) prepared as described by Maciag (24), $13 \mathrm{mM} \mathrm{NaHCO}, 50$ $\mathrm{U} / \mathrm{ml}$ penicillin, $50 \mu \mathrm{g} / \mathrm{ml}$ streptomycin, $2 \mathrm{mg} / \mathrm{ml}$ Fungizone, $10 \mathrm{mM}$ Hepes, $20 \mathrm{U} / \mathrm{ml}$ heparin and $2 \mathrm{mM} \mathrm{L}$-Glutamin). Cells were cultured using $5 \% \mathrm{CO}_{2}$ in air, at $37^{\circ} \mathrm{C}$. For passaging the cells, confluent monolayers were treated with trypsin $(0.25 \%)$ EDTA $(0.2 \%)$ in phosphate buffered saline (PBS) for 1 minute. Trypsin was neutralized with EC Work medium (90\% M199 (Gibco BRL), 10\% inactivated FCS, $50 \mathrm{U} / \mathrm{ml}$ penicillin, $50 \mu \mathrm{g} / \mathrm{ml}$ streptomycin and $2 \mathrm{mM}$ L-Glutamin and $25 \mathrm{mM}$ Hepes).

\section{Cytokine stimulation of RHEC cultures}

Confluent EC monolayers were stimulated with a combination of the cytokines TNF $\alpha$ and IFNy for 24 hours. Recombinant human TNF $\alpha$ (a gift from Prof. Dr. W. Fiers, Gent, Belgium) was used in a $400 \mathrm{U} / \mathrm{ml}$ concentration. Recombinant rat

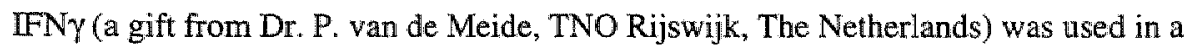
$200 \mathrm{U} / \mathrm{ml}$ concentration.

\section{Detection of allosera reactivity with $E C$}

Suspensions of EC from trypsinized monolayers were ased (see above). $5 \times 10^{5}$ cells were incubated with $5 x$ diluted heat-inactivated allosera in PBS containing $0.5 \%$ bovine serum albumin (PBSA) for 1 hr, on ice. Cells were washed 3 times with PBSA and incubated with saturating amounts of a FTC conjugated second step swine $\mathrm{F}(\mathrm{ab})_{2}$ anti rat $\mathrm{Ab}$ (DAKO, Denmark) $30 \mathrm{~min}$, on ice. After 3 times washing cells were analyzed by flow cytometry, using a FACS-sort (Becton Dickinson, Mountain View, CA, USA). Data were collected from $1 \times 10^{4}$ cells. For data analysis the program Cell Quest was used (Becton Dickinson, Mountain View, CA, USA). 


\section{Quantitation of MHC class I and MHC class II antibody-binding-sites on EC}

The numbers of $\mathrm{MHC}$ class I and II antibody-binding-sites per cell were quantitated using a Quifikit system (Dako, Denmark). As shown by Poncelet et al. (25) the thus quantitated numbers of antibody binding sites closely correlate with the actual numbers of specific antigen per cell. Briefly, EC suspensions, were incubated with saturating amounts of mouse mAb OX18 or OX6 (obtained through the ECACC, Salisbury, UK), recognizing rat MHC class I or MHC class II antigens respectively, for 1 hr on ice. Next, the cells were stained with fluorescence-labeled second step antibody (FITC-conjugated goat anti-mouse IgG (rat-adsorbed, Cappel, Organon Teknika, the Netherlands) diluted in PBSA. Cell suspensions were washed 3 times with PBSA, analyzed by flow cytometry (see abowe), and peak fluorescence intensity was determined. For calculation of numbers of binding sites per cell, a series of reference microbeads coated with known numbers of mAb binding sites was used. These reference microbeads were stained with the same fluorescence-labeled second step $\mathrm{Ab}$ as was used for the cell staining. Peak fluorescence intensities of the series of beads were measured to produce a reference line to relate peak fluorescence intensities of cell populations with numbers of specific antibody binding sites per cell.

\section{Complement-mediated cytotoxicity of alloantisera}

Cytotoxicity against EC was determined using a $5 \mathbb{1}_{\mathrm{Cr}}$ release assay. Endothelial cell suspensions were obtained as mentioned above. Suspensions of $5 \mathrm{x}$ $10^{7} \mathrm{EC} / \mathrm{ml}$ were incubated with $5 \mu \mathrm{Ci}{ }^{51} \mathrm{Cr} / \mathrm{ml}$ (Amersham International, England) in $\mathrm{EC}$ culture medium for $45 \mathrm{~min}$ at $37^{\circ} \mathrm{C}$. During labelling the cells were permanently rotated. The labeled EC suspensions were washed twice with EC Work medium and per well $1 \times 10^{5}$ cells in $25 \mu l$ were incubated with $25 \mu \mathrm{l} 5 \mathrm{x}$ diluted heat-inactivated allosera in EC culture medium, and $25 \mu$ agarose-adsorbed guinea pig (GP) or full rat serum as complement source, for $0.5 \mathrm{hr}$ at $37^{\circ} \mathrm{C}$. For some experiments IgG and nonIgG (IgM) allosera fractions, or mAb against MHC class I (OX 18) and MHC class II (OX 6) were examined for mediating cytotoxicity. In all experiments hyper immune 
serum, made by immunization of BN rats with $L E W$ LNC, was included as a standard for maximal biological release. Hyper immune serum was obtained after 3 immunizations with LNC, sera were collected 3 days after the last immunization injection. Negative controls included were medium or control Tx sera. All experiments were performed in triplicate with the 3 endothelial cell lines. $51 \mathrm{Cr}$ release was measured in a gamma counter. Percentages specific ly sis were calculated as follows: \% specific release $=((\mathrm{cpm}$ alloserum $-\mathrm{cpm}$ control $\mathrm{Tx}$ serum $) /(\mathrm{cpm}$ immune serum - cpm control Tx serum)) $x \mathbb{1 0 0 .}$

Isotyping of the anti-endothelial antibodies in allosera

$\mathrm{EC}\left(0.5 \times 10^{5}\right)$, were incubated with allosera in a $5 \times$ dilution for $1 \mathrm{hr}, 0^{\circ} \mathrm{C}$. Cells were washed 3 times with PBSA and incubated with polyclonal rabbit anti-rat IgM, IgG1, IgG2a, IgG2b, IgG2c (a generous gift from Prof. H. Bazin, VCL, Louvain, Belgium), for 1 hour on ice. Cells were washed 3 times with PBSA and incubated with FITC labeled swine $\mathrm{F}(\mathrm{ab})_{2}$ anti rabbit Ig (DAKO, Denmark) 30 min, on ice. Cells were washed 3 times with PBSA and analyzed by flow cytometry (see above).

Separation of the $\operatorname{Ig} G$ and non-Ig $G$ fractions

IgG was purified from whole alloserum by affinity chromatography on protein G sepharose (Pharmacia LKB, Woerden, The Netherlands). After IgG purification the $\operatorname{IgG}$ fraction as well as the non-IgG (IgM) fractions were used for complementmediated cytotoxicity measurements with EC. Antibody fractions were used in concentrations equivalent to allosera levels.

\section{Detection of complement activation by the alloantisera}

Cytokine stimulated $\mathrm{EC}\left(5 \times 10^{5}\right)$ were incubated for $1 \mathrm{hr}, 0^{\circ} \mathrm{C}$ with of the allosera from the different $\mathrm{Tx}$ models, $5 x$ dilluted in $0.5 \%$ PBSA. Rat or GP complement was added simultaneously (w/v/v: 1/1/1). Cells were washed 3 times with 
PBSA and incubated with directly FITC labeled polyclonal rabbit anti rat C3 serum (1/100) prepared in our laboratory, monoclonal $2 \mathrm{Al}$, a mAb against rat C5b-9 (a kind gift of W. G. Couser, Seattle, U.S.A.) or with polyclonal rabbit IgG ant GP C3 (1/100) (Kindly donated by M. Daha, Leiden, the Netherlands), $1 \mathrm{hr}, 0^{\circ} \mathrm{C}$. Cells were washed 3 times with PBSA and when a not directly labeled first step Ab was used, incubated for 30 min with FITC conjugated swine anti rabbit Ig, 1/200 in PBSA. Cells were washed 3 times with PBSA and analyzed by flow cytometry (see above).

\section{ICAM-I and VCAM-1 induction by the alloantisera}

EC monolayers were incubated with $5 x$ diluted allosera and $2 x$ diluted rat or GP complement in EC culture medium for 8 or 16 hours at $37^{\circ} \mathrm{C}$. Cells were washed and harvested using trypsin/EDTA (see above). EC suspensions were washed with PBSA and $0.5 \times 10^{5}$ cells were incubated for $1 \mathrm{hr}$ on ice with the monoclonal antibodies: OX8, used as non-relevant control Ab, RECA-1 (26), a pan endothelial marker in the rat, 1 A29 against ICAM-1 (27), and 5F10 against VCAM-1(28). Suspensions were washed three times with PBSA and incubated for 30 minutes with FITC-conjugated goat-anti mouse IgG (rat adsorbed, Cappel), diluted in PBSA. Cells were washed 3 times with PBSA and Propidium Iodide $(10 \mathrm{mg} / \mathrm{ml}$ PBSA, Calbiochem, La Jolla, U.S.A.) was added to the cells for 15 minutes to stain nonwiable cells. Data were collected by flow cytometry from $1 \times 10^{4}$ viable cells. 


\subsection{Results}

Both anti $M H C$ and anti non-MHC allosera react with $E C$

\section{Anti MHC and anti non-MHC allosera are reactive with donor heart $\mathrm{EC}$}

\begin{tabular}{|c|c|c|}
\hline & $\begin{array}{c}\text { non-stimulated } \\
\text { EC } \\
\end{array}$ & stimulated EC \\
\hline \multicolumn{3}{|l|}{ Allosera: } \\
\hline control $\mathrm{Tx}$ & - & - \\
\hline anti $\mathrm{MHC}$ & + & +1 \\
\hline anti non-MHC & + & + \\
\hline \multicolumn{3}{|l|}{ Mab: } \\
\hline OX 18 & + & +1 \\
\hline OX 6 & $=$ & $+1-$ \\
\hline
\end{tabular}

$\because$ all cells negative

$+:$ all cells positive

$+f-$ part of the cells positive

1. cytokine stimulation increased the staining intensity of the anti MHC allosera.

Table 1:

Reactivity of the allosera was measured by immunofluorescence staining and FACS analysis of EC from all three RHEC lines. Stimulation of EC was executed with the cytokines TNF $\alpha$ and IFNy for 24 hours. OX 18: monoclonal Ab against MHC class I. OX 6 : monoclonal Ab against MHC class II.

Whether anti MHC and anti non-MHC allosera recognize alloantigens on donor heart EC was studied by FACS analysis of the 3 RHEC lines. As shown in table 1, all cells of the 3 RHEC lines expressed MHC class I antigens, whereas MHC class II antigens were expressed by part of the cells $(55.7 \%)$ only after cytokine stimulation (see also Derhaag et al. (29)). Anti MHC allosera (from LEW $\rightarrow$ BN Tx) showed reactivity with all 3 RHEC lines (Table 1). Allosera reactivity was increased (higher mean fluorescence intensity) with cytokine stimulated EC. Anti non-MHC allosera (from LEW. IN->BN Tx), collected at days 8, 15, 21 and at the day of rejection, showed that reactivity with the EC of all 3 RHEC lines increased in time (Fig. 1). Cytokine stimulation of EC did not increase the reactivity of anti non-MHC 
allosera. Control Tx sera did not react with neither non-stimulated nor cytokinestimulated EC.

\section{Reactivity of antil non-MHC allosera with EC increases during rejection}

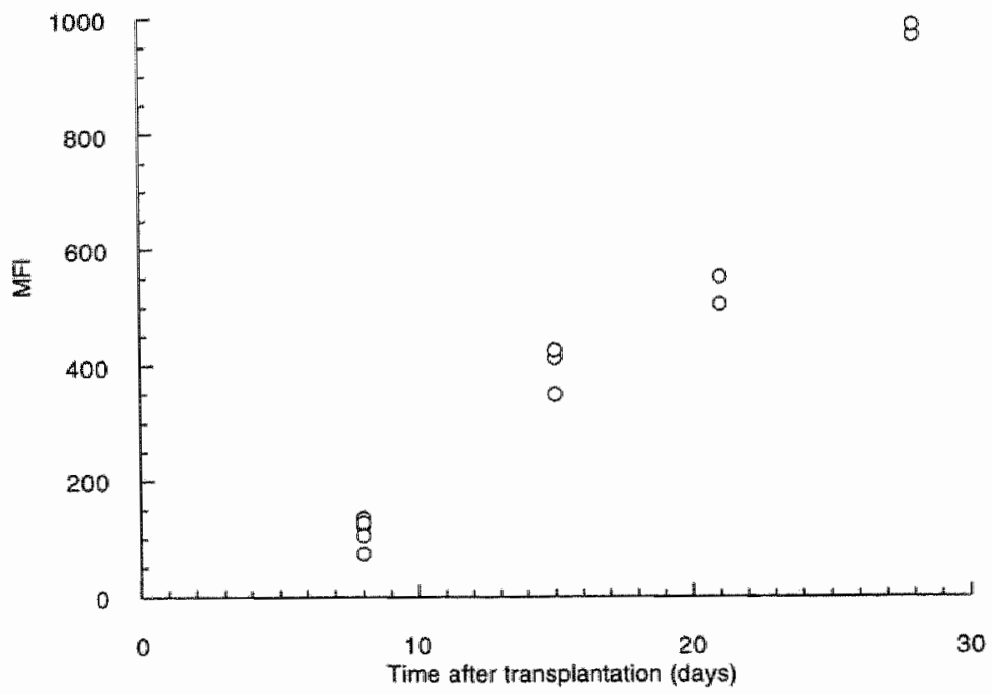

Figure 1:

Anti non-MHC allosera reactivity with EC was detected by FACS analysis. Reactivity is given in mean fluorescence intensity (MFT). Day $8: n=4$, day $15: n=3$, day $21: m=2$ and day $28: n=2$.

To gain information about expression levels of MHC class I and class II antigens on non-stimulated and cytokine-stimulated EC we quantitated these antigens on EC using the Quifikit system (Fig.2). MHC class I antigens were expressed more on cytokine stimulated EC than on non-stimulated EC $(n=3)$. While MHC class II antigens were absent on non-stimulated EC. 


\section{Expression levels of MHC class I and II antigens on EC}

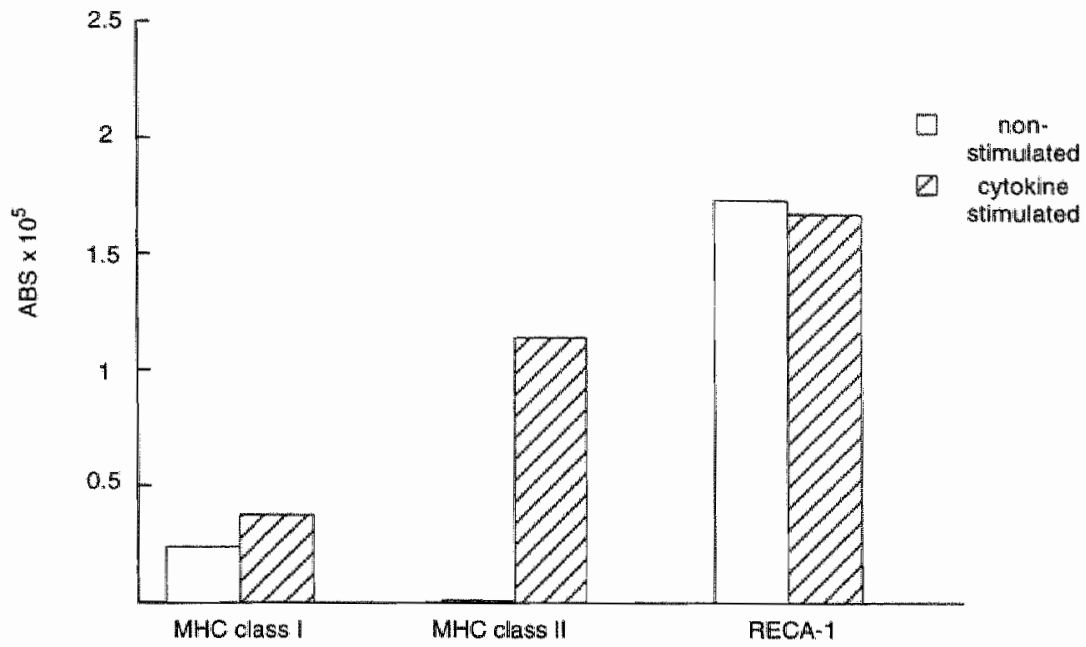

\section{Figure 2:}

MHC class I antigens on EC were detected with the mAb OX 18 and MHC class II with mAb OX6. The numbers of antibody binding sites (ABS) were determined using a Quifikit, see materials and methods. ABS were measured on EC under standard culture conditions and after cytokine stimulation. Data are of one experiment. 


\section{Anti MHC allosera are more cytotoxic for EC than anti non-MHC allosera}

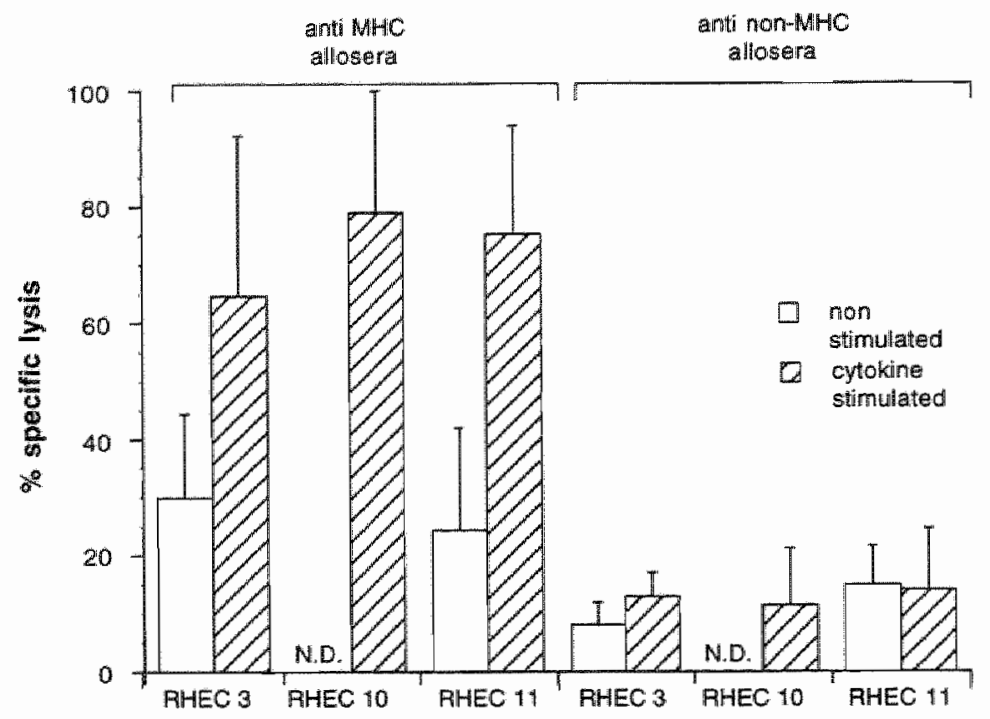

Figure 3:

51 Cr cytotoxicity tests with allosera were executed with non-stimulated and TNF $\alpha+$ IFN $\gamma(24 \mathrm{hr})$ stimulated EC of the RHEC lines, in the presence of agarose adsorbed GP complement. Experiments were executed with a series of 4 anti non-MHC and 9 anti MHC allosera. Values are means with standard deviation of 3 experiments. Specific lysis by the allosera is given as a percentage of the lysis abtained with hyper immune serum collected from BN rats immunized with Lewis lymph node cells. N.D.: not done.

\section{Anti $M H C$ allosera are more cytotoxic for $E C$ than anti non-MHC allosera}

Whether observed reactivity with donor EC leads to complement-mediated cytotoxicity was examined with EC of the 3 RHEC lines. Figure 3 shows that imcubation of EC with anti MHC allosera in the presence of complement of GP origin resulted in $25-30 \%$ lysis. When cytokine-stimulated EC were used, lysis increased to 65-75\% in the RHEC lines. Anti non-MHC allosera showed much lower cytotoxic effects on EC (10-15\% for the 3 RHEC lines), and cytotoxicity was not increased when cytokine-stimulated EC were used. When non-MHC allosera from the series of days $8,16,21$ and 29 days after $\mathrm{Tx}$ were tested, an increasing cytotoxicity was noticed $(5.7 \%, 12.1 \%, 14.1 \%$ and $21.0 \%$ respectively in one representative experiment). To study if cytotoxic effects of the allosera were different with 
syngeneic complement instead of xenogemeic GP complement, cytotoxicity experiments with LEW rat serum as complement source were executed. The use of rat complement resulted in less cytotoxicity as compared to the use of GP complement (Fig. 4).

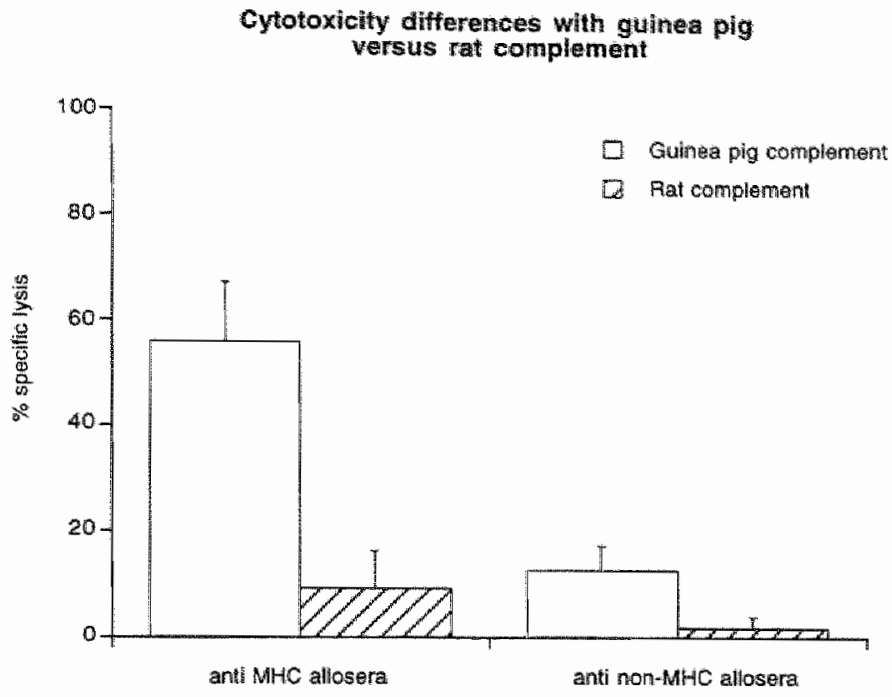

\section{Figure 4:}

51 Cr cytotoxicity tests with allosera were executed with TNFo + IFN $\gamma(24 \mathrm{hr})$-stimulated EC from RHEC 3 in the presence of either rat complement or GP complement. Experiments were executed with a series of 2 anti non-MHC and 2 anti MHC alosera. Values are means with standard devition of 3 experiments. Specific lysis by the allosera is given as a percentage of the lysis obtained with hyper immune serum collected from BN rats immunized with Lewis $\mathrm{LNC}$.

Mab OX 18 and OX 6 (both from the IgGl isotype) directed against MHC class I and II antigens respectively showed only low complement (GP)-mediated cytotoxic effects on cytokine-stimulated EC in comparison with ant MHC allosera (11.6\% for OX 18 and $6.8 \%$ for OX6 versus $65-75 \%$ for anti MHC allosera). No blocking effect was found on the cytotoxicity of anti MHC allosera when EC were preincubated with $\mathrm{OX} 18$ and $\mathrm{OX} 6$ antibodies (data no shown).

It was thought that the lower cytotoxicity measured with syngeneic rat complemeat as compared to xenogeneic GP complement could be rellated to the 
activity of syngeneic complement controlling proteins (CCP) in EC. To obtain information about this, both complement sources were tested for cytotoxic effects on sheep (xenogeneic) red blood cells (SRBC) coated with anti-SRBC Ab. GP complement showed in this system also an about five times higher activity than rat complement, indicating that low effects of rat complement in cytotoxicity of anti $\mathrm{MHC}$ and anti non-MHC allosera is likely not due to CCP activity in EC.

Allospecific $\mathrm{IgM}$ is only present in the anti MHC allosera and responsible for cytotoxicity

We investigated whether differences in cytotoxicity of anti MHC and anti non-MHC allosera was related to the class of alloantibodies in the sera. Isotyping of alloantibodies reactive with EC, performed by FACS analysis of allosera-incubated EC stained with anti-isotype specific $\mathrm{Ab}$, showed a rather similar isotype subclass profile, with the presence of all $4 \mathrm{IgG}$ subclasses, for allospecific IgG in anti MHC and anti non-MHC allosera (Fig. 5).

\section{Allospecific IgM is only present in anti MHC allosera}
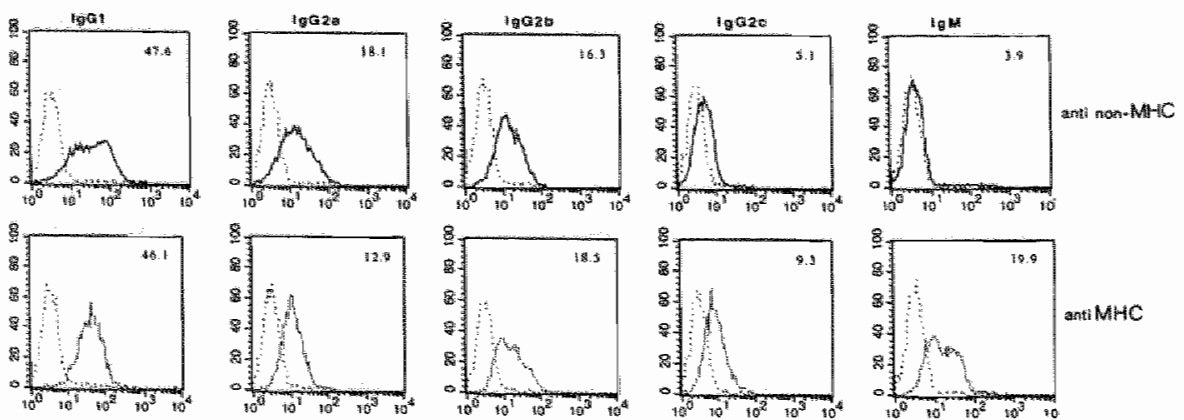

\section{Figure 5:}

Isotype distribution of the anti EC antibody response by FACS analysis. Immunofluorescence staining for the different isotypes was executed on TNF $\alpha+$ IFNY $(24 \mathrm{hr})$-stimulated EC from RHEC 3.

- : control Tw sera,

-inti $\mathrm{MHC}$ allosera

..." anti non-MHC allosera.

MFI of the experimental sera is given bn the upper right cormer. 
However, EC reactive alloantibodies of the IgM isotype were detected in anti MHC but not in anti non-MHC allosera. Even in anti non-MHC allosera collected earlier after Tx, i.e. at day 8,16 and 21 , no IgM alloantibody reactivity could be detected.

We tested if the differences in cytotoxicity against $\mathrm{EC}$ of anti MHC allosera versus anti non-MHC allosera was related to the different isotype profiles of alloantibodies in the sera, i.e. the presence and absence of IgM alloantibodies respectively. Therefore cytotoxicity tests were executed with purified IgG fractions and IgG-depleted (IgM containing) fractions of allosera (Fig.6). The purified IgG fraction of anti MHC allosera showed a dramatic decrease $(87.8 \%$ reduction) in specific lysis of cytokine-stimulated EC. In contrast the IgG-depleted (IgM containing) fraction of these anti MHC allosera showed only a small decrease in cytotoxicity ( $22 \%$ reduction). Apparently the measured complement-mediated cytotoxicity of anti MHC allosera is predominantly an effect of IgM alloantibodies. The fact that purified $\operatorname{IgG}$ fractions prepared from anti non-MHC allosera showed rather similar cytotoxicity in comparison to whole sera, indicated that the low cytotoxicity of these sera is indeed effected by IgG and not IgM alloantibodies. 


\section{Allospectific IgM is responsible for cytotoxicity}

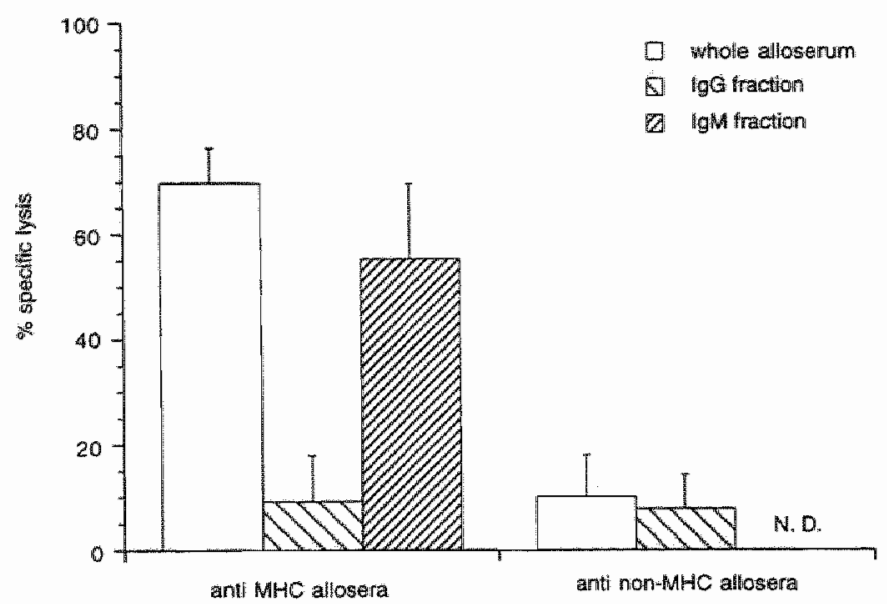

Figure 6:

51 Cr cytotoxicity tests with IgG or IgM containing allosera fractions were executed on TNF $\alpha+$ IFN $\gamma$ (24 hr)-stimulated EC from RHEC 3, in the presence of GP complement. Values and standard deviations are of ome experiment. Specific lysis by the allosera is given as a percentage of the lysis obtained with hyper immune serum from $B N$ rats immunized with Lewis lymph node cells.

Complement activation on $E C$ is effectuated by anti $M H C$ but hardly by anti nonMHC allosera

Complement-mediated cytotoxicity experiments demonstrated that lytic effects of complement activation on EC was clearly effectuated by anti MHC but only slightly by non-MHC allosera. This indirectly indicates that formation of lytic amounts of C5b-9 complexes (MAC) were triggered by binding of alloantibodies (presumably $\operatorname{IgM}$ ) from anti MHC allosera. However, sublytic amounts of MAC and also formation of the early complement activation components $\mathrm{C} 3 \mathrm{a}, \mathrm{C} 3 \mathrm{~b}$ and $\mathrm{C5a}$ on EC may contribute significantly to immunological processes relevant for vasculopathy. We therefore studied effects of anti MHC, anti non-MHC allosera and immune serum on the formation of $\mathrm{C} 3$ and $\mathrm{C} 5 \mathrm{~b}-9$ on cytokine-stimulated $\mathrm{EC}$. Bindinfg of the complement factors by the tested sera was compared to those from 
control Tx sera using the Kolmogorov-Smimov test. FACS analysis (Fig. 7) showed that immune serum and MHC allosera, incubated either with GP or rat complement, induced $\mathrm{C} 3$ formation on EC. Anti non-MHC allosera showed C3 expression levels with GP complement but not with rat complement. Effects of allosera on formation of C5b-9 complexes on EC was only studied with rat complement due to lack of antibodies to the GP C5b-9 complex. Formation of C5b-9 was induced by all sera, i.e. immune serum, anti MHC allosera, and anti non-MHC allosera. Although C $5 b-9$ expression was significantly increased, the relevance of this expression is a matter of debate since no correlation was observed with lytic activity and $\mathrm{C} 3$ binding using complement of rat origin to the same extend.
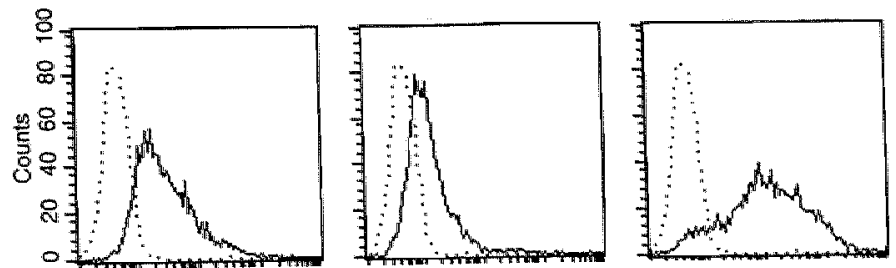

GP C3
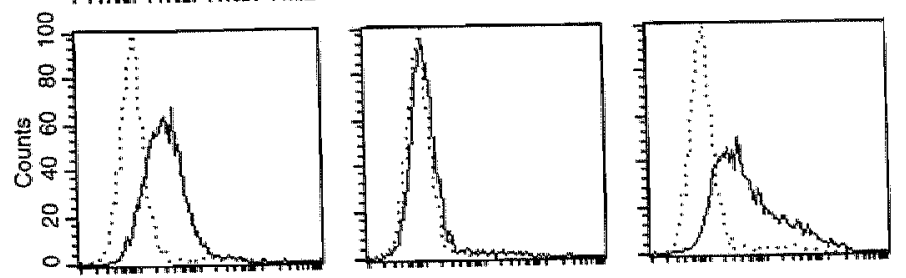

Rat C3
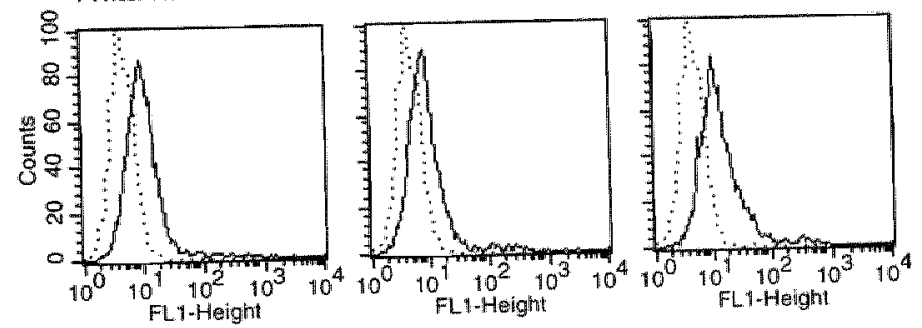

Rat C5b-9

anti MHC alloserum

$$
\begin{gathered}
\text { anti non-MHC } \\
\text { alloserum }
\end{gathered}
$$

\section{Immune \\ serum}

Figure 7: Immunofluorescence staining for $\mathrm{C3}$ and $\mathrm{CSb}-9$ (MAC) expression was performed with TNF $\alpha+\operatorname{IFN}$ (24 hr)-stimulated EC from RHEC 3. For complement activation EC werte incubated for 1 hour with either anti MHC, anti non-MHC allosera, or mmune serum in the presence of rat or $\mathrm{CP}$ complement. Binding of the complement factors by the tested sera was compared with those from control Tx sera using the Kolmogorov-Smimow test, $\mathrm{p}<0.01$. All sera significantly induce the binding of the complement factors $(p<0,01$ ), except rat $\mathrm{C} 3$ induction by anti non-MHC alloserum.

... " control Tx sera.

- : test sera. 
No induction of the adhesion molecules ICAM-I and VCAM-I

We studied if alloantibody reactivity through direct interaction with $\mathrm{MHC}$ or non-MHC alloantigens or through complement activation triggers endothelial processes leading to ICAM-1 or VCAM-1 expression. EC were incubated with anti MHC or anti non-MHC allosera in the presence or absence of complement for 8 or 16 hr followed by ICAM-1 or VCAM-1 detection by FACS analysis. In the absence of a complement source none of the allosera alone showed induction of ICAM-1 or VCAM-1 on EC after 8 or $16 \mathrm{hr}$. Also in the presence of complement, irrespective whether from rat or GP origin, ICAM-1 or VCAM-1 expression could not be detected. Apparently alloantibodies do not react with putative signalling epitopes of alloantigens involved in activation processes relevant for induction of adhesion molecules. Also complement activation with MAC formation, as demonstrated for anti MHC allosera, appears not to trigger EC processes effecting induction of ICAM1 and VCAM- 1 . 


\subsection{Discussion}

Vascular EC can be considered a primary target for the alloantibody response generated in the rejection process of heart allografts. We therefore studied effects of alloantibody reactivity with $E C$ in 2 models for rat heart allograft rejection. By using donor hearts from fully-mismatched and congenic (MHC matched but non-MHC mismatched) strains, allosera reactivity with endothelial MHC and non-MHC alloantigens respectively could be studied. Allosera reactivity was tested in witro using cultures of well characterized rat-heart-endothelial-cell (RHEC) lines with the appropriate donor MHC and non-MHC haplotype (23). Our results show that in MHC mismatched and in non-MHC mismatched heart Tx, alloantibodies reactive with graft EC are generated. Also in clinical studies allosera reactivity with endothelial alloantigens in heart allograft rejection has been described, however in these studies discrimination between HLA and non-HLA alloantigens was not further elucidated $(19,30)$. Both the anti $\mathrm{MHC}$ and anti non-MHC allosera showed reactivity with normal, non-stimulated heart EC cultures. Since in immune reactive processes such as rejection $\mathrm{EC}$ become activated by inflammatory cytokines, the allosera were also tested for reactivity with TNF $\alpha$ and IFN $\gamma$-stimulated EC. Whereas for anti non-MHC allosera reactivity no differences between non-stimulated and cytokine-stimulated EC were found, anti MHC allosera reactivity was increased with cytokine-stimulated EC. From the FACS analysis studies with anti MHC class I and class II monoclonal antibodies it can be concluded that this increase in reactivity was due to cytokineinduced upregulation and induction of MHC class I and class II antigens respectively (see also (29)). Apparently expression of non-MHC alloantigens is not influenced by cytokine stimulation. We noticed that reactivity of allosera was similar for all 3 RHEC lines, and as such this demonstrates that the heterogeneity of heart EC, as previously described in studies using these lines $(23,29)$, seems not to apply to expression of alloantigens. The EC cytotoxicity studies with the allosera showed only minor complement-mediated cytotoxicity effects of anti non-MHC allosera. The observation that for cytokine-stimulated EC no increase in cytotoxicity was noticed is 
consistent with our findings that cytokine stimulation does not affect expression levels of non-MHC alloantigens on EC. Anti MHC allosera, however demonstrated

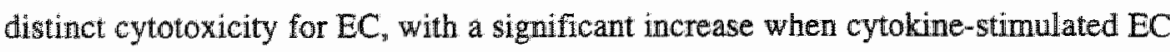
were used as target cells. Clinical heart $T x$ studies also describe complementmediated cytotoxicity by anti-EC antibodies, but notify that $\mathrm{EC}$ are relatively resistant in this respect (31). Interestingly, the cytotoxicity we measured with anti MHC allosera was effected majorly by present IgM alloantibodies. Apparently rat IgG alloantibodies have only minor cytotoxic effects. Isotyping studies of anti endothelial alloantibodies showed that this was not due to the absence of complement fixing IgG subtypes, because all 4 rat IgG isotypes, including the complement-fixing IgG2b (32), were detected. Probably the contribution of $\operatorname{IgG} 2 b$ in the alloresponse is too low for mediating distinct cytotoxic effects. The fact that anti nom-MHC allosera showed a similar IgG isotype profile of EC alloantibodies as anti MHC allosera, but in contrast were devold of $\operatorname{IgM}$ alloantibodies, is consistent with the minor cytotoxic effects of these anti non-MHC allosera. These studies suggest that in rejection of rat heart allografts, destructive complement-mediated effects of alloantibodies for graft EC only play a role in the early alloantibody response, when relatively high titers of IgM alloantibodies can be expected. The fact that anti non-MHC allosera did hardly contain $\operatorname{IgM}$ alloantibodies even at 1 week after Tx indicates that production is low and apparently entirely absorbed by graft tissue. Whether mon-MHC IgM alloantibodies present in the graft are sufficient for EC cytotoxicity remains to be elucidated. Also in renal allograft rejection, alloantibodies reactive with non-MHC alloantigens on graft $\mathrm{EC}$ have been described $(33,34,35)$ and, consistent with our studies, these antibodies showed hardly any cytotoxicity for EC (35).

We noticed that lower cytotoxic effects of alloantibodies were obtained when rat instead of GP complement was used. Also in previous studies on cytotoxicity of antibodies in renal allograft rejection this was observed (36). This lower cytotoxicity could have been effected by endothelial complement control proteins (CCP) such as decay accelerating factor and CD 59, which are known to prevent complement 
activation on homologous but not heterologous cell membranes $(37,38)$. However, no evidence was found that the lower cytotoxicity effects measured with rat complement were due to inhibition of complement activation by CCP. Since the GP serum used as complement source was agarose-adsorbed it is not likely that the relatively high cytotoxicity obtained with GP complement is a result of present natural (xeno)antibodies to rat.

Our FACS analysis studies on $\mathrm{C} 3$ and $\mathrm{C} 5 \mathrm{~b}-9$ formation on EC showed that anti non-MHC allosera gave only C3 expression with GP and not with rat complement . C5b-9 formation, which could technically only be measured in the rat complement system, was hardly present. With the anti MHC allosera distinct C3 formation was observed with GP as well as with rat complement sources. Anti MHC allosera also showed a distinct rat C5b-9 formation. The data on C3 expression induced by the allosera were consistent with the cytotoxic effects observed with these. sera, and illustrated the induction of the complement cascade necessary for cytotoxicity. Although the induction of C5b-9 could be detected, the observed differences found in the cytotoxicity tests with rat complement between immune serum and anti MHC/anti non-MHC allosera (Figure 4) were not observed in the rat C5b-9 induction experiments. The capability of the used antibody to detect rat C5b-9 in these experiments, therefor remains a matter of debate.

Although we demonstrated that complement activation with C5b-9 or MAC formation occurred, we could not demonstrate that this initiated EC perturbation or activation leading to expression of adhesion molecules as ICAM-1 and VCAM-1. In this respect our data do not support previous studies demonstrating that antibody alone or by formation of sublytic amounts of MAC on EC induces endothelial cell activation and adhesion molecule expression $(14,39,40)$. In those studies it is suggested that adhesion molecule expression is effected by autocrine stimulation of induced IL-1 production. Although we did not find evidence for such activation pathway, it may be that MAC formation triggers other activation processes, such as 
production of platelet activating factor or tissue factor, as described in other studies $(9,10,11)$.

In clinical heart and also kidney transplantation studies, the presence of anti EC alloantibodies has been associated with chronic rejection, and in particular yascular rejection including graft arteriosclerosis $(20,30,41)$. It is interesting that in chronic rejection, where predominantly IgG alloantibodies are present, complementmediated cytotoxicity of endothelial antibodies apparently plays a minor role. To which other processes relevant for vascular rejection anti EC alloantibodies may contribute remains to be elucidated. In this respect, it may be expected that, in addition to complement activation effects, anti $\mathrm{EC}$ alloantibodies mediate interactions of FC-receptor positive ADCC or inflammatory cytokine-producing cells with the endothelium of the blood vasculature.

Acknowledements:The authors would like to thank A. P. Gijsen for technical assistance. H. A. M. D. van der Heijden for heart transplantation expertise. We thank Dr Chisholm for donation of 5F10, Dr. Miyasaka for donation of 1A29, Prof. H. Bazin for donation of the polyclonal anti rat isotype antibodies, Prof. W. G. Couser for donation of 2A1, Prof. M. Daha for donation of the anti GP C3 Ab, Prof. Dr. W. Fiers for donation of TNF $\alpha$ and Dr. P. van der Meide for donation of IFN $\gamma$. 


\subsection{References}

1. Colvin RB. Cellolar and molecular mechanism of allograft rejection. Antwal Reviews of Medicin $1990 ; 41: 361$.

2. Colson YL, B.H. M, Zeevi A, Duquesnoy RJ Interactions between endothetial cells and alloreactive $T$ cells involved in allograft immunity. Transplantation Proceedings 1988; 47

3. Russell PS, Chase CM, Winn HJ, Colvin RB. Coronary atherosclerosis in transplanted mouse hearts. Journal of Immunology $1994 ; 152: 5135$.

4. Tixier D, Tuso P, Czer L, et al. Characterization of anti-endothelial cell and anti-heart antibodies following heart transplantation. Transplantation Proceedings 1993; $25: 931$.

5. Moller $\mathbb{E}$. Cell interactions and cytokines in tramsplantation immunity. Transplantation Proceedings $1995 ; 27: 24$.

6. Lowry RP, Gurley KE, forbes RDC. Immune mecharisms in organ allograft rejection. Transplantation $1983 ; 36: 391$.

7. Bolton EM, Gracie JA. Briggs JD, Kampinga J, Bradley JA, Cellular requirements for renal allograft rejection in the athymic nude rat. Joumal of Experimental Medicin 1989; 169:1931.

8. Saadi S, Platt I. Transient pertubation of endothelial intigrity induced by natural antibodies and complement. Joumai of Experimental Medicine 1995; 181: 21.

9. Bevilaqua MP, Pober IS, Majeau GR, Cotran RS, Gimbrone MAJ. Interleukin I(IL-1) induces biosynthesis and cell surface expression of procoagulant aetivity in human vascular endothelial cells. Joumal of Experimental Medicin 1984; $160: 618$.

10. Saadi S. Holzknecht RA, Patte CP, Stern DM Platt JL. Complenent mediated regulation of ussue factor activity in endothelium. Joumal of Experimental Medicin 1995; 182: 1807

11. Camussi G, Bussolino F, Salvidio G, Baglioni C. Tumor necrosis factor/cachetin stimulates peritomeal macrophages, polymorphonuclear newtrophils, and vascular endothelial cells to synthesize and release platelet-activating factor. Jourmal of Experimental Medicine 1987; 166: 1390.

12. Vaporciyan AA, Mulligan MS, Warren JS, Barton PA, Miyasaka M, Ward PA. Up-regulation of lung vascular ICAM-1 in rats is complement dependent. The Joumal of Immunology 1995; 155: 1442 .

13. Kilgore KS, Shen IP, Miller BF, Ward PA, Warren IS. Enhancement by the complement membrane attack complex of tumor necrosis factor-induced endothelial cell expression of $\mathrm{E}$ selectin and ICAM-1. the Journal of Immunology 1995 ; 155 ; 1434.

14. Carvalho D, Savage COS, Black CM, Pearson JD. IgG anti-endothelial cell autoantibodies from sclerodenma patients induce leukocyte adhesion to human vasicular endothelial cells in vitro. Journal of Clinical Investigation 1996; 97: 111 .

15. Brauer RB, Baldwin III WM, Ibrahim S, Sanfilippo F. The contritution of the terminal complement components to acute and hyperacute allograft rejection in the rat. Transplantation 1995; 59: 28.8 .

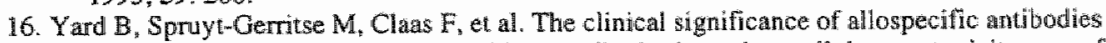
aganst endothelial cells detected with an antibody-dependent cellular cytotoxicity assay for vascular rejection and graft loss after renal transplantation. Transplantation 1993; $55: 1287$.

17. Biadley JA. Mowat AM, Bolton EM. Processed MHC class I alloantigen as the stimulus for CD4t T-cell dependent antibady-mediated graft rejection. Immunology Today 1992;13:434.

18. Adams H, Tilney $\mathrm{NL}$, Collins JJ, Kamovsky MJ. Experimental gratit arteriosclerosis. Transplantation 1992: 53: 1115 .

19. Dunn MJ, Crisp SI, Rose ML, Taylor PM, Yacoub MH. Anti-endothelial antibodies and cotonary artery disease after cardiac transplantation. The Lancet 1992:339:1566.

20. Crisp SJ. Dunn MJ, Rose ML, Barbir M, Yacoub MH. Anti-endothelial antibodies after herart transplantation: the accelerating factor in transplant-associated coronary artery diserse. Journal of Heart and Lung Transplantation 1994: 13:81

21. Schilfgaarde wan $R$, Hermans $P$, Terpstra JL, Breda Vriesman van PJC. Role of mobile passenger lymphocytes in the rejection of renal and cardiac allografts in the rat. A passenger lymphoc yte mediated graft versus hast reaction amplifies the host response. Transplantation 1980;29, 209 .

22. Derhaag JG, Duijvestijn AM, Damoiseaux.JGMC, wan Breda Vriesman PIC. An in vitro model for studying the role of graft endothelial cells in rat heart allograft rejection: A study on the regulation and function of heart endothelial hislocompatibility antigers and cell adhesion molecules. Transplantation Proceedings 1997; 29: 1717

23. Derhaag $J$, Duijvesujm A, Emeis $J$, Engels $W$, Breda Vriesman van P. Production and characterization of spontaneous rat-heart endothelial cell lines. Laboratory Investigations 1996 ; 74: 437 . 
24. Maciag T, Cerendulo J, Isley S, Kellu PR, Forand R. An endothelial growth factor from bovine hypcthalamus: identification and partial characterization. Proc Natl Acad Sci USA 1979; 76: 5674

25. Poncelet PG, Lavabre-Bertirand T. Immunological detection of membrane-bound antigens and receptors. Methods of Immunological Analysis $1993 ; 388$.

26. Dujjwestijn AM, Goor wan $H_{v}$ Kuatter $F$, Majoor GD, Bussel van $E$, Breda Vriesman van PJC. Antibodies defining rat endothelial cells: RECA-1 a pan endothelial specific monoclonal artibody. Laboratory Investigation 1992; 62: 459.

27. Tamatani T, Miyasaka M. Idencification of monoclonal antibodies reactive with the rat homolog of ICAM-1 and evidence for a differential involvement of ICAM-1 in the adherence of resting versus activated lymphocytes to high endothelial cells. International Immunology $1990 ; 2: 165$.

28. May MJ. Entwistle G, Humphries MJ, Ager A. VCAM-1 is a CS-1 peptide-inhibitable adhesion mallecule expressed by lymph mode high endothelium. Journal of Cell Science 1993; 106: 109.

29. Derhaag JG, Duijvestijn AM, Breda Vriesman van PJC. Heart EC respond heterogeneous on cytokine stimulation in ICAM- $\mathbb{1}$ and VCAM-1, but not in MHC expression; A study with 3 rat heart endothelial cell (RHEC) lines. Endothelium 1997; 5:307.

30. Ferry BL, Welsh KI, Dunn MJ, et al. Anti cell surface endothelial antibodies in sera from cardiac and kidney transplant recipients. Transplantation Immunology $1997_{\mathrm{s}} \mathbf{5}(\mathbf{1}): 17$.

31. Orosz CG. Endothelial activation and chronic allograft rejection. Clinical Transplantation 1994; 8 : 299.

32. Sekhavat M, Ravoet AM, Neirynck A, Sokal G. Rat monoclonal antibodies for complement mediated and cell mediated cytolysis.

33. Gilks WR, Gore SM, Bradley BA. Renal transplant rejection. Transiemt immunodominance of HLA mismatches. Transplantation 1990, 50: 141 .

34. Duijvestijn A, Vlek L, Duistermaat L, Rie wan H, Breda Vriesman P. Chronic renal allograft rejection: the significance of non-MHC alloantigens. Transplantation International 1992; 5 suppl 1: 5639 .

35. Joyce S, Flye MW, Mohanakumar T. Characterization of kidney cell-specific, non-major histocompatibility complex alloantigen using antibodies from rejected human renal allografts. Transplantation 1988; 46:362.

36. Breda Vriesman wan PJC, Sanen-Sierag L, Vlek LFM. Cytotoxic and enhancing properties of early $\gamma \mathrm{M}$ alloantibodies elicited by first set renal allografts. Transplantation $1975 ; 20: 385$.

37. Funabashi $K$, Okada N, Matsuo S, Yamamoto T, Morgan BP, Okada H. Tissue distribution of complement regulatory membrane proteins in rats. Immunology $1994 ; 81: 444$.

38. Dalmasso AP, Vercellotti GM, Platt JL, Bach FH. Inhibition of complement-mediated endothelial cell cytotoxicity by decay-accelerating factor. Transplantation 1991; 52: 530 .

39. Briscoe DM, Schoen Fy, Rice GE, Bevilaqua MP, Ganz P, Pober P. Induced expression of endothelial-leukocyte adhesion molecules in human cardiac allografts. Transplantation 1991; 51: 537.

40. Pelletier RP, Morgan CJ, Sedmak DD, et al. Analysis of inflammatory endothelial changes, including VCAM-1 expression in murine cardiac grafts. Transplantation 1993; 55: 315 .

41. Woude van der FJ, Deckers JC, Mallat MJ, Yard BA, Sehrama E, Saae van JL, Daha MR. Tissue antigens in tubulointerstitial and vascular rejection. Kidney International Suppl 1995; 53: 1119. 1127 . 


\section{Summary \& Discussion}

Endothelial cells (EC) form an organ which is wery important in almost all physiological and pathological processes. The EC are important for the control of blood flow, blood pressure and clotting as well as for the regulation of the permeability of the vessel wall to molecules and cells. Pathogenic mechanisms lead to the loss of EC integrity. This results in malfunctioning of prementioned physiological processes in which the EC is involved. In this thesis the role of $\mathrm{EC}$ in immune reactivity, and especially in rat heart allograft rejection, is described. This was studied in an in virro model using cultures of EC lines.

In Chapter 1 the current facts about the structure and physiological functions of $\mathrm{EC}$ are reviewed. Changes of these functions during immune reactivity, and especially during transplant rejection are discussed. During normal physiological circumstances the EC coordinate the transport of molecules through the endothelial monolayer, regulate leukocyte migration, the vascular tone and control the coagulation.

During immume reactivity all these processes change by the intervention of cytokines, chemokines and cells involved in immunity. This results in increased transport of molecules through the EC monolayer, increased migration of specific leukocyte subpopulations, and in changes of the valscular tone by production of vasoconstriction or vasodilatation factors by the EC. Besides, imnune reactivity may also lead to disturbance of the procoagulart/ anti coagulant balance, nomally controlled by the $\mathrm{EC}$.

During allograft rejection $\mathrm{EC}$ contribute to the rejection process by participating in the immune response. In addition to regulation of leukocyte migration, vascular endothelial cells may present antigens together with co-stimulatory signals to $T$ lymphocytes, initiating an immune response against the graft. Besides, EC become a target for cellular or antibody-mediated immune reactions. 
In Chapter 2 the development of an in vitro $\mathrm{EC}$ model is described, as well as the phenotypical and functional characterization of developed EC limes. The lack of EC of proper species and organ origin, the low yield of EC obtained with the isolation procedure, and the limited lifespan of the EC obtained from described isolation procedures, made it necessary to develop immortalized cell lines.

3 spontaneous rat hear endothelial cell (RHEC) lines of Lewis rat origin were produced using an ex vivo perfusion model to isolate $\mathrm{EC}$ from rat heart. It was shown that the cell lines, RHEC 3, RHEC 10 and RHEC 11, are of $\mathrm{EC}$ nature. The spontaneously immortalized EC lines are tumorigenic and develop hemangiomas on in vivo injection. These cellular effects of immortalization on EC are also shown by EC lines obtained via virus infection-induced immortalization. The RHEC lines respond upon cytokine stimulation in adhesion molecule and MHC expression. Functional characterization of the RHEC lines shows that the EC from the RHEC lines express angiotensin converting enzyme, and respond to histamine and ATP. They produce small amounts of endothelin and high amounts of t-PA, which supports their microvascular nature. The EC lines, apparently because of long-term culturing, lost the capacity to produce $\mathrm{PGI}_{2}$, but they do produce $\mathrm{TXA}_{2}$ and $\mathrm{PGF}_{2} \alpha$, and upon stimulation also PGE2.

The modified method to obtain EC cell lines increases the frequency of successfull production of $\mathrm{EC}$ lines. The data suggest that the $3 \mathrm{RHEC}$ lines are representative for rat heart microvascular endothelium of Lewis rat origin in vivo, and could be used to study graft EC in the Lewis to BN rat heart transplantation model.

To examine the role of microvascular EC in inflammation and immune reactivity in transplant rejection the response of EC upon stimulation with the inflammatory cytokines TNF $\alpha$ and IFNy was studied as described in Chapter 3. RHEC lines were studied for the induction kinetics of adhesion molecules and MHC antigens over a time period of $64 \mathrm{hr}$. 
The induction of the molecules by the cytokines TNFo and IFNy occurs not on all cells in the cultures. TNF $\alpha$ is most potent in inducing ICAM-1 and VCAM-1, whereas IFN $\gamma$ is most potent in MHC class II induction. Combined cytokine stimulation result in increased and even synergistic effects on the expression profiles. The cell lines show remarkable differences with respect to ICAM-1 and VCAM-1 induction, with each cell line having an unique expression profile. This in contrast with the induction profiles for MHC molecules which are similarly for all three the RHEC lines. The selective induction of the molecules on not all the EC within a cell line results from an intrinsic regulation mechanisms in the cell culture.

In heart tissue in vivo, the heterogeneity of vascular EC, as demonstrated here in vitro, may have an impact on leukacyte endothelial interactions especially during inflammatory and immune processes. Here, preferential local adhesion and infiltration of specific lymphocyte populations regulated by the stimulated EC may occur. In addition, by expression of $\mathrm{MHC}$ molecules $\mathrm{EC}$ can present antigens to $\mathrm{T}$ cells which in the presence or absence of the necessary costimulatory adhesion molecules may result in initiation of the immune response or the development of anergic or apoptotic $T$ cells respectively.

In order to demonstrate effects of EC heterogeneity for cytomegalovirus (CMV) infection the obtained Lewis RHEC lines were used together with RHEC 50, RHEC 116 and RHEC 191 in CMV infection studies as described in Chapter 4. Since in the pathology of transplantation associated atherosclerosis, cytomegalovirus (CMW) infected $\mathrm{EC}$ are detected, a role for EC in this process is suggested.

The RHEC lines display differences in susceptibility to CMV infection. RHEC 50 and 191 are practically non-permissive, while RHEC $3,10,11$ and 116 are differently permissive for CMV infection. CMV infection does not spread out through the monolayer of $\mathrm{EC}$, although infectious virus is produced. The virus produced appears able to infect fibroblasts but not EC. From the monolayer detached CMV-infected EC are also only able to infect fibroblasts and not EC. 
The heterogeneous response of EC in their permissiweness for CMV of the different EC lines suggest that in vivo, although the EC are relatively resistant to CMV infection, the infection of EC with CMV can be locally different. Detached EC can be responsible for spreading the virus through the vascular system and, at sites of endothelium damage, fibroblast or smooth muscle cells can be infected. As such detached EC may accelerate systemic CMV infection.

To define whether in heart allograft rejection alloantibodies to endothelial MHC and non-MHC play a role in the dewelopment of graft vasculopathy, the effects of these allo-antibodies are studied as described in Chapter 5.

Anti MHC as well as anti non-MHC allosera show specific reactivity with $\mathrm{EC}$ from the RHEC lines. Anti MHC allosera show distinct complement-mediated cytotoxicity for $\mathrm{EC}$, whereas anti non-MHC allosera show only low cytotoxicity for EC. Cytokine stimulation of the $\mathrm{EC}$, which resulted in upregulation and induction of $\mathrm{MHC}$ class I and II (see Chapter 3), increases the cytotoxicity of the anti MHC allosera. NonMHC alloantigens are not upregulated by cytokine stimulation, and consequently cytotoxicity does not increase either. It is shown that complement-mediated cytotoxicity of anti MHC allosera is related to the IgM fraction of the allosera, which is only present in the anti MHC allosera. IgG subclass profiles of both the allosera are rather similar. Highest efficacy in antibody mediated cytotoxicity against EC is obtained when xenogeneic complement is used in comparison with syngeneic complement. Anti MHC allosera activate complement on EC, while anti non-MHC allosera hardly activate complement on $\mathbb{E C}$

The results of these experiments suggest that both $\mathrm{MHC}$ and non-MHC alloantigens on EC are target structures of the alloantibody response in heart allograft rejection. Complement mediated cytotoxicity is only present in allosera reactive with MHC alloantigens, and is effected by IgM alloantibodies. Whether the alloantibodies against $\mathrm{MHC}$ and non-MHC alloantigens on the $\mathrm{EC}$ do not destroy but activate the $\mathrm{EC}$, and so influence the rejection process, needs further investigation. 
Data from in vitro studies with RHEC lines indicate only a minor role of antibodymediated cytotoxicity against EC during heart transplant rejection. This suggests that next to alloantibody mediated cytotoxicity other mechanisms may effect the graft, resulting in transplant rejection. The rejection process is characterized by cell infiltrates in the graft in which the endothelium appears to be the initial target. In preliminary cellular cytotoxicity test executed with different effector populations out of transplant rejecting reciplents, no cytotoxicity against cytokine stimulated EC can be detected, even when wery high effector target ratio"s are used (data not shown).

In summary our study indicate that the RHEC lines which show to be representative for the microvascular EC of the Lewis heart, are heterogeneous in their response upon cytokine stimulation and also in their permissiveness for CMV infection. Observed heterogeneity accentuates the difficulties in studying EC processes in for instance only one cell line. Observed heterogeneity among the vascular bed in wivo together with the presented in vitro data suggests that local different events occur during immune reactivity. The obtained RHEC lines increase the possibility to study the heterogeneous EC in vitro. During the transplantation rejection EC are a target for the cellular as well as the humoral immune response. Our studies show that humoral immune reactivity against graft EC does not result in destruction of EC, but most likely results in EC activation, effecting the rejection process. 


\section{Samenvatting \& Discussie}

Endotheel cellen (EC) vormen een orgaan, belangrijk voor bijna alle fysiologische en pathologische processen in het lichaam. EC spelen een belangrijke rol bij de controle van de bloedstroom, de bloeddruk en de stolling, maar reguleren ook de permeabiliteit van de vaatwand. Pathogene mechanismen leiden tot het verlies van deze $E C$ integriteit. Dit resulteert in een ontregeling van de voornoemde fysiologische processen waarbij EC betrokken zijn. In dit proefschrift is de rol van EC in immuun reactiviteit en meer specifiek in rat hart transplantaat afstoting beschreven. Dit is bestudeerd in een in vitro EC model dat gebruik maakt van rat hart EC.

Hoofdstuk 1 is een overzicht van de actuele feiten over structuur en fysiologische functies van het endotheel in het algemeen. Veranderingen in deze functies gedurende immuun reactiviteit, en in het bijzonder tijdens transplantaat afstoting, worden bediscussieerd. Tijdens fysiologische omstandigheden coördineren EC het transport door de endotheel monolayer, reguleren leukacyt migratie en de vaat tonus en controleren de stolling.

Tijdens immuun reactiviteit veranderen al deze processen door tussenkomst van cytokines, chemokines en cellen betrokken bij de immuun response. Dit resulteert in een toegenomen transport door de EC monolayer, toegenomen migratie van specifieke leukocyt subpopulaties, en in veranderingen van de vaattonus door productie door EC van stoffen die leiden tot vasoconstrictie of vasodilatatie. Daarnaast kan immuun reactiviteit de procoagulant/anti coagulant balans verstoren, welke onder fysiologische omstandigheden in stand wordt gehouden door EC.

Door deelname aan de immuun respons tijdens transplantaat afstoting hebben EC een rol binnen het afstotings proces. Naast regulatie van de leukocyt migratie, kunnen vasculaire EC samen met de benodigde co-stimulatoire signalen antigeen presenteren aan lymfocyten, en daarmee kumnen ze een immuun respons tegen het transplantaat initièren. 
Bovendien zijn EC het doelwit van de cellulaire en/of antilichaam gemediëerde immuun reactiviteit

In Hoofdstuk 2 wordt de ontwikkeling van een in vitro $\mathrm{EC}$ model en de fenotypische en functionele karakterisering van de ontwikkelde rat hart EC lijnen beschreven. De afwezigheid wan EC van het juiste species en het juiste orgaan, de lage opbrengst werkregen met de beschreven isolatie procedure en de gelimiteerde levensduur van de EC verkregen met eerder beschreven opzuiverings procedures maakte de ontwikkeling van de cellijnen noodzakelijk.

Drie rat hart endotheel cel (RHEC) lijnen van Lewis rat origine werden geproduceerd met behulp van een ex wivo perfusie model voor EC uit rat hart. De cel lijnen, RHEC 3, RHEC 10 en RHEC 11, zijn zuiver EC. De spontaan geimmortaliseerde EC lijnen zijn tumorigeen en ontwikkelen hemangiomas wanneer zij in vivo worden geinjecteerd. Deze cellulaire effecten van de immortalisatie op EC zijn ook aangetoond bij EC lijnen die geïmmortaliseerd zijn met behulp van virus infectie. De RHEC lijnen reageren op cytokine stimulatie door adhesie moleculen en MHC moleculen tot expressie te brengen. Functionele karakterisering van de RHEC lijnen toont aan dat EC van de RHEC lijnen angiotensin converting enzyme, $A C E$ expresseren op hun membraan en dat zij reageren op histamine en ATP. Ze produceren kleine hoeveelheden endotheline en grote hoeveelheden $\mathbb{P A}$, wat hun microvasculaire oorsprong benadrukt. De EC lijnen zijn hun capaciteit om $\mathrm{PGI}_{2}$ and $\mathrm{PGE}_{2}$ te produceren verloren, waarschijnlijk door de langdurige kweek periode, maar produceren een weinig TXA2 en PGF2 $2 \alpha$.

De gebruikte aangepaste methode om EC lijnen te verkrijgen uit EC isolatie heeft de frequentie van het succesvol produceren van deze lijnen verhoogd. De verkregen data omtrent deze 3 RHEC lijnen suggereren dat ze representatief zijn voor rat hart microvasculair endotheel van Lewis rat origine in wivo en dat ze gebruikt kunnen worden om transplantaat EC te bestuderen in het Lewis naar BN rat hart transplantatie model.

Om de rol van microvasculair EC in ontsteking en immun reactiviteit tijdens transplantaat afstoting te bestuderen is de respons van EC op stimulatie met de ontsteking 
cytokines TNF $\alpha$ and IFN $\gamma$ bestudeerd zoals beschreven in Hoofdstuk 3. De inductie kinetiek voor adhesie moleculen en MHC antigenen van de RHEC lijnen is bestudeerd in een periode van 64 uur.

De inductie van deze moleculen door de cytokines TNFO and IFNy vindt niet op $100 \%$ van de cellen plaats. TNF $\alpha$ is het meest potent in het induceren van ICAM-1 en VCAM-1, terwij] IFN $\gamma$ het meest potent was in MHC class II inductie. Gecombineerde cytokine stimulatie resulteert in toegenomen en zelfs synergistische effecten op de expressie profielen. De cellijnen vertonen opmerkelijke verschillen met betrekking tot ICAM-1 en VCAM-1 inductie, waarin elke cellijn een uniek expressie patroon heeft. Dit in tegenstelling tot de inductie profielen voor de MHC moleculen welke voor alle drie de RHEC lijnen gelijk zijn. De selectieve inductie van de moleculen op niet alle EC binnen eẻn cellijn is het resultaat van een intrinsiek regelmechanisme in de weefselkweek.

In hart weefsel in vivo heeft de heterogeniteit van vasculaire EC, zoals hier gedemonstreerd in vitro, mogelijk een impact op leukocyt/endotheel interacties, met name gedurende ontsteking en immuun processen. Er kan dan sprake zijn van preferentiele lokale adhesie en infiltratie van specifieke lymfocyt populaties gereguleerd door het gestimuleerde EC. Daarnaast kumnen MHC expresserende EC antigeen presenteren aan T cellen, wat in de aan of afwezigheid van de noodzakelijke costimulatoire adhesie moleculen kan resulteren in initiatie van respectievelijk de immuun response of de ontwikkeling van anergische of apoptotische T cellen.

Om de effecten wan deze EC heterogeniteit voor cytomegalovirus (CMV) infectie te demonstreren zijn de verkregen Lewis RHEC lijnen gebruikt samen met RHEC 50 , RHEC 116 en RHEC 191 in CMV infectie studies zoals beschreven in Hoofdstuk 4. Omdat tijdens de pathologie van transplantatie geassocieerde atherosclerose, CMV geïnfecteerde EC zijn waargenomen, wordt er een rol voor EC in dit proces gesuggereerd.

De RHEC lijnen vertonen verschillen in hun gevoeligheid voor CMV infectie. RHEC 50 en 191 zijn vrijwel niet toegankelijk, terwijl RHEC 3, 10,11 en 116 
dufferentieel toegankelijk zijn voor CMV infectie. CMV infectie verspreidt zich niet door de EC monolayer, alhoewel er wel infectieus virus wordt geproduceerd. Het geproduceerde virus blijkt fibroblasten te kunnem infecteren maar niet $\mathrm{EC}$. De van de monolayer losgelaten CMV-geinfecteerde EC zijn ook enkel in staat om fibroblasten te infecteren en niet $\mathrm{EC}$.

De heterogene respons van $\mathrm{EC}$ in hun toegankelijkheid voor $\mathrm{CMV}$ van de verschillende $\mathrm{EC}$ lijnen suggereert dat in vivo, ondanks het feit dat de EC relatief resistent zijn voor CMV infectie, de infectie van $E C$ met CMV lokaal heel verschillend kan zijn. Losgelaten EC kunnen verantwoordelijk zijn voor verspreiding van het virus door het vasculaire systeem en, op plekken waar het endotheel beschadigd is, fibroblasten of gladde spiercellen infecteren. Op deze manier kunnen de losgelaten geïnfecteende EC systemische CMV infectie doen accelereren.

Om vast te stellen of gedurende hart transplantaat afstoting alloantilichamen tegen endotheliale MHC en non-MHC moleculen een rol spelen in de ontwikkeling van transplantaat vasculophatie zijn de effecten van deze alloantilichamen bestudeerd zoals beschreven in Hoofdstuk 5 .

Anti MHC en ook anti non-MHC allosera vertonen specifieke reactiviteit met EC van de RHEC lijnen. Anti MHC allosera vertonen duidelijke complement-gemedieerde cytotoxiciteit voor $\mathrm{EC}_{\text {, }}$ terwijl anti non-MHC allosera alleen lage cytotoxicity voor $\mathrm{EC}$ vertonen. Cytokine stimulatie van de EC, resulterend in opregulatie en inductie van MHC klasse I en II (zie Hoofdstuk 3), leidt tot verhoogde cytotoxiciteit van de anti MHC allosera. Non-MHC alloantigenen worden niet opgereguleerd door cytokine stimulatie en als een gevolg hiervan wordt de cytotoxiciteit ook niet verhoogd. In dit hoofdstuk wordt getoond dat de complement-gemediëerde cytotoxiciteit van de anti MHC allosera gerelateerd is aan de IgM fractie van de allosera, welke alleen aanwezig is in de anti MHC allosera. De IgG subklasse profielen wan beide allosera zijn vrijwel gelijk. De hoogste efficientie wan antilichaam gemediëerde cytotoxiciteit tegen EC wordt verkregen wanneer xenogeen complement wordt gebruikt. Anti MHC allosera activeren complement op de 
membraan van EC. Anti non-MHC allosera zijn nauwelijks in staat om complement op EC te activeren.

De resultaten van deze experimenten suggereren dat zowel $\mathrm{MHC}$ als non-MHC alloantigenen op EC doelwit structuren zijn van de alloantilichaam respons tijdens hart transplantaat afstoting. Complement gemedièerde cytotoxiciteit is alleen aanwezig in de allosera die reactief zijn met MHC alloantigenen en wordt veroorzaakt door IgM alloantilichamen. Of de alloantilichamen tegen $\mathrm{MHC}$ en non-MHC alloantigenen op EC de cellen niet vernietigen maar wel activeren, en zo het afstotingsproces beinvloeden, vraagt verder onderzoek.

De data van de in vitro studies met de RHEC lijnen impliceren een ondergeschikte rol voor de antilichaam-gemedièerde cytotoxiciteit tegen EC gedurende hart transplantaat afstoting. Dit suggereert dat er naast alloantilichaam gemedièerde cytotoxiciteit andere mechanismen het transplantaat beïnvloeden, wat uiteindelijk resulteert in transplantaat afstoting. Het afstotingsproces wordt gekarakteriseerd door cel infiltraten in het transplantaat waarin het endotheel het initiele doelwit lijkt te zijn. In preliminary cellulaire cytotoxiciteit testen, uitgevoerd met verschillende effector populaties uit transplantaat afstotende ontvangers, kan in vitro geen cytotoxiciteit tegen cytokine gestimuleerd EC waargenomen worden, zelfs niet wanneer er gebruik gemaakt wordit van zeer hoge effector target ratio's (data niet getoond).

Samenvattend laat onze studie zien dat de RHEC lijnen, welke representatief zijn voor microvasculaire EC van het Lewis hart, heterogeen zijn in hun respons op cytokine stimulatie en ook voor hun toegankelijkheid voor CMV infectie. Deze geobserveerde heterogeniteit accentueert de problemen die er ontstaan bij het bestuderen wan EC met behulp van bijvoorbeeld een enkele cellijn. De geobserveerde heterogeniteit in het vasculaire stelsel in wivo samen met de gepresenteeerde in vitro data suggereert dat er gedurende immuun reactiviteit lokaal verschillende gebeurtenissen plaatsvinden. De verkregen RHEC lijnen verbeteren de mogelijkheid om heterogene EC in vitro te bestuderen. Tijdens transplantaat afstoting zijn EC een doelwit voor de cellulaire maar 
ook voor de humotalle immuun respons. Onze studies laten zien dat de humorale immun reactiviteit tegen transplantaat $\mathrm{EC}$ niet resulteert in vernietiging van $\mathrm{EC}$, maar, naar alle waarschijnlijkheid, resulteert in EC actiwatie en zo het afstotingsproces beinvloedt. 


\section{Publications}

Wander SL, Ten-Kate J, Van der Linden E, Derhaag JG, Dinjens WN, Bosman FT. Does ex vivo labelling of proliferating cells in colonic and vaginal mucosa reflect the $S$ phase fraction in vivo. Histochemistry, 1992; 4: 267.

Derhaag JG, Duijvestijn AM, Emeis JJ, Engels W, van Breda Vriesman PJC. Production and characterization of spontaneous rat heart endothelial cell lines.Laboratory Investigation 1996; 74: 437.

Vossen RCRM, Derhaag JG, Slobbe-van Drunen MEP, Duijvestijn AM, van DamMieras MCE, Bruggeman CA. A dual role for endothelial cells in cytomegalovirus infection? A study of cytomegalovirus infection in a series of rat endothelial cell lines.

Virus Research 1996; 46: 65.

Duijvestijn AM, Derhaag JG, Koornstra I, and Zierhut M. Lymphocyte homing to lymphoid and inflamed joint and eye tissues: the role and control of high endothelial venules and adhesion molecules. Immunology of the joint and the eye, M. Zierhut, and H.-J. Thiel, 1996; 35.

Derhaag JG, Duijvestijn AM, Damoiseaux JGMC, and van Breda Vriesman PJC. An in vitro model for studying the role of graft endothelial cells in rat allograft rejection, a study on the regulation and function of heart endothelial histocompatibility antigens and cell adhesion molecules. Transplantation Proceedings 1997; 29: 1717.

Haaster van CMCJ, Derhaag JG, Engels W, Lemmens PJMR, Gijsen AP, Hornstra G, Van der Vusse G, and Duijvestijn AM. Mast cell-mediated induction of ICAM-1, VCAM1 , and E-selectin in endothelial cells in vitro: constitutive release of inducing mediators but no effect of degranulation. European Joumal of Physiology, 1997; 435:137.

Derhaag JG, Duijvestijn AM, and van Breda Vriesman PJC. Heart EC respond heterogeneous on cytokine stimulation in ICAM- 1 and VCAM-1, but not in MHC expression. Endothelium 1997; 5: 307.

Duijvestijn AM, and Derhaag JG. Mechanisms controlling leukocyte migration to inflamed tissues, emphasizing lymphocyte homing to skin and eye.

Immunology of the skin and the eye, M. Zierhut, and H.-I. Tiel, In press.

Derhaag JG, Duijwestijn AM, Damoiseaux JGMC, and van Breda Vriesman PJC. Effects of antibody reactivity to MHC and non-MHC alloantigens on graft endothelial cells in heart allograft rejection. Submitted for publication. 


\section{Dankwoord}

To him that absent is, all things succeed arniss

Cervantes

Een "boekje" schrijf je nooit alleen.

Het leven van een AlO gaat niet over rozen!

Ik wil graag iedereen bedanken die, elk op zijn eigen wijze, heeft meegeholpen aan de tot standkoming van mijn proefschrift, of mij in enig ander opzicht tot steun is geweest gedurende mijn promotietijd.

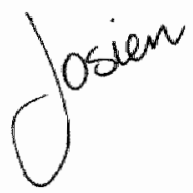




\section{Curriculum vitae}

Josien Derhaag werd geboren op 25 maart 1967 te Sittard. Na het behalen van het Atheneum $\beta$ diploma aan de R.K. Scholengemeenschap "Serviam" te Sittard begon zij in 1986 met de studie Gezondheidswetenschappen met als afstudeerrichting Biologische Gezondheidkunde aan de Universiteit Maastricht. In augustus 1991 werd het doctoraal diploma behaald. Na een jaar werkzaam te zijn geweest bij de vakgroep Moleculaire Celbiologie \& Genetica van de Universiteit Maastricht begon zij in 1993 als assistent in opleiding in dienst van de Universiteit Maastricht bij de vakgroep Immunologie. Onder leiding van Prof. Dr. P.J.C. van Breda Vriesman en Dr. A.M. Duijvestijn werd gedurende deze periode het onderzoek verricht beschreven in dit proefschrift. Vanaf april 1998 is zij werkzaam als bioloog bij de afdeling Obstetrie \& Gynaecologie van het Academisch Ziekenhuis Maastricht. 